iia 
$E / 68$.

LIBRARY

University of California

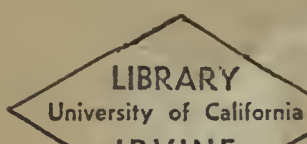

IRVINE

IRVINE

68

2

LENDING LIBRARY

LOCAL NOL 1, S. R. GF C 
U) $\frac{C}{E / 68}$

\section{DERTIRE LIERARY}

LOCAL NO 1, 5. P. OF C.

Juscouves. B. C.
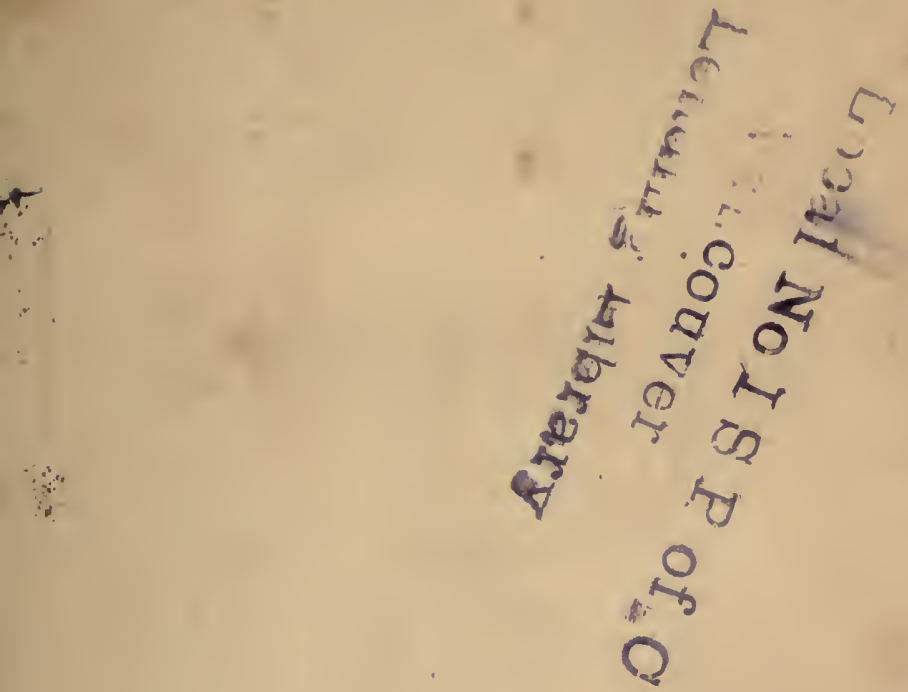
Digitized oy the Internet Archive in 2007 with funding from Microsoft Corporation 




\section{UNIVERSAL EVOLUTION}

\section{Michael Hendrick Fitch Author of \\ "The Physical Basis of Mind and Morals" \\ "The Chattanooga Campaign" "Echoes of the Civil War"}

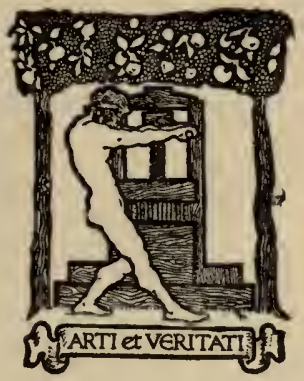

RICHARD G. BADGER THE GORHAM PRESS BOSTON 


\section{COPYRIGHT I9I3 BY RICHARD G. BADGER}

All Rights Reserved

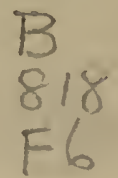

The Gorham Press, Boston, U. S. A. 


\section{CONTENTS}

Chapter

Page

I Inorganic Evolution.............. 9

II Organic Evolution ................ 33

III The Method................. 68

IV Mental and Social Evolution........... 105

V Mental and Social Evolution (continued)... 132

VI Mind is Function................. 157

VII Mind is Function (continued)......... 177

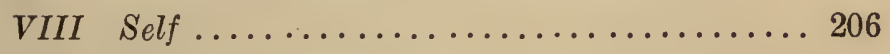

IX Ethics and Altruism............. 238

$X$ Ethics and Altruism (continued)........257

XI A Final Word................... 280 



\section{UNIVERSAL EVOLUTION}





\section{UNIVERSAL EVOLUTION}

\section{CHAPTER I \\ INORGANIC EVOLUTION}

CHOOLS of Philosophy.-During the last fifty years the theory of Evolution has produced a revolution in the thoughts of the civilized world. Scientists have generally adopted the theory, and at present, after years of analytic study of all its features, are dividing themselves into two, or more schools. But in all the divisions there seems to be no denial of the basic principle, but merely, as usual upon all theories, a division of men along the lines of materialism and idealism. The aspect, which such a theory presents to the brain, depends upon the organization of the brain. To those brains which, before the renaissance of the idea of evolution, were not wholly in accord with finality, the theory now presents a material aspect, -one that can be called mechanistic. On the contrary, to that brain which was thoroughly. imbued with the old order of ideality, or mysticism, it would take the form of a creative principle, in some way guided by some power either abstract, or personal. There are many forms of these two schools of evolutionists. This is natural, because no two brains are alike in structure, and therefore are dissimilar in ideas. The mechanistic school is that of Darwin, Huxley, Haeckel, Carl Vogt, etc. These philosophers take for granted matter and motion, with- 
out trying to trace the origin of either, and assuming nebulæ, trace the evolution of forms from thesc, by condensation. Another set of philosophers try to reverse that process, by summoning to the aid of intellect, something called intuition, a kind of enlarged instinct, and which one of them calls a "nebulosity surrounding the bright core of intellect" and growing out of the same basis, viz: experience. This intuition is to dive into the stream of creative evolution to the center, from which the stream of becoming starts, and works as nature works, or is supposed to work, from a center of mobility, and impetus, toward the circumference where visible forms are being made. It is difficult for a brain, whose habit of thought has been along the lines of intellect alone, to pluck the meaning of another brain, whose peculiar formation, enables it to go beyond intellect, in accounting for the universe and its laws. Mathematics and logic have been the means by which, heretofore, ordinary men have reasoned upon material things. They have thus established the present understanding of the laws of nature, and naturally apply the same methods to the evolution of life. But these, heretofore, have mentioned, not as a reality, but as a subjective thought only, the Unknowable Absolute. Darwin reasoned only from the facts apparent to the senses, and never thought that the power beyond appearances could be used to any advantage. Spencer started out well to find the Unknowable Absolute, but stopped short at the end of first part of First Principles, at the impassable barrier of the relativity of all things. But, by means of the intellect, the later philosophers of creative evolution think they see other forms of consciousness which express something more than symbolism in the evolutionary movement. It is 
proposed by them to bring together these assumed forms of consciousness, and the present form known as intellect, and have a resulting consciousness as wide as the universe. If reality can be thus conceived in its generation, and growth, no one would be willing to place a straw on its path. That is what finality undertook to do, in the teleological movement. But the new Creative Evolution repudiates teleology, yet, says the latter is nearer the truth than mechanism.

Finality assumes that a personality, comprehensible to man, created the universe out of nothing. That is, everything is given. But there is no nothingness. Nothing is a relative term. If one tries to perceive, or conceive nothing, he finds it impossible, because, in making the effort he, himself, is still existing, or he could not be perceiving it. If he could succeed in annihilating both himself and notself, then there would be no perception, nor conception of the fact. Therefore we use the word nothing to mean, there is always something. It is, therefore, not logical to think that anything was created out of nothing.

Monism.-Assuming the eternal existence of matter and motion, the human intellect perceives that all nature, - the self and notself,-is in perpetual change, and that such change evidently has an order, that can be reduced to a system, at least partially satisfactory, to the reason of man. A close observation of motion and matter discloses that the motion of the earth, in the solar system, and throughout that limited portion of the universe, so far brought within the view of man, is acting in unison. All movement is relative. There is absolute dependence of every form, and motion, upon every other, throughout the known realm. A monistic view of nature cannot be avoided, after the 
bearing of certain facts has been observed. The similarity, between the action of the physical and psychical law, is the most important fact. Inorganic matter is very much more stable than organic. But it is very far from being inert. It is in constant change. No inorganic body remains the same for any long period. Our earth, both internally and externally, is undergoing constant change. Volcanism, in earthquakes and eruptions, shows there is a perpetual readjustment occurring internally; and the surface is being modified by the denudation of it by water, wind, frost, and ice.

There is a slow, but irresistible uplift of certain regions, and in others a depression of the crust of the earth. The oceans are likewise moving in correspondence with the movements of the earth at their bottoms, or on the shores. Coral islands, and shore reefs are being built in certain parts, where there is more or less uplift, or subsidence of the oceans. These subsidences and uplifts are of the solid parts of the earth, either of the continents, or of the ocean's bottom; and the waters adapt themselves to these changes.

The matter thrown out by rolcanoes builds up again some of the denuded heights, and this is being changed by the action of weather and water into pliable soil, and eventually finds its way to the bottom of the ocean. The accumulation of debris at the mouths of rivers is the disintegrated rocks of the mountains, washed down by water. When it attains a magnitude of suff- cient weight, there is apt to be a giving way at the faults near the shore line and earthquakes result, as occurred at San Francisco in 1906. Rocks and earth are formed of crystals. As these crystals degenerate, the atoms of matter of which they are formed, again begin to integrate, into new crystallized forms, always 
bearing a close resemblance to the prior form. What does this mean? That these atoms are not inert, and unintelligent. They are always active and carry with them, in making new forms, the memory of former combinations, just as surely as the bee uses the memory of inherited instinct, in the making of comb honey. These atoms not only have memory, they have also reason. Reason anticipates the future as if it were present; and the combination of atoms of matter in building from the homogeneity of the nebula, the heterogeneity of stellar globes, exhibits the same memory, and reason, that a builder of a house does in constructing from raw materials a many roomed and useful dwelling. For, it is more than probable that every nebula has before been in the solid form. When these atoms come together in the plastic forms of organic matter through the intermediate adaptability of oxygen, hydrogen, nitrogen and carbon, there results, a higher degree only, of this same reason and memory, in a form we call life. When, by a little added phosphorus and sulphur, nerve matter is formed, there results a still higher degree of mobility, which we call psychic. But, at every step, it is always the same atom that does the work, which we find in the nebula, the globe, and the organic form; and everywhere it is found, it is active, intelligent, doing that which appears to us as just the proper thing to do in carrying on its multiplicity of effects throughout nature. This is materialistic monism. The reason of man constructs from the known, the unknown; and the atom, in its tendency to condense, builds from the known, which is its own form, the unknown erystal, globe, cell, and organism. The atom is truer in its certainty, and ultimate achievement, than the reason 
of man. The latter is only the manifestation of the action and intelligence of certain combinations of the atom: for in the final analysis the brain of man, which produces the reason, the memory, the imagination, is only a very complex condensation of the original center of motion called an atom of matter. It could be called just as well an atom of mind, for it carries with it, in all its combinations, the same tendencies, in potentiality, that finally result in mental phenomena in the brain of man. There is a oneness in all its combinations.

M. Henri Poincaré, in a recent lecture stated that the objective reality of the chemical atom is now beyond dispute. Every atom is an individual to us, a closed world, but, in fact, it is a universe of electrons, which he compares to fixed stars and comets.

The opposite of monism is dualism. The adherents of the latter idea contend that there is a power outside of the atom, who created the atom, and superintends all its actions, and combinations : and that the mind of man is a separate and distinct thing from the atom of matter. That is, that there are two principles in nature, the one natural, and the other supernatural.

Humanism.-However, no view, of evolution, can be taken, that is of any use to human reason, that does not include the value it has to humanity. It must be an every day working hypothesis, the truth of which consists, in the way it works for man. It must have a pragmatic value. We are not the reality, but its manifestation. It is well, that our daily attention is directed not to the primary movement of atoms in themselves, but to their end, with reference to human problems. We could not spend the time necessary, in contemplating the minute and complex movements of so simple an act as 
the raising of a finger, and if the rapid vibrations of the ether in a ray of light should be visible, it would absorb attention, at the expense of the necessary relation of light to the real welfare of our bodies. This favorable condition of our perceptions is the result of the evolution of mind, or intellect, in its correspondence with environment, entirely along practical lines. We know only the useful. The organs of sense are formed by their adaptation, for the preservation of our bodies, and we readily recognize only those phenomena which contribute to that end. Whatever the reality may be, behind the phenomena, it would likely not be useful if known to us, and therefore is of no real importance. We therefore do not see the "thing-in-itself" but its qualities. These we recognize before we are aware of forms. Color, sound, resistance, are the first facts apparent to the baby's senses. They are perceivable by their instability. This instability makes them the representatives of the primal reality of the universe, which is most likely a flux of becoming; and the forms, which become visible to the more matured brain, are merely the emphatic points of protest, by matter, against the positive explosive nature of the reality. Color, light and sound are perceivable; by their inconceivable and invisible vibrations, of which they are constituted: yet we fortunately do not perceive the vibrations.

InstabiLtTY.-Every quality is change, and we seek in vain, anywhere for the unchangeable. The reality then, to the intellect, is the flowing movement of the evolution of all things. Nothing is stable. Nothing is ever made, it is only being made. That process of being made is the ground work of evolution. The scientist's intellect seizes upon this movement of matter. By following that part of it, perceptible by the senses, he 
has formulated a theory of "a change of forms through the production of new configurations." Herbert Spencer's definition is "Evolution is the integration of matter and the concomitant dissipation of motion, during which the matter passes from an indefinite, incoherent homogeneity to a definite, coherent heterogeneity; and during which the retained motion undergoes a parallel transformation." In this definition there is no mention of his "Unknowable Absolute." There is no teleology, nor finality. Therefore it is not the definition of an idealist. We will discover later on the reason why an idealist objects to it.

All listory reveals, that thoughtful men have, for centuries, pondered upon the origin of the universe, but especially upon the solar system, the earth, and its astonishing variety of organic forms. The account in Genesis was written by a very able observer. Considering the probable want of scientific knowledge, at that period of man's development, that solution of the difficult problem is the best that could be expected. It attributes the origin of everything visible to a creative power, and that, at first, "the earth was without form and void." The word "void" is not now used by scientists, but according to the nebular theory the earth and all bodies were without form.

Definition of Evolution.-The theory of evolution grew out of the observations of a number of able students of natural phenomena. Their studies convinced them that matter and motion could not be rationally traced to any origin, but that the globes of space, and the organic forms of the earth, as well as, those of other globes, if any, had their origin, by the method of the apparent laws of all matter and motion, by the condensation of matter, from attenuated nebulæ. The 
formation of the earth, the sun and all astronomical bodies has been studied with eminent success by astronomers. Both the nebular and planetesimal hypotheses are reasonable and acceptable. The study of geology has made great progress. But biology, or the science of life, on the earth, is that part of evolution which lies the closest to man, and therefore interests him more than all others. The immense number of species; or life forms, each being characterized differently from other forms, and each being descended from common ancestors, in both the vegetable and animal kingdom, presented to the intellect of man a most profound and important study.

Origin of Species.-For the last fifty years the intellectual world has been wonderfully agitated upon the origin of these species. The great majority of investigators and writers had, prior to the publication of the "Origin of Species" by Darwin in 1859, looked upon specics, as spccially created, as stated in Genesis, with immutable differences, impassable by any natural process. In the light of the proofs given by Darwin, of their actual mutability, and these facts, especially that of experiments in breeding, in domestication, having been familiar to the farmer, the botanist, and the breeders of food animals, it is astonishing, that others did not see the bearing of the facts, in the same way Darwin did. Darwin's theory is, that all species vegetable and animal have originated by variations from the forms of their parents, in the anatomy and plysiology of the offspring, which variations, making them better adapted to the environment, and to spread over a larger area for food, werc continued and increased by heredity. In this way all species have arisen from a lowly form, whose origin Darwin does not discuss. The theory and its proof are discussed in future pages of this volume. 
Creative Evolution.-Bergson's observations upon Spencer's definition of evolution is, that Spencer takes things already evolved, and patches them together to prove evolution. It is using the thing to be proved, as evidence of the process. But Spencer does not hold that the atom, or the ultimate unit is either evolved, or created. The human intellect cannot account for matter and motion. So the evolutionist begins with matter and motion, and by following the integrations and dissipations of them, in the growth of vegetable and animal forms, and their decay, delineates, what the intellect perceives, in the method. That is a sensory and mechanistic evolution. But Bergson is not satisfied with that procedure. He say's, that is correct for intellect. But intellect acts only on matter. He desires to go behind matter, and for the purpose evokes intuition, as something superior to intellect to penetrate beneath or through matter to the flux. Intuition divines a "vital impetus" which gives direction to the life process, which is always a becoming, a creative evolution. Forms are only the emphasized points of this supposed flux of life through matter, the latter being the negative of life. Matter only degrades, or impedes the creative movement. The antiintellectualism of Bergson has received considerable approval in France, and perhaps in other countries, because, heretofore in the 18th and 19 th centuries metaphysical, and other philosophers, derided materialism, and neglected it. Matter has been looked upon, as Bergson regards it, as a degradation. Mentality was not regarded as the product of physiology. It is only of late vears, that the brain has been given, by a few psychologists, as the substrate of mentality, while he who thought as Hume and Huxley and Büchner did upon this problem, was more or less isolated in the belief of the 
theory. If others thought kindly toward materialism, they did not make it public. In another volume, the writer, expressed the opinion that Spencer, in the position lie took in the first part of "First Principles," regarding an "Unknowable Absolute" made a mistake, and weakened the argument of the "Synthetic Philosophy." He practically acknowledged as much in his "Autobiography." But Bergson thinks that "First Part," the best of Spencer's work. Of course when Spencer came to the real work of writing his philosophy, by beginning it with an exposition of biology, along the lines of evolution, he found it impossible to retain the conception of an "Absolute." His intellect could, or would see noth. ing, but matter and motion, integrating and disintegrating. There is nothing else to the intellect. Intellect of course only cuts into matter. Therefore man must summon more than intellect to aid him if he desires to cut into the real movement of becoming; he must work from the center as nature does. Intuition, the "aurora around the core of intellect" and growing out of it Bergson thinks must be the proper instrument for a new philosophy of creative evolution. He acknowledges, however, that he is unable, as yet, to give more than an intimation of it. Materialists will grimly wait for further developments. The finalists long before the time of Bergson had a theory that intellect is not usable in a system of philosophy. But Bergson also repudiates them, not because they have started wrong, but because they have gone too far, and that they are too anthropomorphic. He is compelled to acknowledge, however, that evolution is the true theory of the cosmic movement. But the intellect of Darwin, the materialist, had already demonstrated this, not the intuition of an idealist. The theory of Bergson, is that in the flux of life, forms are merely 
the marks of the flux, and are so constantly changing that they are of little importance compared with the real movement. It is much like the theory that the invisible ether is the hard unchanging, unimpressible substance of nature, and those forms, like the earth, which we have been calling the solids, the immutables, are really the mutable, the changing, the mobile part of nature. The movement is the reality, and not the forms. The latter are in constant evolution, by a change, and their morphology is governed by the "vital impetus" inherent in the movement of the whole. The creative principle is the movement itself. But man has been looking at the forms only, and founding his theory upon them, calling them matter. The changes in these he calls "time." Bergson says "The forms, which the mind isolates and stores up in concepts, are then only snap. shots of the changing reality." Yet they are the only parts of the general flux perceptible to the senses, and thus the conception of man must be made up from their qualities.

"It will be found that form is essentially extended, inseparable, as it is, from the extensity of the becoming, which materialized it in the course of its flow. Every form thus occupies space as it occupies time." But the philosophy of "Ideas" follows the inverse direction. It starts from the form; it sees in the form the very essence of reality.

There is a creative evolution of forms, and may be of matter and motion, but Bergson does not prove it inductively, he merely states it metaphysically. He drifts into the most radical statements of metaphysical idealism. We know nothing of a "Vital Impetus," nor of a vital principle, nor of a real cause. We know only what is apparent through the senses, and this is what he 
calls the operation of intellect on matter, or on the material only. The plainest explanation of what we are, is that mentality is the presentation of environment to the psvchical device, and the ability of that to reason out, from these presentations, the philosophy of life and - nature. The truth is what works in man's brain, with this correspondence; el'ror is the want of a proper conception of harmonious working. Whether the intellect is thus cutting into a flux, or duration, in which the solid matter is a degradation, or an inverse motion of descent, or whether the image on the brain is the reality by which human action should be guided, is of importance only, as the one, or the other view, will effect man's welfare, as a denizen of this globe. We must act upon sense impression, and not intuition, or mysticism. It is a practical question, not an academical one. The hunt for something beyond the reach of the human intellect, is a waste of precious time, and as William James said he could not always understand Bergson, it is not worth while for others to try.

Evolution Not Mechanism.-It cannot be said, in truth, that the process of evolution described above by Spencer is the same as that of mechanism. There is no analogy between the method of nature, and the operations of the hands of a man, in manufacturing a machine. In fact, the operations of nature are not explainable, by comparing them with those of man. Paley's illustration of the watch, as being parallel, and proving design, in works of nature, or any endeavor to use the works of man, as in any way appiicable, in the elucidation of natural evolution, falls far short of satisfactory reasoning. Especially is this so in the development of an organism from an egg cell to a mature form: This process is a division of cells from within out, and not the 
putting together of parts by building up from the eircumference.

So much for the schools of science and philosophy. The above is more of an introduction to this volume than a part of this chapter on inorganic evolution, which will be treated in a very general way in the next paragraph.

INORGANIC Evolution.-Inorganic Evolution is that of the universe, of the globes of space, including our solar system. But organic evolution is necessarily confined to the earth, because we know organisms exist here, but do not have a sensory knowledge of them elsewhere. Inorganic evolution is proceeding now upon the earth, side by side, with organic evolution. But it is apparent that the former infinitely preceded the latter in its duration, and that the latter could not have occurred until the former had progressed to the condition, when some of its elements assumed the chlorophyllian function : that is the process of decomposing carbonic acid and water, under the action of sunlight. The evolution of the earth had proceeded for ages, before this occurred. This was the period of the divergency of the organic method of evolution, from the inorganic. It is to be presumed that this divergence has occurred on other stellar bodies also, and that, in reality, it is not a divergence at all, but only appears so to man.

It will be seen that Spencer's definition describes, in technical language, the transformation of a nebula into the solid bodies of the solar systen, as well as the integration of a condensed form of matter, probably by chemical combination, into forms of life. The integration of matter, composing the nebula, into globes, and the concomitant dissipation of motion, in form of heat and energy,-the same as is now going on in the sunis a theory generally accepted by physicists. The scope 
of this volume will not permit going into the details, as Arrhenius has done. The immense space oceupied by the nebula of planets is incomprehensible. The largest among them is situated near star B in the Great Bear. It is perhaps many hundred times as large as the orbit of Neptune. In the very densest portion it is not more than a billionth of the density of our air. Their luminosity is feeble compared with that of the stars. Their temperature is equally low. The immense time it will take for the condensation of this nebula into a system of globes like our solar system, whether by the method laid down by La Place, or by the Lockyer and Chamberlain hypothesis, is inconceivable by us. But nature is duration, not time, as we conceive it. So that, the theories of world formation are true, upon the basis of the known laws of gases and of matter. The nebular theory of Kant, La Place, and William Herschel, in accounting for inorganic evolution, presupposes the homogeneity and gaseous condition of all matter: and from that nebular condition, the present heterogenous stellar universe has been evolved. The greatest advance in astronomy, made in late years have been the disclosures, by photography, of nebulosity, existing throughout space. More than 120,000 nebulae are known; they are being frequently discovered, and by observing these, astronomers are studying the phases, through which, our earth, and solar system, seem to have passed.

The theory presupposes that the nebula, from which the sun and the planets, for example, have integrated, filled the space within the orbit of Neptune with homogeneous matter in a very attenuated gaseous state. Or it is likely the nebula extended a sufficient distance beyond that orbit to leave Neptune in the relative position it now occupies, in the solar system, after the 
subsequent concentration of his arm of the original nebula. The nebula was the result of the collisions of the globes which had been formed previously in the same way. Granted the existence of this nebula, and the attraction of gravitation, and it can be mathematically proved that condensation would begin. In the process of condensation a rapid circular, or spiral motion, would be set up; and by the force thus generated, the different planets would eventually be formed upon self-appointed centers in succession; each planet representing a minor center of condensation, and being, at first, a mass of incandescent gas, according to the planetesimal theory, separated from the original mass by the attraction of a solid meteor penetrating the nebula from the outside. The momentum of each planet given it while remaining a part of the nebula would keep it moving. The velocity would increase as the planet solidified; and the pull of the central mass would convert this forward motion into motion in an elliptical track; the law of moment of momentum would perpetuate the character of the motion begun in the nebula, resulting, in the course of untold ages, in the separate planets as we now see them, moving in perfect harmony in their co-ordinate orbits around a central sun. The sun is the remaining portion of the original nebula, many times larger than all the planets thrown off, and retains its luminosity and high temperature long after the planets have lost theirs. It is still shrinking, and its heat is produced by the friction of condensation, and the chemical action of its elements. When energy seems to be lost it has only taken another form. Should all the bodies of the solar system come together in such way as to reform the nebula, would there be in such resulting 
nebula the same force, in quantity and power, which in the original nebula integrated the solid bodies and their motions as they now exist? The present mathematical method of solving this problem would perhaps answer this in the negative. But this does not necessarily imply that any of the force, or energy has been lost in reality. It is continually changing from one form to another. Some of it perhaps has taken forms, in regions outside of the solar system. The moment of momentum remains always the same, and this is the product of mass multiplied by the velocity; and that product again multiplied by a perpendicular drawn from the center, (such as the sun), to the line of direction of the moving body; for instance, the orbit of the earth. The moment of momentum, of a system like the solar, is the aggregate of that of all the bodies composing it. Energy is the aggregate work represented in phenomena. The multiplicity of effects, in the process of evolution, as well as the process itself, are phenomena. The energy of the solar system is represented in the quantity of work which could be done if all its bodies came together. The energy of each of its bodies can be ascertained by multiplying one-half of its mass, into the square of its velocity. The persistence of force, which is the most important law of physics, and is perceptible, to our senses, in attraction of gravitation, molar, and molecular motion, chemical attraction, in short, in the sensory perception the eye has of environment, is the manifestication of energy:-it is the same power that theology has personified, and given intelligent control of phenomena. Or perhaps it would be more accurate to say that the first conception by man of an omnipotent power was not that of natural energy, or the persistence of force, 
but of a personality above; or beyond, and producing phenomena.

It must be understood, also, that a separate system, like the solar, or the nebula, is constantly losing energy in the form of heat, by condensation. It is a curious fact that it may lose heat and yet retain its temperature. As it loses energy its motion decreases, and as its motions change, so does the relative position of its bodies. At the same time the relativity of its atoms changes; but there is no evidence that they will ever come to absolute rest even when all its matter comes together in one body. The movement of the atoms, in the process of condensation, is called arrested motion. The term "separate system," used above, must be taken to mean separate in form only. There is no "system," in reality separate, from the general monistic system, constituting what we call Nature.

The Planetesimal Theory.-A modification of the nebular theory has been made by certain scientists. Comets and many so called stars consist of swarms of meteorites, which though normally cold and dark are heated by repeated collisions, and thus become luminous. In time, the force of gravity condenses the meteoric swarm into a single globe. The parentage of the solar system is a spiral nebula, composed of planetesimals, and the planets, such as the earth, are formed from knots in the nebula, where many planetesimals have been concentrated, near the intersection of their orbits. Then these groups of meteorites, already as solid as a swarm of bees, are packed closer by the influence of gravity. The contracting mass is heated by the pressure above the uormal melting point of the material, but is kept rigid by the weight of the overlying mass. It is evident that this theory is as much in accordance with the theory 
of inorganic evolution, as is that of the nebular hypothesis. The meteors are composed of the atoms of universal matter, and must be compounds of simple elements. They are probably formed in the suns and thrown out by radiation pressure. Either theory comports with the principles herein advocated. The theory of evolution leads us to assume that the matter of the universe was never homogeneous. There was no beginning, and will be no end to phenomena. The theory now seeming most plausible is that world bodies are evolved from nebulae. These are produced by collisions of celestial bodies after they have become dark and cold. Such bodies may sometimes wander for a hundred thousand billion years before colliding. The nebula resulting from collision will have a central portion of high density, surrounded by a gaseous envelope, illuminated by the friction of its particles. The violent rotation given it by the collision, together with the centrifugal forces, will give a disk-shape to the "central mass. Meteorites, or planetesimals penetrating the nebula integrate upon themselves the gaseous matter, and, taking the motions of the nebula, form centers of potential planets. The rotational movement, the concordance of plane, and direction of it, thus acquired in the nebula by these nascent planets will remain with them for all time, with slight modification of velocity, and distance from the central body. The central mass will remain infinitely larger than the aggregate planets evolved, and by the radiation of heat, and the pressure of this radiation, will provide the planets with the conditions of life.

Nebulae are seen everywhere in space, and celestial bodies are as widely distributed. Therefore all forms of energy, such as heat, that are being radiated, while 
the evolution of worlds proceeds, are not lost. They hit upon either the nebulae, or the bodies evolved from them. While our sun radiates 2260 million times more heat than the earth receives, yet the excess finds places in the cosmical phenomena for its utilization. Every ray of light from any star will eventually be transformed by some other body. Life could not exist, and phenomena could not occur without the constant radiations from a hot body to the colder surroundings of space. A homogeneous and equilibrated condition of all, or any of the substance, or energy, is incompatible with this theory. But the rhythm of the production of nebulae by collisions, and the evolution of bodies from these, in the manner above mentioned, are the only tenable statements that can now be made. It is necessary to notice still further the planetesimal theory It seems that the prevalent form of nebulae is the spiral, and that these give a spectrum not of the bright lines of incandescent hydrogen, helium and nebulium, but one that is continuous. This means, that the matter here is of a low temperature, and in a liquid, or solid form, conceived to be in a solid form, finely divided, and is immensely spread out. The prevalence of the spiral form of these nebulae, with two arms thrown out on opposite sides, is significant of a process of world evolution. It is a scientific inference, by Mr. Chamberlain, that they are thus nascent solar systems, and that each one of them will become a sun, planets and attendant moons, such as is now our system. Any one who examines an illustration of a photograph of one of these spiral nebulae will see a very large central nebula, knots upon the arms, and surrounding the whole, finely divided matter. The theory supposes that this attenuated matter will condense upon the large nucleus and form a central sun, 
and that matter nearest the knots will condense upon these; and thus the sun and planets and moons will in the course of countless ages, become similar to our own system.

The constant falling of meteors upon our atmosphere now, and their matter fivally reaching the surface of the earth, after being fused into gases by the friction of their rapid flight through the air, are illustrative of the accretion of particles of matter in a nebula by the nuclei, and the evolution of worlds. This theory differs in many respects from the La Placean nebular hypothesis, but not in the fact that worlds are evolved continually in space by rotations of matter, whose origin is unknown. The nebular theory assumed that the planets were thrown off in succession in rings. The planetesimal hypothesis assurnes that they were all formed at the same time. There are other differences, not necessary to mention, in the elucidation of the principle of inorganic evolution. But all the facts when critically examined by $\mathrm{Mr}$. Chamberlain and Mr. Moulton, scientifically, accord with the well known facts of our solar system.

The Elements.-Chemists have known for many years that the matter of our earth can be reduced to about eighty elements. There are many facts which indicate that these are merely varying forms of one primeval element, yet undiscovered. "The elements that form one per cent or more of the earth's crust are only eight in number. They are given in the following table:

Per cent.

Oxygen ................. 47.02

Silicon ................. 28.06

Aluminum ............... 8.16

Iron $\ldots \ldots \ldots \ldots \ldots \ldots \ldots \ldots, 4.64$ 
Calcium ................. 3.50

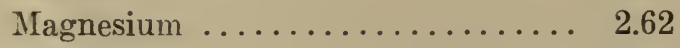

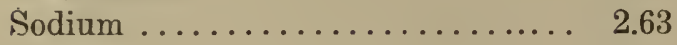

Potassium ............... 2.32

Total ................. 98.95

The elements forming less than one per cent, but more than one-tentl of one per cent of the earth's crust, are titanium, hydrogen, and carbon. It will be seen from these figures that neither the common compounds, nor the common elements, are bewildering in number. Examples of the chief rock-forming minerals can be found in nearly every locality." (Paddock)

The materials of the sun, planets, stars, and nebulae are essentially the same as those of the earth. The spectroscope has revealed this fact. The elements of which the earth is composed, when heated to incandescence, produce, in the spectrum, the same lines that some parts of the light of the sun, and stars, and the nebulae produce. This is a weighty piece of evidence in favor of the theory that earth, sun, and planets are all portions of the same primeval nebula. "In the spectrum every 'element' gives a perfectly distinct set of lines or bands; so that the spectroscopist may take any substance and heating it to incandescence, know from the characteristic lines, exactly what elements it contains." (Snyder).

La Place and Kant.-Neither La Place, nor Kant, knew of this evidence, yet they gave the theory the support of their names upon the evidence of other facts; La Place deducing it from the theory of probabilities. Kant maintained the nebular theory, which is directly subversive of special creation and, also, contended that 
the existence of a Creator and the immortality of the soul could not be proved by the unaided "faculties", of men. He, also, asserted that these unprovable things, must be believed upon authority. This means that the proven theories of science shall be disbelieved, for the sake of assertions, by those in power, which cannot be proved.

One fact in nature strikes one very forcibly, as at least a strong inference, in favor of the nebular theory. Heat, in sufficiently high temperature, resolves all solids into gases. In the sun's photosphere the spectroscope shows that many metals, and similar elements, that are in a solid form on the earth, are components of the gases of the sun. It is not only known that the gases of the sun are gradually condensing as heat is radiated, but that when, under the blow pipe, in the laboratory, a solid is converted into gas, that the reverse process occurs when the heat is withdrawn, viz., the gas naturally condenses into the former solid condition. Even the atmosphere can be condensed irito a solid. All heat has its origin in the sun, and is produced by the condensation of its units, radiating heat by friction. The inference is, that all matter has been condensed from a nebulous condition, in this way.

Concordance of Planetary Motion.-The other evidences of inorganic evolution are the remarkable concordance of the planes of the orbits, and the motions of the planets therein, around the sun, and the still further concordance of the orbits and motions of the satellites of the planets, with the orbits of the planets. The greatest inclination that any of the planes of the orbits of the planets have, to the plane of the ecliptic, is 7 degrees, that of Mercury. All the bodies move in the same direction, and this direction is that in which the 
law of motion in a nebula proves they would move, on the nebular theory. The satellites of Uranus and Neptune alone revolve in a direction opposite to that of the others; but the motions of those planets themselves correspond with the theory. There is a sufficient explanation of this anomaly; and the conclusion of astronomers is, that these satellites will revolve later on, in the true direction.

The satellites of Uranus revolve around the planet in one plane, inclined 83 degrees to that of the ecliptic, and in an opposite direction from the motion of the planet in its orbit. The law of dynamics implies that this means an excess of energy,-the inner satellite making a revolution in one and a half days,--which in the course of ages will be regulated, by gradually lessening this angle of plane, and decreasing the velocity. At first the angle will rise to 90 degrees, and then continue on the other side until it reaches 180 degrees. This would bring the motion in the right direction; not by any change in the absolute direction of movement of the satellite, but by lessening the energy of the movement, and at the same time increasing the angle of its plane to more than 90 degrees. This will bring the motion that now appears to be in the opposite direction into the same direction with that of the planet, or from retrograde to direct motion. This is, likely, what will occur to the satellites of both Uranus and Neptune. The latter are now only at an angle of 35 degrees to the ecliptic, but it is supposed that this plane will pass through inovements parallel to that of the satellites of Uranus.

"The movements of the satellites of Uranus and Neptune do not disprove the nebular hypothesis. Rather they illustrate the fact that the great evolution 
which has wrought the solar system into form has not yet finished its work; it is still in progress. The work is very nearly done; and when that work shall have been completed the satellites of Uranus and Neptune will no longer be dissociated from the general concord." (Ball).

Arrhenius thinks that the outer portions of the primeval nebula were so attenuated, that the immigrating bodies which formed the nuclei for Uranus and Neptune, did not attain sufficient volume to have the large common rotation, in the equatorial plane of the sun, impressed upon them by the tidal effects. For this reason, their moons are independent of the general concordance of movement in common plane.

RADIUM.-The discovery of radium is likely to change the ideas now in vogue regarding the age of the earth, and is most important to its geology. Heretofore it was thought there was nothing to replace the apparent loss of heat which flows from the interior to the surface. If there is nothing within the earth to replace this heat, then, according to the calculations of Lord Kelvin, the earth is only about a hundred million years old. But since a small particle of radium has been derived from the earth by Madam Curie, new estimates have greatly extended this time. Professors Strutt and Joly have determined that there are in the earth only five grammes of radium to a cube, whose side is one hundred miles; yet the heat given out by this small particle is so great that it is more than enough to replace the lost heat. It is calculated that if there were as much radium throughout the interior as in the crust, the heat would increase much more rapidly than it does from the surface toward the center. According to this theory, the rocks of the 
earth extend from thirty to forty-five miles only from the surface. At a greater depth than this the matter is fairly homogeneous. By an ingenious method, starting with the fact that from radio-active bodies the gas helium is given out, it is found that a specimen of thoranite, one of the metals of the earth, must be more than 240,000,000 years old. Of course, the earth would he of equal age. Another curious fact is, were there no carbonic acid, and invisible aqueous vapor in the atmosphere, there would be little continuous heat on the earth. The internal heat of the earth has little effect at the surface,-about one-twentieth of a degree, -but the heat increases about one degree every sixty feet from the surface toward the center. 


\section{CHAPTER II \\ ORGANIC EVOLUTION}

T $N$ the earlier stages of the evolution of the earth there could have been no organic forms, such as we know them now. But if the nebular or planetessimal theory is the correct one, there came a time in the condensation of our globe, after it had passed through a gaseous, and then assumed a comparatively solid form, that the surface temperature became greatly reduced. At some favorable juxtaposition of earth, air, temperature, and moisture, life must have arisen from inorganic substances in a manner entirely unknown to us, except by scientific inference, no man being there to see it; at first in a very lowly form, by a combination of elements which we find in all organisms,-carbon, hydrogen, oxygen, and nitrogen. As shown heretofore, three of these elements form a large part of the earth's crust, and nitrogen is one constituent, very large in bulk, of the inorganic atmosphere. The evolution of living forms, as we now see them, from the first true moner, which perhaps came into existence in a natural way in many places at the same time, is what we mean by organic, or biological evolution, as distinguished from the older theory of special creation. It followed after inorganic evolution, as a natural result of the upward, or progressive change of matter, from the homogeneous to the heterogeneous. Life could not exist without the inorganic for its support. It is never found except in contact with matter, and its own form is always composed of inorganic elements. The inorganic and the organic are never separate. A life form is not made up of certain inorganic. 
elements, and then disconnected, to remain without the necessity of a renewal of its parts from the inorganic. Its birth in its first state, its growth of matter taken from the earth, ocean and air, and its elements, returning to the inorganic environment at death, all indicate very clearly a transformation from the inorganic, and back again to the same. This connection, during the whole career of a living body, is of great significance to the principle of materialistic monism.

Probably life began in the water. Certainly the lowest forms of life are marine. From these, by gradual hereditary variation in form, and the integration of matter from the immediate environment, all species were developed. As said by Robert Kennedy Duncan, "Some instant, it may be, between the time when the geologist knows that living matter was not, and that, at which the paleontologist knows that living matter was, living matter began."

"The elements contained in sea water are sodium, calcium, magnesium, potassium, chlorine, sulphur, carbon, hydrogen, oxygen, and iron. The elements contained in living matter are these identical things."

Professor Macallum, of the University of Toronto, has shown that the relative proportions of the inorganic elements of blood-plasma and sea water are as follows: Sea-water 100 parts sodium, 3.81 calcium, 3.66 potassium. Serum of mammals 100 of sodium, 2.58 calcium, 6.69 potassium. Duncan asserts that the earliest seas were still nearer the composition of the organic elements of the mammalian tissue. These facts are very significant as to the origin of life in those early seas. The facts go toward proving that when the nebula of our solar system began to evolve, as we now see other 
nebulæ evolving, there was no break in the coutinuity of the evolutiou, from that first beginning to the present time; that the elements of the inorganic, which are now known to he in the organic, came together at some favorable epoch of such evolution, and formed a living organism, as naturally, as they did in the nebula, to form the globes of the universe. This theory is more plausible than that the germ spores of life float through space and fall upon globes everywhere, to develop into organisms.

Germs Eternal.-There was either the above described origin of life spores, or they are as eternal as matter. In the latter supposition they had no origin. It may be that when the atoms of the nebula come together in certain chemical combinations they become compound physiological units, in which the peculiar form of matter and motion called life, or the "vital impetus" is potential. But either theory of life is not supported by sensory proof, and it is therefore unprofitable to pursue it. What is apparent to the senses is the following: It seems the organism is a medium only which nature adopts for the continuity of life. The principal thing is this continuity. The successive forms are the momentary vehicles to carry on the invisible flux of life, from generation to generation. The germ cells carry the potentiality of variation, heredity, and all human action. Nothing is visible in them under the microscope, which would convey to the observer any prophecy of their imminence, power and importance. There is no microscopical form of future species, or individuals; nor is there the registration, in letters of fire, of the biology of all past life, which they carry in their tiny biophers, with which they are going to endow the future organisms, into which they will develop. 
But their significant burden is, that they will convey, to the sexual organs of these future organisms, the continuous power of creative life, and the essential elements of organic variation, required by the law of evolution. This is the great function of procreative germs of life.

It is not possible to put into artificial time, the period 'life has existed on the globe. Joly says, that about a hundred million years have passed since the age when the oceans originated. The temperature of the earth in this time fell from $365^{\circ}$, the lowest at which water vapor will condense to liquid water, to its present temperature. Life forms soon appeared in the ocean, which did not differ so very much from some of those now existing. We know matter and energy, or rather that aggregate of sensations which we call by these names, could have no origin, because it has been inductively demonstrated that both are indestructible. It may be the same with life. Arrhenius holds that life spores may be carried through inter-stellar space, and still retain power of fertilization on distant globes. This theory would class life spores with indestructible matter and energy, to which the word "origin" should not apply.

EMBRYology.-All organisms now develop from an egg-or-germ-cell. Here and there a scientist asserts that life is now arising from the inorganic by archebiosis. But the propagation, by cells, is the process apparent to everybody. All animals begin their development in a cell from $1 / 120$ to $1 / 100$ of an inch in diameter, having the same formation and the same composition in every instance. The worm that crawls on the ground, and man, who is the most complex and heterogeneous of organisms, have precisely the same 
beginning, in an egg-cell. But the egg-cell of man has altogether different potential energy from that of the worm. This difference is not perceptible until the development occurs. In its development, however, the embryo of man is not differentiated from that of other animals, until after the third month. Two cells appearing alike may develop, one into a man, and another into a worm. It does not seem that even microscopy can discern in the cell forms, the potential difference of the two cells.

In chapter 4 of the "Principles of Biology," Spencer treats of the proximate definition of life, and shows that it means the same as his definition of evolution given heretofore. The phrase "from homogeneity to heterogeneity," means the evolving of the higher forms of life from the lower. The term, "higher form," means a more heterogeneous structure and function. The "moner" of Haeckel is the lowest evidence of life that we read about, it being a splotch of organic matter, without form, and having no cell formation. The matter of the "moner" is as nearly homogeneous as any organic matter can be. From this first life substance, or protoplasm, it is reasonable to infer, that the cell was slowly evolved, which probably has taken more time, as geology marks time, than all the ages since the first cell was formed.

Trme.-It is necessary in the above sentence to insert the expression "as geology marks time," and it seems pertinent to interject here some observations on "time." There is no time, as our ordinary intellect conceives it. The only way we mark it, is either by the measurement of space, as the second, minute, hour, day, week, year, etc., or by noting the changes in phenomena, or the material forms of life, or matter. But in those things, or prineiples, upon which we base so much of our being we 
notice no changes. The principles of logic, or of mathematics, never change. The demonstrations of arithmetic, of geometry, - such as the right angled triangle,- -are the same now as they have always been. The golden rule never grows old, but is new, and bright, as it was first uttered by man. So with the cell, the basis of life, and the atom, or ion, or explosion, the basis of matter. There is no change to these. Unity, continuity, condensation, conservation, never change by duration, and hence the usual marks by which we note the flow of time, in mere forms, do not apply to these. So that time, as a reality, is a mere conception of the human brain. It is merely a name we apply to other realities. When the attention is withdrawn from the ordinary succession of the movements of the sun across the sky; that is, the artificial division of time, and concentrated on an object remote from any connection witl the passing hours, then to the brain there is no flow of time. If there were no visible sun, moon, or stars, nor any artificial instruments, to denote duration, there would be no time, except the rhythmic action of the vital organs, and the coming and going of forms of matter.

Heterogeneousness.-Montgomery, in "Analysis of Racial Descent in Animals," contends that racial advancement is not from the homogeneous to the heterogeneous, but that it is the degree of morphological departure from the original ancestor. Now, it is true, the cell is a lieterogeneous organ, as he contends, but only in its potential growth energy. But, compared with the heterogeneity of a matured man, both in structure and function, it is quite, though not entirely homogeneous. Evolution in its broadest scope, including inorganic and organic, is certainly a development from the homogeneous to the less homogeneous. if the hypo- 
thetical nebula is to be considered homogeneous, and as the beginning of evolution. If the atoms were all alike they would constitute a homogeneous nebula.

The unicellular protozoon, which never develops beyond one cell, but grows in bulk only, differs from the multicellular metazoon, in its beginning, not in the size, or form, or substance of the cell, but in the absence of fertilization of its nucleus; and the consequent addition of new cells, in building up a multicellular organism. A multicellular organism grows by fission, but in doing so the birth of new cells is accompanied by a membrane that holds the cells together. The significant fact, for evolution, is that in its beginning every animal, also every vegetable; is a cell analogous, if not homologous, with every other, in appearance. That fact, coupled with another fact in embryology, viz., that all mammals, including man, in their embryological development, before they arrive at the mammalian form, parallel the embryological forms of all the animals below the order of mammals, viz., radiata, articulata, molusea, and fish and reptiles of the order of vertebrata, is very strong evidence that they were, at some period of their development, existing in the adult forms of these lower orders. This is strong and very convineing evidence of derivation from lower orders, by variation and inheritance. There are scientists, however, who deny the exactness of the parallelism. Montgomery contends, that when a variation occurs, that is racial, there is not only a modification of the matured form, but what makes the variation racial is the fact, that the germ cell is modified correspondingly. This is Weissmanism. Therefore all subsequent embryos are modified, not only at the point, where they assume the form of the new race, but at all stages, prior as well as subsequent. So that there can- 
not be in such embryos, which means all embryos, any real parallelism between the ontogeny, and the phylogeny. "The relation between the two is always that of an inexact parallelism." This means that, in a general way, there are points in the ontogeny that can well be interpreted as indicating a parallel to the phylogeny. More thorough experimentation is needed in embryology to determine in just what points the parallelism consists.

Classification.-The usual proofs of organic evolution by natural selection, or the survival of the fittest, are drawn from classification, morphology, embryology, paleontology, and geographical distribution. These are all important branches of biology. While the scope of this volume will not permit an elaborate treatment of these very interesting studies, yet a few facts, prominent in each, will perhaps stimulate the reader's attention toward a larger study of those scientists' works who have made a more elaborate practical analysis of them.

Naturalists, prior to Darwin, had busied themselves in making collections of specimens, and studying the facts of affinity and variation, without seeming to arrive at any theory regarding the origin of forms. They took for granted the statements in Genesis, and classified accordingly. Species were asserted to be immutable; each the result of a definite creative act, and each separated from every other by impassable differences. These were the bases of the Linnean classification, and also of Cuvier's. The naturalists, St. Hilaire, Lamarck, and Erasmus Darwin were exceptions. They conceived the idea of evolution founded on methods not properly established by science at that time. The theory was not adopted by naturalists until a more correct method was established by Darwin and Wallace. 
Any classification of organisms, however, was an analysis made by man as a means of logical study, and was more or less artificial. The elassification of Linnaeus was largely artificial. It was based on superficial qualities, and special creation. But he first used the binomial nomenclature, a terse formula for description, and fixing attention on species, and in use at the present time. His classification was not based on internal structure, or anatomical and biological or generic features. He extended his lists by description of species only, under the presupposition that they were created.

Cuvier classified by comparative anatomy, but still based on fixity of species. He believed in special creation. He conceived four types of animals: the vertebrated, the moluscan, the articulated, and the radiated. He first wrote a pamphlet in 1795 . He first gave expression to the idea of correlation of parts; viz., that, for instance, a cloven hoof indicated certain forms of other parts. He was the founder of comparative anatoiny. But he was also the inventor of catastroplism. He asserted that apparent differences, and likenesses, of fossil forms in the strata of the earth, were caused by the destruction of all life forms in the different epochs, and the special creation of new ones.

Von Baer founded the science of embryology, which supported Cuvier's comparative anatomy. When the theory of evolution was born, in 1859, it supplemented Cuvier and Von Baer, by eliminating special creation and substituting close genetic affinities. Embryology, and comparative anatomy, after that, had a new meaning for classification. Man was then dethroned from the position of a special artificial order, which Cuvier created for him, and given a family in the order of 
mammalia. Instead of being created at the head of animals, he had the same genetic origin as all other mammals. It also became then plain that the line between the different orders, families, genera, and especially of species, was not distinct, but that the demarcation became very obscure at the margins, and the species of former epochs gradually merged into others.

By a general sweeping classification of all organisms, Linnaeus, Cuvier, and other naturalists quickly found that two organic kingdoms could be established,- the vegetable and the animal,--but not by strictly impassable boundary lines. They merge into each other at all points of attribute and quality. In some degree, the characteristics of a vegetable are found in every animal, and every animal possessed at some moment, and in some species, the peculiarities of a vegetable. This is not surprising when it is found that the vegetable is but one step in the evolution of higher life, and that animal life is not possible without the vegetable. The cells of both are propagated by like methods, and are similar, in being formed of identical protoplasm. The two can be classified into groups, characterized by certain qualities, which are emphasized by the group, but not possessed exclusively by it. The most important distinction between the animal and the vegetable is their method of alimentation. The vegetable takes directly from inorganic nature its sustentation. But the animal draws its sustentation only secondarily from the inorganic, through the vegetable, which has stored, by its chllorophylian power, a reservoir of fixed carbon, directly from the soil and air. Yet, there is the enigma of the Drosera and the pinguicula, which live like vegetables partly, and, like animals, feed also upon 
insects. The fungi feed like animals, as do all vegetable parasites. Yet there are sufficient other similarities between these lowly organisms, and the vegetable kingdom in general, to classify them with the latter. In the matter of mobility, and fixity, there is the same quality in some degree in both kingdoms. Yet the matter of moving from place to place is so overwhelmingly in favor of the animal in general that there is little difficulty in making the classification.

Linnaeus, Cuvier, and all naturalists who undertook to reduce the innumerable living organisms on the earth to an orderly system, soon discovered analogous structure and function in all. Both kingdoms are made up. of such numerous diverse forms, that it required wonderful intellectual ability and judgment, to so arrange them, in groups subordinate to groups, having such abiding characteristics in common, that the members of each group could always be properly placed, by means of their group characteristics. At first it was thought that those animal structures whose functions were of the widest use to the individual, and most apparent to the eye, should be taken as the abiding characters for classification. That was the method of Linnaeus. Form and outline were the elements. Darwin says that, "Linnaeus misled by appearance actually classed an homopterous insect as a moth." But experience demonstrated that really the most persistent structures, -and the most helpful in classification,-were the more obscure, and the least useful. Cuvier made the beginning of the internal method, by dissection, anatomy, and physiology. This is also a very strong proof of evolution, or derivation, by variation and inheritance; because, if, for example, all the vertebrates have backbones internally, and the orders of that division include such wonderful dif- 
ferences of form, and structure otherwise, as fish, reptiles, birds, and mammals, then all these differences must be variations of, and derivations from, a common ances tor, having only one form, and a backbone.

The great variety of forms in the vertebrate division. is a differentiation of structure that is called adaptive. But the inner vertebral structure persists through all the variations, and this classifies the orders of fish, reptile, bird, and mammal, under the single division vertebrate. The same principle applies to each of the other divisions of the animal kingdom, viz.: "Mollusca, Articulata, Radiata and Protozoa. In each it is a persistent, and unadaptive structure, often obscure, which marshals the different orders, group by group, with their great variations of outward form, under these five great divisions. For example, man's vertebral and mammalian structures do not dissociate him from the order of vertebrate mammals, although his superior brain and its psychial manifestations do. But the latter are such variable qualities, that they cannot be used as bases of classification. They are secondary characters, having grown out of the physical. The physical and genealogical, alone, can be made the basis of classification. $\mathrm{He}$, therefore, must be classified as a family of the order of mammals. He was, therefore, not created at the head of the animal kingdom.

Classification of plants and animals is made in groups subordinate to groups. This can be done only because of structural resemblances, and structural differences. For example, a porpoise lives in the water and has th: form and habits of a fish. Yet it gives suck to its offspring, and is therefore a mammal. It is rare to find a mammal an inhabitant of the water. The order as a whole is terrestrial. Yet it is clear that the whale, the 
seal, the porpoise, on the theory of descent from a preceding form, common to all mammalia, by so decided a change of habits, from land to water, changed only such structure as was necessary to adapt them to marine habits. But the structure necessary to suckle the young: persisted in the new habitat. It is this persistent, but less apparent structure, that classifies them, and not the more adaptive structures of legs and feet, clianged to paddles, and the terrestrial general form changed to the shape of a fish. Should the whale eventually adopt a terrestrial habitat, the fish-like form would change to an adapted form, but it would still retain its persistent mammalian structure, by which it is classified. Darwin says that community of descent is the bond that is par tially revealed to us by descent. Outside resemblances are of no importance. The resemblance of a whale to a fish is worth nothing in classification. Nor are any organs, connected with special habits, of value. Adaptive characters are not valuable in classification.

The rudimentary teeth in the upper jaws of young ruminants, and certain rudimentary bones of the leg, are highly serviceable, in exhibiting the close affinity between ruminants and pachyderms. This shows how parts unimportant to the organism, in its movements, are of the highest importance in classification. The object of classification is to show genetic affinity of the members of the groups. Every feature, or character, showing this, is a proof of descent by inheritance with modification. It would almost seem that true and enduring classification is merely bringing together the evidences of evolution of organisms from lower orders. (Darwin).

If classification is made by neans of those characters showing genetic affinity, it is also found that when the 
organisms are actually placed together in groups that most other characters correspond also. The embryological characters are of more value in classification than those of the adult form, because the embryo in its development parallels, in a greater or less degree, many of the embryological forms, through which the ancestors of the embryo have passed. This is an important point of proof of the truth of evolution, and the close parallel, observable between classification and descent with modification. "Community of descent is the hidden bond which naturalists have been unconsciously seeking, and not some unknown plan of creation, or the enunciation of general propositions, and the mere putting together, and separating, objects more or less alike." (Darwin).

The Great Significance of Natural ClassificaTION.-The importance of the broadening advances of biological discoveries, from Linnaeus, who studied life forms, from their most common and apparent outside appearances, to Darwin and Wallace, who discovered the methods and principles of evolution, cannot be overstated. Each step in advance tended to disclose the homology and unity of all life forms. Cuvier, and the comparative anatomists, made the first step from mere outside form to structure. Then Bichat, the wonderful genius, who died at 31 , asserted that tissue made up the bones, and flesh of all animals. Then Schwann and Schleiden discovered that all tissue is formed by cells, thus establishing the cell theory. Then Von Mohl, and Max Schultz, showed that the cell is lined with a universal substance which Von Mohl named protoplasm, and Schultz showed to be common to vegetable and animal life. This protoplasm is the basis of all life, forming all the parts of every life form, while Darwin showed that 
all life forms have been derived, with modifications, from preceding forms, by variation and inheritance. These discoveries were made after science broke away from the blighting influence of authority, and investigations were made by the human senses alone; "the dark ages had passed away," and civilization had changed from the cloister, to the light and fresh air of nature; after men began to gain knowledge by actual experiment and the study of nature.

These advances in biology are paralleled by the achievements in astronomy, geography, geology, psychology, sociology, chemistry, and natural ethies; all done without the aid of mysticism and finality, by the natural brain, and peripheral senses of man.

In making classifications, the naturalists had no written pedigrees of the organisms to guide them, but the characters, which nature stamped on the forms, probably were more instructive, to the trained classifier. These formed a pedigree without error, when read accurately enough to formulate a true classification.

The advance made in the method of classification from time to time, from the purely artificial plan of Moses, down to the more natural system of Cuvier, and from him to Darwin, while not so intended by the classifiers, yet at every step showed more clearly, the close genetic relation of all plants and animals. Had these naturalists entertained the theory of descent by modification, as taught subsequently by the theory of evolution, they could only in a few instances have made their classifications more complete evidences of that theory. All classification not only shows close affinity, accompanied by modifications, but a gradual advance from the earliest fossil forms, in heterogeneousness, - a constant multiplication of effects, and a development 
from the simple to the complex. These are the cardinal principles of the theory of evolution.

Morphology.-Members of the same class of organisms resemble each other in the general plan of their organization. This is unity of type. This is morphology. Darwin says, "What can be more curious than that the hand of man, that of a mole, the leg of a horse, the paddle of a porpoise, and the wing of a bat, should all be constructed on the same pattern; should include similar bones, in the same relative positions?" In some degree all animals are alike in some points, not only in form, but in growth.

A tiny round cell, in the embryo, as said before, is common to all, at first. From that period, to the adult form, there are innumerable points of homology, and more of analogy. The embryological form, common to all animals, is the first to be developed, in any vertebrate; this is the formation of a round ball of cells held together by a membrane, the gastrula. Then follow, in regular order, in the same embryo, as it develops, the structures common to the embryos of the radiata, articulata, mollusea, and then the vertebrata; and lastly, appear the characteristics marking the species to which the embryo belongs.

Rudimentary Organs.-And, on the upward development, each species carries with it, in vestigial form, many structural organs, useful in the lower forms, but useless, or even harmful in the higher. In the human body, we have hair covering the fœtus, and shed prior to birth; the thymus gland; the muscles moving the scalp, the ears, and other parts of the skin; the peculiar fold in the tip of the ear; the hair on the arms; the valves in the horizontal, and not in the perpendicular veins; the pineal gland in the brain; the 
semi-lunar fold in the eye; the coccyx, or trace of tail at the end of the vertebral column; the milk teeth. All these are what are called rudimentary organs. None of them,--save possibly the pineal gland,-plays any appreciable part in the human economy. Some of them, as the hair on the arms, and the valves in the (now) horizontal veins, would have been useful to an animal walking on all fours. Others, as the vermiform appendix, would be useful to an animal whose diet was chiefly fruit, having four legs and needing longer intestines. On the theory of special creation, how shall these rudimentary organs be accounted for? Being of no use to the organism, why should they have been created in it? But on the theory of evolution, by variation and heredity, they are understandable.

It would seem difficult to name one of the higher animals, in which, some part is not in a rudimentary condition. In all mammalia, for instance, the males possess rudimentary mammæ. The teeth in the upper jaws of unborn calves, which never cut through the gums, and also, in fœtal whales, there are teeth, while the matured whale never has any. How can these be accounted for by special ereation? G. H. Lewes mentions the Salamander which lives on land, away from water. Yet, the pregnant female bears tadpoles with finely feathered gills, and if taken from her, in the embryonic state, and put in water, swim like the tadpoles of the water-newt. It is stated, that in some older works on natural history where authors were believers in special creation, rudimentary organs are accounted for, by saying they have been created, for the sake of symmetry, or to complete the scheme of nature. As remarked by Darwin, what would be thought of an astronomer who maintained that the 
satalites revolve in elliptic courses round their planets, for the sake of symmetry, because the planets thus revolve around the sun? He also remarked, "It is probable that disease has been the main agent in rendering organs rudimentary, as in the case of the eyes of animals inhabiting dark caverns, and of the wings of birds inhabiting oceanic islands, which have seldom been forced to fly, have ultimately lost the power of flying."

SIMILARITY OF PARTS.-In comparing one organism with another, the organs, and the parts of the anatomy, are always in the same order. In vertebrates, the names of bones in one can be applied to the bones in the same location in another. Illustration of the principle can be made of the mouths of insects. However different in shape, they are all the same mouth, in anatomical construction. Darwin has shown, how hopeless it is to try to explain this similarity of plan, by utility, or the doctrine of finality. But on the theory, of the selection of successive slight modifications,-each modification being profitable in some way to the organism, the explanation is easy. The common progenitor of insects, it is reasonable to suppose, had an upper lip, mandibles, and two pairs of maxillæ, then natural selection would account for the great number of variations from that primitive form. But would special creation of each form, to be succeeded by a new form in the next generation, be a reasonable supposition?

"Comparative anatomy proves to the satisfaction of every unprejudiced and critical student the significant fact that the body of man, and that of the anthropoid ape, are not only peculiarly similar, but they are practically one, and the same, in every important respect. 
The same two hundred bones, in the same order and structure, make up our inner skeleton; the same three hundred muscles effect our movements; the same hair clothes our skin; the same groups of ganglionic cells build up the marvelous structure of our brain; the same four-chambered heart is the central pulsomer of our circulation; the same thirty-two teeth are set in the same order in our jaws; the same salivary, hepatic, and gastric glands compass our digestion; the same reproductive organs insure the maintenance of our race." (Haeckel). And he should have added, the same physical, and mental habits; the same sleeping and waking; the same emotions of fear, anger, and effection; subject to the same diseases, and the same death. The same medicines have like effects, on man and monkey, horse and dog. Under like environment the monkeys, in less degree of intellectuality only, respond to like excitation of their peripheral nerves, in the same manner that man does. The evolution of man has occurred just as that of other animals. Darwin puts the erect position of man, as the result of natural selection. This position brought about correlated variations in the body, as do all heritable variations. When man could make artificial tools for defense, his natural tools degenerated for want of use, for instance, his canine teeth, and jaws. His social instincts and intellect make up for his physical weakness, compared with other mammals.

The Formation of Types.-Morphology is the science of life forms, as crystallology is that of inorganic forms. It was of more importance to Linnaeus who largely classified by its law, than it is now, when internal structure and function are considered of greater usefulness. It is of very great benefit in the science 
of evolution, however, in that, the forms of organisms closely coincide at all points of their development, and especially in the study of embryology, which is also designated by another word closely allied to morphology, and that is morphogeny-the genetic source of form. When vital energy starts a cell by division into first two, then four, and then eight cells by growth, why do these aggregations of prolific cells take certain familiar forms, instead of assuming some other? There is a wonderful analogy in all animal forms, but an especial similarity among the higher orders. Yet, at certain periods, in heredity, the form suddenly changes in its growth, by a more or less variation, and sometimes by a change so radical as to form a new species. But however radical, in the eye of the naturalist, the change may be, yet the general form of the new species is clearly in general accord with all life forms, or the type, as it may be called, of animal life on the globe. There is always a conformity to the local rhythm, so that, as said in another place, the organism can always be divided through its axis into two equal halves, similar in form, at least, at all its points. It is altogether probable that the life forms on the earth conform to the local rhythm of that globe; and the life forms of another planet, whose distance is greater from the sun, whose bulk and weight are different from those of the earth, would have a typical life form, correspondingly different from that of our world. When we shall know more of the forces of attraction and repulsion, and the rhythm, compelling the globular shape of matter, when it integrates into solid forms, from that of the earth, to that of a germ cell of an organism, we may be able to formulate accurate sciences of morphology. Yet the mere form of an 
organism, so corresponds with its qualities and attributes, that its mentality is clearly allied to its physical features. How much more interesting are the antics and movements of a chimpanzee, than those of a sloth; of ants and bees, than those of a snail, or worm. The forms of all these are perfectly adapted to their psychical manifestations. In the same manner man, standing erect, with arms and hands free, to seize upon matter, and mold it as he chooses with a far range to his vision, because he does stand erect, has also a mind corresponding to his shape, in its free choice of many methods open to him to use his superior vision, and his free, well formed hands; while his nearest brother in the animal kingdom, the orangoutang, not being able to maintain the upright position, and not having free hands, is also, low in his methods of mental action. Yet, the man and the monkey, as said above, are very much alike in anatomy, and differ in psychical action, only in degree, not in kind. The chief difference between the vegetable, and the animal forms, is that the cells of the former are bound in a sac, the walls of which are composed of cellulose. The nature of cellulose in its character, as a binder, to prevent freedom of action, such as an animal exhibits, is best illustrated, by saying, that cotton, and the bleached fibre of flax and hemp, are nearly pure cellulose. The animal could not have its peculiar characteristics, if cellulose covered each cell of the body.

Development of aN Embryo.-One of the most beautiful and wonderful phenomena of nature is the development of the embryo of an organism. From the moment of fertilization to the maturity of the form, it unfolds in the most marvelous manner, as if the delicate touch of an artist's fingers was molding it into 
predetermined shape. Its beginning is a minute spheroid which, seen under the microscope, reveals nothing resembling a pattern of what it is to becomeonly a little sac of fluid, with a tiny dot, near the center, called a nucleus. But, when it comes in contact with the proper sperm cell, it inaugurates a movement of its particles, and division of its nucleus, which lead to a geometrical multiplication of the one cell, until thousands and millions of them are aggregated into first one form, and then into another, until there appears a heterogeneous organism almost exactly like that from which the tiny original cell emanated. So marvelous is this development, that the student is struck with astonishment, that he does not see the sculptor while the work proceeds. Yet it is only an invisible artist, called cosmic energy, with the molding power of the universe, guicling its unseen fingers, in pinching the matter here, and pushing it out there, placing the brain matter within a hard protecting covering, and at the fore-front of the body; the wonderful pulsomer, and its vascular organs as delicate, in tissue, as a gossamer thread, yet as strong as steel bands. The proportions are perfectly preserved at every step; yet at the first stage the student thinks it must be designed for a protozoon; at the next, for a member of the articulata, at the next for a vertebrate, and so through the embryological forms of all animals, it at last may become the body of a human genius, who will astouish the world, with his mental powers.

The same wonder can be expressed at the formation of a crystal, and from that, the fabrication of a globe, like the earth. The universe is an aggregation of morphological bodies, all made of matter and motion, manipulated by the unseen, but marvelous principle of 
evolution. It is the stream of movement in an orderly developınent, in which millions and trillions of integrations, and dissipations occur, only a tiny part of which is seen by the eye of man. 'This part consists only of that which is useful to him in the little act he plays, upon one of the smallest globes of the universe. He never sees the artist.

Paleontology.-Paleontology does not disclose the beginnings of life. It reaches back in animal life only to the evolution of organisms with hard bodies. The fossil evidence from plant life is less complete than from animal life. The former reaches back into the geology of the earth much further, however, than does the latter. The fossil forms of plants of the earliest epochs must be rather obscure, and the origin of them is not in evidence. They lacked the bony parts characteristic of animals, by which fossil forms of the latter are preserved in the rocks of the earth.

Examples of Fossil Forms.-Darwin says that the evidences from geology are few and scattered; that only a small portion of the earth's crust has been penetrated, and that fossil remains are not so satisfactory as he could wish. But, when he was in South America, during the voyage of the Beagle, he noticed that the fossil species, of the region, were only modifications of the living species. The evidences have increased largely, and at the present time, there are groups of the deer tribe, of the horse, and many others. The first ruminants were without horns. The first fossil antelopes in the middle Miocene had tiny horns. These increased in size in the later epochs, until the present. There is a progressive development of fossil deer horns from the lower Miocene to the present. In fact, fossilized animals show the evolution of form from the earliest 
specimens in the Cambrian to the Post Pliocene. Romanes thought the evidence from Paleontology is very rich. Prof. Marsh's geological specimens prove the evolution of the horse, from a very inferior form, in the Eocene epoch to the fine forms of the present day horse. In each epoch, the feet were structurally adapted to the then surface of the earth, for locomotion; and the teeth to the mastication of the existing food of the period. But the principal point is, that each successive form was a modified descendant of a preceding one, changed by the natural method of variation and heredity. In this case of the horse and his ancestors, the missing links are produced by Prof. Marsh.

In speaking of the missing links in general, Prof. Le Conte says, in reply to the question, "Where are intermediate forms?" "We answer, the intermediate forms are eliminated in the struggle for life, and are not reproduced by cross-breeding." This disposes of the missing link. It is absurd to talk of the missing link, for the further reason, that the gradations are so gradual, each modification has been so slight, that it could not be perceived by the human senses, even if it did exist, except in mutations, and in those there is but one link, which may not be noticed in the wild state. Each gradual change from a low type, toward a higher animal, would be classified by naturalists as either a variety, or a new species, and would be the missing link, but unrecognized as such.

Were all the variations through which the first form has passed in its development into the species now existing, before the naturalist for classification, the whole might be called one species with innumerable varieties. Agassiz examined several thousand shells of one species, and found no two exactly alike. Those 
species which De Vries claims are formed by one variation would show no "links" when the actual mutation is not seen in the wild state. In fact, in mutations there would be no link. The derived form would not be recognized as a modification of the preceding one. It is for this reason that De Vries makes his experiments upon domestic species entirely.

VARIATION, A LAW.-The fact is, that variation is a law of nature. Not only two things seen at the same moment vary, but the same thing seen in successive moments is not the same, to the human mind. There is a ceaseless flow of variations, in the attitudes and conditions of human cognition, and a slower change in the object. Our bodies, and especially the physiognomy, change from day to day, not only because a real molecular change has occurred, but also because at each period they are a day older. Flow and duration are said to be the very essence of reality. The more stable an object is, the more degenerate. The inorganic is on that account, far less interesting and important than the organic. The latter moves and reproduces itself, then the reproduction is never just like the producer, and the descendants of an organism are not themselves alike. "We may say summarily that there seems to be a tendency, when experiments are repeated again and again, for the results to vary more or less about an ideal standard, form or type. For we may regard each human individual, say, as a repetition of the experiment of producing a human being; each rainstorm as nature's repeated attempt to produce rain, etc. That many such experiments are conducted simultaneously does not effect the logic of the situation, just as the result is indifferent whether we toss one penny many times, or many pennies at 
once. The examination of large collections, or repetitions of similar phenomena, thus suggests that we could not discover from the single case, namely, that besides the general law which says, 'be so and so,' there is another which says, 'be not quite so and so.' Such at least is the superficial impression we get from the facts." (W. H. Sheldon of Dartmouth College). The only meaning of Time is that it is a change in phenomena. Phenomenon itself is a manifestation of movement, in the abstract, and movement is the evolution of nature, with constant variations, and the survival, but for a short fleeting duration, of the fittest. Matter seems to be merely the resistant to the flux of reality, and forms, while they exist, the momentary triumphs of such existence. In this sense, there is a struggle in the inorganic, as well as in the organic. The seeming steps in the onward flow are merely our mental percepts, and concepts, of the solid forms, of which the intellect has a constant apparition. A psychic being, above and greater than intellect, if there could be such, would note, not the steps and states, but the whole movement and struggle, as a movement only.

Fossil Discoveries Since Darwin.- "Since the 'Origin of Species' was written, our knowledge of that record" (paleontological) "has been enormously extended, and we now possess, no complete volume, it is true, but some remarkably full and illuminating chapters. The main significance of the whole lies in the fact, that just in proportion to the completeness of the record is the unequivocal character of its testimony to the truth of the evolutionary theory. The test of a true, as distinguished from a false theory, is the manner, in which, the newly discovered and unanticipated facts arrange 
themselves under it. No more striking illustration of this can be found, than in the contrasted fates of Cuvier's theory and that of Darwin. Even before Cuvier's death, his views had been undermined, and the progress of discovery soon laid them in irreparable ruin; while the activity of half a century in many different lines of inquiry, has established the theory of evolution upon a foundation of ever growing solidity. It is Darwin's imperishable glory that he prescribed the lines along which all the biological sciences were to advance, to conquests not dreamed of, when he wrote." (W. B. Scott), (1909). "If the doctrine of evolution had not existed, paleontologists must have invented it, so inevitably is it forced upon the mind, by the study of the remains of the Tertiary mammalia which have been brought to light since 1859." (Huxley). In 1909, fifty years from the publication of the "Origin of Species," the evidence must have been very much more complete.

Adaptive VARLATION.-It is more than probable that since organic life first appeared upon the earth there have been many changes, in the contour of the globe, and consequent changes of climate. These have profoundly affected organisms. Those living on the border of the change, where no barriers interposed, were, many of them, enabled to migrate to more favorable regions. But the great majority of the flora and fauna would give way to changed conditions, and die out. Organisms better adapted would eventually come. A few of the more vigorous individuals, of the old form, would survive, and gradually form new habits, compatible with the changed features. There is not a perfect adaptation of all individuals in any region, for changes minute and gradual, are taking place everywhere. Paleontology shows this. The 
fossil specimens in the different geological formations are generally those of extinct species. These have been followed by others in seemingly quite regular succession, each adapted for a time to the slowly changing environment, and especially to the climate, the feet to the surface, the teeth and digestive organs to the natural vegetation of the period, the morphology to the local general features of sunshine, humidity, composition of the air, the electric and magnetic conditions, and the necessity of any peculiar requirements, in the method of obtaining their sustentation. These general principles of variation and their causes run through the whole fossil forms of flora and fauna. The forms of one period differed in some particulars from those of another, but only in modification, not in discontinuity, showing a close genetic affinity running through the whole series, clearly indicating continuous descent, and not discontinuous catastrophism.

Geographical Distribution.-Paleontology can only give evidence of the evolution of species in geological time. But geographical distribution furnishes arguments from widespread location of species, in earth space. If the theory of special creation were true, then there is no reason why forms, whether fossil, or living, adapted to a given environment, should not be found in all localities, furnishing such environment.

The Fauna of Australia.-For example, the rabbit when carried in ships to Australia, found itself so well adapted to the locality, that it overran the island, until it was declared a nuisance. Other mammals carried to the island throve as well. Yet the only mammalian life indigenous to Australia,- the dingo being plainly an importation,-is one of the oldest and least developed kinds, the marsupial. The 
duckbill is a very low form of vertebrates, being a monotreme. In Australia the forms of animal life found upon the discovery of the island consisted of those found, also fossilized in the Cretaceous rocks elsewhere. The inference is that, in the Cretaceous period, Australia was connected with the continent of Asia, and was then, or soon thereafter transformed into a large island, but not of sufficient dimensions to make geographical distribution efficient, as an element, in the evolution of new species, from the lower orders of vertebrates then existing. About one-third of the island-the interior,-is a desert without animal life. If Australia had remained a part of the continent of Asia above, as it is below the surface of the ocean, the same mammalian forms would have evolved there, as in Asia. The absence of mammals, and the persistence of marsupials are thus accounted for by natural cause and effect. It was while on the voyage of the Beagle, that Darwin noticed a similar anomaly in the fauna of the Galapagos Island, six hundred miles off the west coast of South America. The fauna there consisted almost entirely of birds, with three species of land tortoise, and five species of lizard,- -no mammals. But he noticed that the forms of these were very closely related to those on the mainland. The inference was, that the islands had been colonized by such of the continental forms as could cross the intervening strip of the sea, the birds by flying, the lizard, and the tortoise, or their eggs transported on drift wood, or carried by water direct. But why, if special creation were a fact, was there an absence of such forms of the animal kingdom, as could not have been brought in some way from the continent? These islands are as well adapted to mammal life as the continent is, and if all mammals were specially created, why not here? 
In the formation of species. by evolution through natural selection, geographical distribution is one of the leading proofs. When variations occur in the offspring, which enable them to spread out over a larger habitat than that exclusively occupied by the parent stock, if they happen to cross natural barriers, either of mountains, or water, isolation then takes place. There is not then apt to be cohabitation between the parent stock and the variated offspring. In this case the existing species will undoubtedly persist not only by virtue of the isolation alone, but be also greatly assisted by the effect of the new environment of new food, air, climate and all those objective phenomena that act upon the senses. But there seems to have been no new species formed in Australia since the Cretaceous epoch. The fauna of the Cretaceous period therefore persisted. Had it been possible for higher forms of vertebrates (mammals) to invade Australia from Asia, the Cretaceous forms would not have persisted, at least not to a noticeable extent, and such of the marsupials and monotremes as could cross with other forms, would have produced new species. For these reasons Australian species of animals remained of a lower grade.

The evidence everywhere shows that it is illogical to conclude that species, anywhere, was specially created. On the contrary, it is evident that organisms everywhere have a close genetic affinity, and spread from locations to other locations, acquiring new characters. But when natural barriers existed, such as water, mountains, or deserts, these prevented the natural distribution, and caused the persistence of - local forms. Yet in some instances, as in the Galapagos islands, some species could cross the water and still live and grow. 
Distribution of Vegetable Forms.-Especially is the distribution of seeds of plants accomplished by water, wind, and birds. It is hardly necessary to discuss further such wide distribution in the light of its being accessory in producing many new variations, in widely distributed areas. Wherever seeds are thus carried, and dropped in soil, and climate, not sufficiently different from those from which the seeds came, to prevent fructification, there would arise some variation from the parent-stock, due to environment, and often a great deal of variation. Experiment has shown that many seeds are not injured by passing through the digestive system of birds. Locusts carry tiny seeds of grasses from mainland to island, and from island to mainland.

The Glacial Epoch.-The glacial epoch distributed the aretic flora as far south as the ice extended, in both continents. That flora still remains on the tops and sides of mountains, and corresponds today with the same species of high latitudes, in proportion to the altitude of the mountains. For example, that on top of the White Mountains of New England is the same as that of Labrador; and that of the Rocky Mountains of the real aretic regions. The lowlands both in Europe and America, as the glaciers receded, not being congenial to the seed left by the melted ice, failed to produce the arctic flora, but resumed that which was adapted to such climate. The identity of plants, on mountain tops in Europe and America, is thus accounted for in a natural way.

The importance of glaciers as geographical distributors of the florae and faunae of the earth is shown the reader by Mr. Croll's theory of the alternate and rhythmical occurrences of glacial epochs, in the north and south hemispheres. The period he claims is about 
ten thousand five hundred years. That is, a glacial epoch follows another in the northern hemisphere in about twenty-one thousand years; and also in the southern hemisphere in the same time, but each will come between the time of the other. This time corresponds with the revolution of the north magnetic pole of the earth about the point in the universe toward which it apparently points. This revolution is made in twenty-one thousand years. At opposite points of this orbit, first one hemisphere, and then the other, of the earth, is so shut out from the heat of the sun, and the earth's orbit becomes so eccentric, and so affects ocean currents, as to produce a glacial epoch. During the glacial epoch in one hemisphere, the other has a milder climate than the normal. This is a very curious and important fact. These alternate cold epochs must have a radical effect upon all life upon the globe.

Man's Distribution.-Geographical distribution is illustrated by the way man has spread over the earth. $\mathrm{He}$ is the animal which travels most, goes the farthest, climbs the highest, burrows the deepest. He is able to build vehicles on land, tame the horse, and the $o x$, and teach them to pull himself and vehicles to whatever point he desires to reach. He can construct boats on the water, and propel them by steam engines to the remotest parts of the earth. When a region bea comes too thickly inhabited, the young men and women emigrate to other regions less occupied, or not inhabited at all. It is notorious how those emigrants from Europe and Asia are now (1912) flocking to the United States, and how markedly their physical, and mental characters change in the new environment, especially in the second, and subsequent generations. These changes are favorable variations in their struggle 
for existence, and are typical of the influence of external conditions, upon the organism in producing new variations. These facts are apparent to any observer, who has in view the causes, in nature, that produce favorable changes in organisms. This is especially noticeable in the children of sharp-featured, awkward, heavy-minded types of immigrants; those children, especially born sometime after arrival in this country. It is natural to conclude that the difference in the physical features of the United States, compared with those of the eastern continent, has produced these improvements in the body and mind of these individuals. At least, this difference is a large factor. There is also a difference in the social environment. These immigrants have come from a different form of government, a monarchy, or empire, where military service is compulsory, where the heavy hand of power is constantly felt, where real personal liberty is a fiction, where labor is poorly compensated, and biting want, and poverty are always in evidence; because the sources of life, such as land, and its precious mineral deposits of great value, are monopolized by a few, and a conditional form of slavery, of a great majority of the people always exists. They have come to a republican form of government, where the military spirit is feeble, where the land is yet open, in places, to the home-steader, where there is little restraint of personal liberty; where, as yet, there is ample room to spread and grow; where the means of sustentation are easily procured, leaving some leisure to the worker, with a fuller stomach, and less fear, than in the old world. It is natural, under these changed conditions to attribute to these better conditions of life the new and better physical and mental variations, which are apparent in the offspring of immigrants. 
Social UNiTs.-The facts above stated in regard to the advantages to the immigrant, offered by the United States, constitute a variation in forms of society, that is a good illustration of the principle of natural selection, in states and nations. These are social units, and are governed by the same laws of evolution that animal organisms are. Those social units that happen to be organized with a variation, favorable to their struggle for existence, are the ones to survive, and thrive, at the expense of those states, or nations not possessed of such variations. The United States has attracted to itself an influx of millions of people from other countries in the last fifty years. These immigrants have coalesced into the citizenship of the country, and are helping to make it most prosperous internally, and a world power externally. Why did not these immigrants go to Canada, or Mexico, or to South America, or to Australia? These countries could offer them free land for homes and farming. Canada is settled already by English people,-the Anglo-Saxon race,- - the same as the United States. Several reasons can be given. With regard to Canada the most potent reasons are the rigorous climate; and it is a colony of Great Britain, a monarchy. As to Mexico and South America two reasons are sufficient: the unsettled conditions of society and government, and the class of people now inhabiting them. As to Australia, it is a dependency of Great Britain. The advantages of the United States are, it is an independent nation, its government is republican in form, its constitution is based on the principle that all political power is derived from the people, and there is no state church. Religion is perfectly free, its climate and soil are superior; its agriculture is great. In the struggle 
for existence between nations, as in the struggle for existence between individual organisms, natural selection favors those variations beneficial to the nation, and that nation will best survive, which can best maintain its people in intellect, freedom, prosperity and patriotism. The United States is so far ahead of most nations in these requirements that there is no doubt of her perpetuation. It is done by the natural selection of variations favorable to the social organism.

The facts above given regarding the favorable improvements in physical form made by immigrants to this country, caused by environment, will apply also to the geographical distribution of all organisms in space, in different degrees. New environment causes a variation in the form of organisms, and especially in the offspring they produce in the new habitat.

From the very limited number of examples of geographical distribution given above, it can readily be seen why naturalists have made so free use of its significant illustrations. It has undoubtedly been a large factor in producing those variations, which being perpetuated by means of that most important factor inheritance, have eventually evolved into new species. 


\section{CHAPTER III}

\section{THE METHOD}

$7 r^{\mathrm{HE}}$

confined to data which seem to support the principle. But the method is equally interesting.

DARWIN AND WALlace.-Not until Darwin, did anyone draw the same conclusion, as to the method, from the same well known facts as he did, except Alfred R. Wallace, who published his paper on Natural Selection simultaneously with Darwin's "Origin of Species." But Darwin undoubtedly preceded him in the conception of the theory. For in 1839 Darwin wrote a foreshadowing of it, and was really at that time convinced that variation, and natural selection, formed the principal method. He arrived home from his voyage on the Beagle in 1837; and in 1844 he wrote the "Origin of Species," very much as published in 1859.

Darwin and Wallace both noticed that living animals had a close resemblance, not only to each other, but, also, to fossil animals of the same region. They experimented, by breeding domestic animals, and also noticed, that structural variations, from the parent forms, appeared frequently in the offspring. This led them to speculate and theorize, upon the probable parallel, between the method in domestication, and that in the wild state, until they both published, at the same time, the hypothesis of natural selection, in the survival of the fittest, as the method by which all species had been produced. Their speculation however, was inductive, not metaphysical. It was the re- 
sult of experiment, carried on extensively for years. It was confined to the realm of natural cause and effect, and therefore scientifically legitimate.

There is a metaphysics of science, in the sense, that many things, like the nature of the atom, or composition of matter, or of the medium called ether, are speculative. But these are simply assumptions of the unknown probabilities of matter and motion, based on known phenomena. There is a very important distinction between natural and supernatural metaphysics. An extreme, and the newest form of natural metaphysies is a statement by Lodge, "What electricity itself is we do not know, but it may perhaps be a form of, or aspect of matter. Now we can'go one step further, and say that matter is composed of electricity, and of nothing else." The use of metaphysics in the ordinary meaning of the term, is confined to speculations in the realm of the "Unknowable Absolute," where no experiment can be made.

MALthus.-Darwin was impressed with the theory of Malthus. This is, that human life increases in geometric ratio, while the means of subsistence multiply only in an arithmetical ratio. It is a curious coincidence that Wallace should have independently concluded, as Darwin did, that natural selection of variations is the method of evolution, in the organic kingdom, but still more curious, that both should have been pointed to the conclusion by the reading of Malthus' "Principle of Population."

The theory of Malthus would seem to apply more truly to animals in the wild state than to man, because they have no way of artificially increasing their food supply, and adopt no methods of their own to restrict, or increase, reproduction. 
Animals Under Domestication.-Darwin made innumerable experiments on domestic animals and plants. Of course he could only set the animal forms around him to doing what nature had always been doing, in the perpetuation of wild animals. In domesticity, man, when making a business of producing animals and vegetables for his own use, destroys the undesirable variations, and preserves only those useful to man. This makes the process of artificial selection operate only more rapidly than natural selection does in the wild state; and the changes that occur could be seen by man; while natural selection producing individuals in the wild state adapted to the environment, for their own benefit, away from the vision of man, occupies such long periods, and operates so obscurely, that man can seldom note its action directly. The object of man's selection is entirely different from the meaning of natural selection. Nature takes her own time, which undoubtedly is very long, in most instances, in deriving a new species; not for the benefit of man, but for the benefit of the organism selected, and of the race to which it belongs, by the preservation of those best adapted to perpetuate the life of the species, under the existing natural conditions.

Experiments in breeding, both in vegetables, and animals, have continued for many generations, by man. Domestic eattle have been bred both for meat and milk, almost ever since the wild species were domesticated, by the Aryans and Semites. Horses have been domesticated, and bred for burden bearers, for racing, trotting, carriage, and wagon transportation; sleep for meat and wool; the hog for his meat; chickens and turkeys, for meat and eggs; geese, for meat and feathers; song birds for their music and beauty; and the other birds 
for meat and beauty. In all instances of breeding in domestication, the animals have been withdrawn from their natural environment, and habits, placed in restricted quarters, artificially fed and protected, handled by man in every way for an artificial result, which nature never had in view. Their habits were changed, their natural way of procreation was regulated by man, not for any supposed benefit to the species in its struggle for existence, but for the benefit of man, who did the selecting, which therefore was artificial, while in the wild state, it is a natural selection. In this artificial selection for breeding by proper crosses, many new variations have been produced, and apparently new species, which breed true, as long as the proper selection continues to be made by man. But as soon as the artificial selection is withdrawn, and the organisms are left to their former natural conditions, the artificial varieties, and species, revert to the former natural species; the variations then occur according to the law of nature, and selection becomes a very different principle. Man's artificial selection was done by preserving and placing together those males and females which showed the variations, or qualities which would be most useful to him, in serving him in his wants and fancies, in life. For instance, a dairyman selected for his own use, those animals with the largest milk production, or the producers of the most butter; those lacking in these qualities, he sold to the butcher. The breeder of stock, for the butcher, selected for sire and dam, those which would cut up, when slaughtered, into the most sirloin and porter house steaks; the breeder of sheep those that would produce the most wool, or mutton.

But these methods of selection are not those of nature. The object is different. Here animals of all 
kinds breed from those males and females which happen to come together. The males fight each other for the privilege, and the selection of the female. is made by the conqueror. This generally insures vigorous offspring, most capable of surviving, in the struggle for existence. This is the perpetuation of the strong. and not the weak. Should any of the offspring prove to be weak, and unadapted for the rigorons requirements of a natural environment, they are unfit. and die. That is, nature selects the adapted to survive, and allows the weak, and unadapted to die. This is natural selection in the survival of the fittest.

BEES.-In the procreation of bees another method of selection is adopted. The drones of the hive are the males. The queen bee alone is the productive mother. The drones do not fight for her favor. She does the selecting of the father of the future hive. This is her method. When her time arrives she informs all the males, and starts her flight straight into the upper air. Her capacity for flight is much greater than any of the males. They all follow her, and one at a time, according to their lack of endurance, fall out of the race. When there is but one male left, he being nearest the queen, she returns to him, seizes him, and the future honeymakers of a vigorous hive, by the fecundation of the strongest male, is assured.

As said elsewhere, man cannot control the innumerable forms of cosmic force, which nature uses, in bringing abont the phenomena of biogeny, or, in fact, any natural phenomena. He has the power only, which his natural organization gives him, to do the acts conducive to preserving his own life. His methods of artificial selection to produce new species, as set forth' above, prove this. They are the only methods open to 
him. They are done for his own benefit. He cannot breed for the benefit of the animal.

The Meaning of Natural Selection.-For, man does not know just what is for the animal's benefit. The animal itself does not. Notling suffices, as far as is now discernible, for this purpose, except natural selection, and that is a negative, not a positive force.

It is not likely that an increase in the amount of milk in the udder; of prime beefsteak in the carcass; of wool on the body; or large production of eggs; or of music in the bird, are such variations as nature would select as being the most beneficial to an animal in its struggle for existence. So that, while these artificial selections of man are proper for the purpose, for which he does them, yet they are only indirect evidence of how real species are formed.

They have shown, however, that selection will produce new varieties, in inheritance, and that sometimes, in the vegetable kingdom, what may be called a new species is formed, by one variation, per saltum.

All the facts, both artificial and natural, prove that species of both vegetables and animals are not immutable, and that is the main principle, most important to be established. The experiments, in domesticity, have been of great value, in bringing to the eye of man, empirical knowledge, that the slow and obscure process of nature did not give. It took the theory, to a large extent, out of much speculation, on account of the long time, as man marks time, it was supposed to take, to form a new species, and brought it, partially at least, within his scientific control. When a method is seen from beginning to end by man, then polemics become superfluous.

It is simply this, the dying of the weak, seemingly 
to prevent their perpetuation, and the survival and perpetuation of the adapted, which we are in the habit of calling the strong. It is not always the most powerful animal, as man looks at it, but the animal which possesses those qualities, most essential to defense, the procuring the natural food for its preservation, and the best fitted to perpetuate its kind. And this form, very likely, is, also, best fitted to produce those variations in its offspring, if not in the first generation, at least at the proper time, when such variations will be of the most benefit to that species of animals, or to the genus to which it belongs.

Some of the experiments of Darwin on pigeons, and of De Vries on vegetables, may show more than man's mere physical welfare as the object. But these merely prove that if, in the infinite happenings of nature, in the formation of species, exactly the same individuals should cohabit, under the same confinement, and artificial surroundings, the same result might happen. But a bare statement of the suppositions shows the improbabilities.

Tower's experiment with the potato beetle, conducted for, from ten to twelve generations, gave no evidence of producing permanent changed types.

Pearl tried to produce a breed of chickens of high egg laying capacity. He concluded that artificial selection alone has no effect in changing type.

The constant selection of seed corn and seed wheat, have greatly improved the production of these grains, so valuable to man. But the personal selection has to be constantly renewed in order to maintain the new varieties. This is not what is meant by natural selection. The factor common to both natural and artificial selection is, that procreation is produced by natural 
processes only in both cases; the environment, method, and object of selection being different.

HyвRIDS.-It seems that all the supposed species yet produced in domesticity easily cross, and their hybrids are usually fertile. This appears to indicate that they are not pure species. But may not this be the result of the manner of domestic breeding? Man brings together, sexually, species, that very likely in the wild state, would not be attracted to each other, and, as said before, in case of animal breeding, almost universally man breeds for his own benefit, not for the animal's. This, however, does not solve the problem of sterility, in some hybrids, nor the abstract question of sterility. In case of the mule it has been stated that the impotence is caused by the rudimentary character of the sexual organs.

Natural selection, then, is the preservation of the favorable individual; hereditary differences and variations. "An individual is said to possess variation when it shows a character not present in its ancestor." (Montgomery, 1906). Variation shows in from ten to twenty per cent of all organic forms. Variations, neither useful nor injurious, would not be affected by natural selection, except to keep them in the adopted form, when they are perpetuated by heredity.

Says Huxley: "In my earliest criticisms of the 'Origin,' I ventured to point out that its logical foundation was insecure, so long as experiments in selective breeding had not produced varieties, that were more, or less, infertile." He means that the domestic breeds would cross, which seems to show that they are not real species, while real natural species would not. But nevertheless, it is a fact, that artificial selection in domesticity has produced, under 
the eye of man, new forms, before unknown, without the interposition of special creation.

True SPECIES ARE WILD.-The great number of slight variations, and individual differences, occurring in domestic production do make the fact stand out boldly, that organisms are very plastic to hereditary experiments. If it is so in domesticity, it will be more so, in the wild state. In nature, the environment of an animal, is more variable, and trying to the organism, than in domesticity. Under the care of man, animals are less liable to accidents, and if not used for food, more liable to die a natural death. They are protected from their natural enemies. Those that survive in the wild state are certainly more liable to be the survival of the fittest, for the coddling by man results in preserving both weak and strong; but nature does no coddling. We know that an immensely larger number of individuals are born in nature than can possibly survive. So that, it is here, that the true test of natural selection must be made, where the factors entering into the test are so many and so acute; that the investigator has a wide field of complex and obscure phenomena from which to draw his conclusions. It is here, that organisms having any variation giving them an advantage in the struggle, would be the ones to thrive and procreate. A variation, injurious, would greatly handicap the individual possessing it; would soon die, and leave the field to the better equipped. That is the nature of natural selection. It is the description of a condition, not a force. It is not creative like the causes of variation and heredity. It is the survival and the thriving of the well fitted, and the dying out, for the lack of natural tools useful in producing the necessaries of life, of the deficient. 
As numbers increase, there arises a struggle for existence. This struggle results in favor of those organisms best fitted to spread out over more territory, and adapt themselves to new sources of sustenance, and to new conditions of life. If animal life continually increased, and no deaths occurred, it would, in a comparatively short time, fill the whole earth, and devour all means of subsistence. This would destroy all animal life. But only the best fitted have survived; the less fit have been overcome.

When variations occur in the offspring which are of benefit to them in obtaining food, or in increasing their means of defense of life, such variation, if it become heritable, is continued. That is, nature selects that for continuance. That is natural selection. The result has been a constant progress from the weak to the strong, from the simple to the complex, from the comparatively homogeneous to the heterogeneous. The principle can be illustrated, by the gradations of nerve structure in the organisms, from the nerveless protozoa, to the brain of man. The latter is complex in his mental, as well as in his physical structure, and therefore has almost infinitely wider relationship with his environment, than has the former. He therefore has the knowledge and power to sustain himself in a much higher degree than any other animal. $\mathrm{He}$ is, therefore, better fitted to survive, under any and all conditions; while the trilobite, for instance, could survive only under one condition, and that a very lowly environment, from the Cambrian to the last of the Carboniferous periods. This holds good with all grades of animal life in proportion to the complexity of the nerve structure.

Death is an important factor in the principle of 
natural selection. Those organisms which die prematurely, are the unadapted, the unfit. The strong, and adapted, are the ones which survive. The old, who die, are those who were adapted, and fit at one time, but have become unfit, by the changes in their structure.

Vigor IN THE OFFSPRING.-All the methods of nature in reproduction are those that will produce vigor in the offspring, so that the strong only are perpetuated. In this way, also, a certain per cent of the young are found to vary from their parents in eertain organs and characteristics. These are termed variations. If these are found upon trial, to be beneficial to the organisms, possessing them, in their efforts for capturing food, for self defense, or procreation, then naturally these variations are preserved, and in many instances are inherited by the offspring. The latter may also have additional variations useful to them, added to those inherited from their parents, which still further aid them in the struggle for existence.

The accumulation of useful heritable variations thus occurring, generation after generation, will finally produce a form so different in its anatomy and physiology, from the original parents of the first variation, that a new species results. One test of a new species is, that it is less likely to cross with other species than with its own. However this may be, and there seem to be exceptions, the theory of natural selection of variations in nature in the survival of the fittest, is the most reasonable one to account for the origin of species.

Given heredity and variation, or as Haeckel calls it, adaptation, then natural selection simply means. the continuation of the favorable, and the dying out of the unfavorable. Among the lower organisms especially, 
it is apparent that favorable always means those variations that can easiest procure the means of subsistence, and this is called the survival of the fittest. So that the full definition is: Evolution by natural selection in the survival of the fittest. It will become evident by careful study that this method is really the only one adapted to build up a strong, enduring, and capable species, or race, so far brought forward. In doing this, new species naturally result from the adaptations constantly being made.

Environment Non-ADAPTIVE.-The big-horned sheep is the boldest mountaineer among animals, in the Sierras of western America. He possesses many anatomical and physiological features that contribute toward his special adaptation to his habitat. His coat of hair is of such thickness and density, that when he lies, at night, upon a bed of snow, the heat of his body makes no impression on his frozen bed. $\mathrm{He}$ is, therefore, unconscious of a low temperature. His stomach is adapted to the digestion of mountain verdure. His body, legs, and hoofs, are adapted to climbing, or descending steep, rocky cliffs, or jumping great chasms, or leaping from the edges of precipices. The believer in special creation will contend that this animal was created, with this kind of a body and coat, to enable him to lead his peculiar life, in such a region. That is, that his habitat, and adapted morphology were predetermined, or designed. But the evolutionist says, that the sheep's primitive ancestor was not formed as he is. Neither was his habitat, nor the mountain region, at first, in the shape it now is, nor was its temperature always Aretic, nor much different from the contiguous territory. As the mountainous region has been evolved by gradual changes in altitude, by slow 
uplifts, or alternate subsidences, in the earth's crust, in its terrestrial adjustment to the constant shrinkage of the globe as it lost heat; so the big-horned sheep has been evolved from its primitive ancestor, to its present form, by a series of variations, in its hereditary anatomy and physiology; and that those variations best adapted to the environment, or habitat, were the ones to survive and perpetuate themselves. The unadapted variations gradually died out as the evolution proceeded. While the environment changed, from time to time, under the same evolutionary law of constant readjustment to new conditions, due to the condensation of the matter of the sun and earth, yet the environment is the more constant, and persistent factor, the animal being the more mobile, and variable, and inconstant factor.

In evolution the environment never adapts itself to the animal, not even to so complex, and seemingly powerful an organism as man. If it did, then there would be no natural selection in the evolution of organisms. The surface of the earth, the temperature. the humidity, and many other forms of the environment are in constant change. But there is no change of any kind ever taking place with reference to an adjustment of the total environment to the welfare of man, as man himself views his welfare. The wind is not tempered because the shorn lamb needs a higher temperature. For instance, when the glacial spoch had covered the northern hemisphere with ice, all life, in that region, not adapted to that condition, was destroyed; only the Arctic flora and fauna could survive.

The shepherd has his flock shorn in the spring time, when the subsequent natural temperature is rising into the heat of summer. But it is absurd to say that this 
natural condition is designed for the purpose of protecting the shorn lamb, or any other organism. When a considerable change occurs in any region inhabited by animals, some of them may be so organized as to survive the change. Some of them may migrate to other regions, adapted to their existing forms. But whatever occurs in the complex and sometimes slow changes of both animal life and environment, the life forms must, in order to survive, become adapted to the environment, unless they happen to be already só adapted.

The mutual correspondence between the animal and its environment brings about, what we call an evolution in the order of all life forms, by which, the necessary forms of present races correspond with the present natural conditions of the earth's surface; and the great differentiation in species, now inhabiting the earth, is accounted for, in a logical manner, by descent with modification. Not only the observations of naturalists on the methods of nature, but the artificial experiments of breeders, prove that species are mutuable, at least within certain limits of variability.

Universality of Natural Selection.-Persistent types, being so well adapted to every change in the environment, have no variation because none of the supposed causes of variation, inherent tendency, polarity, mutation, sexual selection, use or non-use, and the more potent of all, external conditions, which means simply environment, is powerless to effect any ehange of form. But natural selection operates here as elsewhere, in keeping a form so well adapted in the adapted form, without the necessity of variation. In other words, natural selection is the principle of adaptation, and is equally efficient in sudden, or slow, and minute variations, or in 
case of persistent types, no variation at all. Neither is it confined to the evolution of new biological forms. When the atoms of the nebula, from which the solar system was evolved, selected the proper direction of movement, which finally resulted in the condensation of the atoms into the present forms of the solar system, that was a process of natural selection which has characterized that, and all other atoms in every combination they have since made, whether into molecules, ids, physiological units, ions, biogens or electric discharges. Nature, itself, is a selective process, by which integration, and dissipation are, for the time being, always adapted in every locality, and in every phase of them, to the requirement of the universe as a whole.

Darwin confined his work to organisms, and did not elaborate this feature of natural selection, as above stated. Yet the reader will recognize that the principle has a very wide application, and may thus be recognized, in the minds of naturalists, a universal one.

Sexual Selection.-Whether the process of organic evolution is accounted for by natural selection, which Darwin defines as the preservation of variations favorable to the individual, in its struggle for existence; or by sexual selection, which contributes to the perpetuation of the race; or by the use, or disuse of parts, yet all these processes elaborately discussed, also by Darwin, are natural, as contradistinguished from special creation. It seems also, that they could all be classified under the head of natural selection, in which case the definition should be enlarged to read, the adaptation of individual variations favorable to the organism, in its struggle for existence, and to the propagation of a strong race.

In sexual selection, such as occurs when the males fight for the females, and the latter almost uncon- 
sciously take up with the conqueror, or as has been said in case of the bee, when the female makes the choice, there is little difference between natural and sexual selection. It is always a natural impulse, according to a law of nature, which determines the parentage in such instances.

As said by Mr. Darwin. "In most cases of this kind it is impossible to distinguish between the effects of natural and sexual selection." If there occur, in the brain of a bird, for instance, a variation of structure making it a lover of the beautiful, as is the case of the bower bird; while that fact may not seem to us to materially aid the bird in its struggle for mere existence, yet it undoubtedly does so, in the maintenance of the correspondence of its aestheticism, with a similar aesthetic environment.

Certain humming birds decorate their nests with great taste. But the bower-bird in Australia, exhibits the most decided love for the beautiful in the construction of its bower. "The satin bower bird collects gaily colored articles, such as the blue tail feathers of the parrakeets, bleached bones and shells, which it sticks between the twigs or arranges at the entrance. *** These objects are continually, carried about or rearranged, by the birds while at play.' (Darwin).

The beautiful plumage of some male birds, and the fine forms of larger size, characteristic of males, generally, throughout the animal kingdom, are an aesthetic, as well as a physical contribution to the perpetuation of the strong in biological evolution. The love of the beautiful is shown in all animals, where sexual selection is apparent. This applies to mammals, birds, reptiles, fishes, insects and crustaceans. It is thus shown that the perpetuation of the races is largely in- 
fluenced by it. Indeed, as sexual selection has been a large factor in the evolution of animal forms, and as the most vigorous and beautiful males are the ones who display the most artistic variation, it follows that the love of the beautiful is biologically connected with the preservation of the individual, and the race. The female, by accepting the most virile male, as shown by his fine form, gaudy colors, and his triumph over his rivals, thus insures the same qualities in her offspring, and thus produces favorable variations in such offspring, which being inherited from generation to generation, builds up a race of increasing strength. These variations, also, tend all the time, to the slow production of new species.

Eтнісs.-The same truths follow from the facts of ethics, or altruism. The struggles and the sacrifices made by the males, in winning the females are more than equalled in the female care of the offspring. Fatherhood and Motherhood, in nearly all animal life, are full of illustrations of the great principle that all function, from the lowest to the highest, is based upon the preservation of the individual, or the race. Even the lowest vegetable takes special care of the seeds for its future propagation, by placing them in the most protected places in the fruit, and elsewhere, provides them with the means of suitable sustenance, and sufficient, for their maintenance, during their most helpless period. In other words, not only is the organic form as a physical unit, the result of biological evolution, but thought, reason, memory, aesthetics, ethics, and altruism, have the same basis. In the present form of civilized society, with the family as a unit, living in homes, the more beautiful and attractive those homes are made, so much are they adapted to prolong the lives of the individuals, and perpetuate the race. 
The main point is, however, that all these causes and effects are within the realm of natural law, and the theory does not require the investigator to assume any other. Evolution is a theory which scientists have generally adopted, not entirely because of its capability of conclusive demonstration, but because it requires less assumption, than any other. It depends upon the manifestations of phenomena only, for its verification, and not upon assumptions of either cause, or origin.

Protective Features.-When the insects on a black space are black, and on a white space white, when those, on green leaves, are green, and on the bark of a tree, or shrub, or seaweed, grey; when the animals of an arctic region are white, and those on heather moor are reddish brown, it will be found that the variations of color are not caused by the similar tints of the environment, except in a very limited degree, but that all natural colors of these organisms are born with them in their different habitats. But those which are black on a white ground, being conspicuous are devoured by their enemies, and the white ones left, because they are inconspicuous. This is natural selection. It is the same with the other colors, the conspicuous individuals are devoured, and those corresponding to the color of their back ground are preserved. The exception to this law is that some species of insects are distasteful to the insect eater, and these are preserved in all the colors natural to them. These distasteful ones are apt to have more or less imitators, as is well known, for example, among certain butterflies. Certain individuals have the form and color of the leaves, or twigs, on which they feed, and thus escape destruction by being inconspicuous. These are 
facts showing that variations of this character. so favorable to the individuals, are preserved and perpetuated, while those which are devoured, failing to lave the favorable variations, are not perpetuated. They are fine examples of the way in which natural selection operates.

Color lias entered largely into the action of natural selection, in protective resemblance, warning colors, and mimicry. In contrast with the facts, above set forth, regarding the protective features, by which certain animals, whose color prevented them from attracting those which prey upon them, the colors of flowers, on the other hand, are the means of attracting to them, those insects necessary to their fertilization. It seems, for instance, that the red clover would die out if it were not kept fertilized by the bumble bee.

The rattlesnake of the mountains and plains, is almost exactly the color of the ground. The lion, and the tiger have adaptive colors, which not only protect them, but enable them to approach their prey with more security. A very wonderful example of protective coloring and form, is given by Professor E. B. Wilson of a mollusk living on floating seaweed-sargassum. A piece of sargassum had been in a glass jar in the laboratory for sometime, and no one had noticed the mollusk attached to it. Someone looking closely at the sargassum, exclaimed "why the sea weed is moving its leaves." The fact was disclosed by a closer examination. The animal was about two inches long.

Mr. Bates, a collector of butterflies for eleven years, was frequently deceived by a Leptalis, which imitated the flock of Jthomia with which it mingled. When he caught specimens of each, supposing from the external resemblance that they were the same, he found them to be very different in essential structure. 
A curious fact is, that an imitator is never found living apart from the form which it imitates. The mocked forms are distasteful to the birds, which eat butterflies, but the mockers are tasteful, and are therefore not found in large groups. The survivors of the edible groups are the mockers, and thus escape being devoured.

Natural selection is merely a term, and perhaps not a very apt one, to indicate the process going on in a state of nature by which particular forms, assumed by matter and motion are perpetuated, or persist, while other such forms do not persist. It is so analogous to what theology has ascribed to a personal creator, or to what man does in breeding animals, or in cultivating vegetables in a garden, that Mr. Darwin and Mr. Wallace, both called it, "Natural Selection." Mr. Spencer's term "survival of the fittest" better describes the fact, and seems also to make the process appear less a matter of personal intelligence, which the word selection, in one sense implies. The term "natural selection" however, does not imply the creation of something out of nothing, and therefore it is not a full substitute for the theological conception of a personal creator. It does not even create forms from matter and motion. When forms come into existence by the unknown tendencies of what we call the rhythm of motion, and condensation, the perpetuation of some, and the annihilation of others, is the process we call "natural selection."

Weissman.-Natural selection does not produce variations, nor does it cause heredity, although Weissman adopted a theory that variations are produced, by the selective process in the determinants of the germ plasm. Weissman is a very bold and interesting writer upon 
evolution, and defends very ably the theory of natural selection. He applies the selection theory to the determinants located in the ids of the germ plasm. An id is the bearer of the hereditary qualities. Thousands of the determinants go to the make-up of an id. They are so small that they are invisible under a microscope, but they feed, grow, and multiply by division. These determinants control the parts of the developing embryo. They differ among themselves. Those of a nerve cell differ from those of a muscle. These tiny determinants are made up of yet smaller units, called biophers, or bearers of life. These determinants vary in growth, and give rise to corresponding variations in the organs, cells, or cell group, of the organisms, into which they develop. They ceaselessly fluctuate in size and quality, because of their unequal nutrition. Like blades of grass in a meadow, they vary in accordance with the different amounts of nutriment carried to them. Weissman says, "If a determinant; for instance, of a sensory cell receives for a considerable time, more abundant nutrition, than before, it will grow more rapidly-become bigger and divide more quickly; and later, when the id concerned develops into an embryo, this sensory cell will become stronger, than in the parents." This is the way he accounts for variations in organisms.

If this theory is correct, then there is a natural selection going on in the ids, determinants, and biophers, by which the fittest to produce the most vigorous organisms do the work, produce the variations, and when the new forms are born, then the same principle of natural selection works in preserving some and annihilating others. This is a very fascinating and plausible theory. But it is too speculative to be ap- 
proved by Haeckle, Spencer, Gegenbauer, or Kolliker, all, very able naturalists.

The Work of Hugo De Vries.-Hugo De Vries, of Amsterdam, contends that species are formed by variation and heredity, but that the process is not a slow adaption of minute variations. He contends that the species is constituted by the required variation from the parent stock at once. This, Darwin recognized as a "sport." Whether this is true or not, in all instances, it does not invalidate the principle of evolution, by the survival of the fittest, in the struggle for existence. The theory of De Vries simply shortens the process of the same essential facts of Darwin's theory in certain domestic classes of primroses. Some writers have asserted that De Vries undermined Darwin's theory. The following extracts will disprove those assertions.

De Vries says: "Those individuals survive that find their life conditions most favorable, and they are therefore the most vigorous. Natural selection, in the struggle for existence, between the newly originated elementary species is quite different. These originate suddenly, unmediated, and multiply themselves, if nothing stands in the way, because they are, for the most part completely, or in a high degree heritable. If then the increase leads to a struggle for sustenance, the weaker succumb and are rooted out."

"I do not pretend that the production of horticulture novelties is the prototype of the origin of new species in nature. I assume that they are, as a rule, derived from the parent species, by the loss of some organ or quality, whereas the main lines of the evolution of the animal and vegetable kingdom are, of course, determined by progressive changes." This is a very significant admission of De Vries. It means that 
simple forms like the primrose are easily and quickly mutated by the dropping out of a character, but that this is not the way that changes occur in the animal kingdom. He makes the distinction between "fluctuations," which constitute one type, and always occurring, but are not of value in forming new species, and "mutations," which happen to occur from time to time.

Mutations do not necessarily produce greater changes than fluctuations, but such as may become, or rather are, from their very nature, constant. He says: "Some authors have tried to show that the theory of mutation is opposed to Darwin's views. But this is erroneous. On the contrary it is in the fullest harmony with the great principle laid down by Darwin."

He says that in natural selection, environment usually plays the larger part.

"Even if saltatory variations do occur we cannot assume that these have led to forms which are capable of survival, under the conditions of wild life." * * * (August Weissman). He remarks, in the same connection, that the experiments of De Vries with the evening primrose, were made with the artificial, not the wild plant. It was first discovered in the Jardin des Plantes; in Paris, and does not appear to exist anywhere in America, as a wild species.

Alfred M. Girard says : "A great number of biologists have believed that they found in the splendid studies of De Vries, unanswerable arguments against the theory of selection. It is impossible for me to share their opinion. I should say, even in examining the question closely, and in penetrating to the bottom of the matter, it is impossible for me to find in the theory of mutations, anything except a useful complement of the Lamarkian and Darwinian doctrine of continuous variation." 
Now, if by the mutation theory of De Vries, any one or more of these causes of variation, produces suddenly a sufficient variation to establish per saltum a new species, its perpetuation will depend upon its adaptation to its environment, and this is the process of natural selection. It is probable that some species of vegetables are suddenly formed by one jump. But is it not more probable that Darwin is correct that most species, in the natural state, have been formed by the survival of slow minute hereditary variations upon which the principle of natural selection could operate.

The difference between the theory of Darwin and De Vries, is not that between evolution, and special creation. Both believe in the evolution of species. De Vries transfers "natural selection" from the evolution of species, to the preservation of it. Either theory is in accordance with the thesis of this book. It is held by De Vries, that every few years variations appear, as if there is an inherency of such tendency, and that when these variations do come they are the new species.

It would be exceedingly interesting to follow De Vries further in his exposition of his mutation theory, but space will not permit. He does say this, however, "The origin of new species, which is in part the effect of mutability, is, however, due mainly to natural selection." It is probable that the method of natural selection is the most important, if not the only method, by which the great variety of species, now occupying the land and water, have come about. Of course, variations, whether inherent, or brought about by external causes and heredity, are essential factors with natural selection in the evolution of new species.

But the causes of variation must not be identified with natural selection. The latter follow the former, 
and simply determine what shall survive, and what shall die. If the species is formed at once by mutation, it may be the result of some combination of conditions, both internal and external, that is not of sufficient permanence, in time and space both, to insure its long survival. Natural selection then annihilates it, as soon as the conditions of its origin are modified. It seems plausible that sudden "sports" or jumps of this kind, made in domesticity, are apt to be ephemeral. But a species in the wild state that has developed gradually, has had time to be tested in a sufficiently widespread variability of climate, soil, in abundant, or scant sustentation, in calm and storm, to be pretty certain of permanence.

VARIATIONS ARE OF Form.-It must be understood the variations upon which natural selection operates are not fanciful, unseen, or artificial changes in the cells only of the body, or internal organs, or in the psychical device, giving the individual a life separated in its sources from the old form, a new way of development of the germ cell, nor do they change any persistent law of nature relative to man's relation to his environment. They are plain common sense changes of form, color, size, or in the neural ares, by which a new nerve is added, or a new connection is made, by which the speed is increased, or a greater tendency to caution, or a keener use of the peripheral sense is induced. If an increase occur in the size of a muscle, or a bone, the legs of a growing animal shortened, or his body made more compact, or more power put in the digestive surface, or in the thickness of the skin, and the density of the hair on the skin, to better withstand cold and rain, it is readily seen that all these are of benefit to the individual; and if future variations of the same 
parts are added by inheritance, to future offspring, how immensely the organism, in time, will become changed in its morphology from what it was in its ancestors. For the law of correlation is that, when one part of the body is changed, other parts are also altered, to maintain the equilibrium of the whole. Of course, not all the changes that occur are useful, and if not, are not likely to be hereditary.

If they are injurious they decrease the chances for survival of the organism. Immense numbers born, never arrive at maturity, and therefore are not perpetuated. But from all the facts so far discovered, there is little doubt, that in the long ages, that organisms have lived, the immense number of varieties, and species, have come about by reason of slow and minute changes, on which natural selection in the survival of the fittest, has operated, or by so sudden a change of all the parts in one generation, as to form a new species. As said by De Vries, "Eventually all the acquired characters, being transmitted together, would appear to us, as if they had been simultaneously developed." It seems, that when minute variations are of sufficient importance to induce correlation of other parts, the germ cells must take notice, as it were, of so significant a change, and hand it down to the next offspring. But the eye of man would not likely notice the changes, until they had accumulated sufficiently, to suddenly produce so noticeable a new form, as to be recognized, as a new species. Reversions, as noticed further on in Mendelism, may prove that many characters are carried in the recessive biophers, for several generations, without showing in the intermediate forms, but then suddenly appear. May not accumulations of characters be thus carried and all 
appear at one time as in mutation? Reversions may also prove that variations, not useful, may be carried, like rudimentary organs, for several generations, and then suddenly disappear.

Natural selection acts as a sieve; it does not sift out the best variations, but it simply destroys the larger number of those, which are, from some eause or another, unfit for their present environment. In this way, it keeps the strain up to the required standard, and, in special circumstances, may even improve them. (De Vries.)

Spontaneous Generation.-There are many authors who write on biology and evolution in a very learned way, who discredit natural selection, as a method of evolution. These dwell very learnedly on the mode of appearance of living units from non-living matter, and the innate tendency of living matter to variation. They believe that archebiosis and heterogenesis frequently occur. "Variation" is only another term to express these two modes of bio-genesis. Archebiosis is really spontaneous generation, or the formation of protoplasm from inorganic elements. Heterogenesis is the production of a different, and more complex form, and function, from that of its progenitors. Both of them, therefore, can be termed methods of variation. "Organic polarity" and "mutation" belong to the same category. They are theoretical causes of variation, and simply express an unknown process of change, by, either, continuous, or discontinuous growth. It is so with "seasonal dimorplism." There are three other factors of evolution mentioned by Bastian, and also by Däwin, viz., "sexual selection," the "effects of use and non-use," and "the direct influence of external conditions." These are all 
causes of variation, and when variation, and heredity, are combined in one process, the continuation, or perpetuity, of the varied forms depends wholly on adaptability, or natural selection. Therefore, natural selection is not a cause of variation. It makes no difference, whether the cause of any given variation has operated, by way of the determinants of Weissman, or in any other manner, natural selection only begins, where all the causes of variation leave off. For instance, if sexual selection produces a variation from either, or both parents, which is beneficial to its possessor, in the struggle for existence, and that variation proves hereditary, then its continuance is a selective process. Or, if a variation arise by use, or non-use of some of the bones, muscles, or internal organs, of an animal, and that variation becomes hereditary, then its continuance is a selective process, and the individuals of the same species who have not the same, or an equally efficacious variation, will naturally die out by the increase of the ones who inherit the valuable variation.

Darwin did not claim that natural selection was a cause of variation, although it has been stated that he did.

Origin of Organic Matrer.-Evolutionists do not pretend to account for the origin of matter and motion, nor of life, because they have no sensory proof. Bastian says: "The inorganic is being continually fashioned into the organic, and this after passing through successive changes, and after having displayed the manifestation of life, is ever passing again into the inorganic." But this assertion, that the inorganic is being continually fashioned into the organic, must be taken to mean, that after the birth of organisms naturally from egg-cells, their development is caused by accretion of inorganic matter. 
There is no doubt, in the minds of many investigators, that the earliest form of life on the globe was spontaneous, although now life forms appear to arise only from the germ cell of a previous form. Yet there are naturalists, Haeckel and Bastian, for instance, who think there are still spontaneous minute organisms appearing at the bottom of the oceans. There is little doubt, but that organisms arose from inorganic substance, as heretofore stated. Of this, there is little direct proof. But the fact that all organisms, so far analyzed, have shown no constituent elements, except the inorganic, is very strong evidence. The experiments of Professors Loeb and J. B. Burke in the chemical laboratory, lead strongly to the same conclusion. Yet, it is doubtful if ever real life forms will be produced by the chemistry of the laboratory. We know at the present time, that a thousand eggs, or seeds are formed that do not germinate and grow, for every one that develops and lives. So it was, in the beginning of life. All the incipient beginnings, of any life forms may have died out, for a very long period, before all the conditions became just right for growth into matured forms. And, of course, there arose simultaneously, with the forms, the conditions, that is, the means of their sustentation. It could not be otherwise. But the simultaneity may not have been exact, with the edible plants, and the plant eaters. It is altogether likely that it was more of a co-incidence without any special design, that is, in the Miocene epoch, there were the plants, and the animal forms that devoured them. When a naturalist landed on the island of Madagascar he found a certain plant, with a flower, which required for its fertilization an insect with a bill six inches long, and he at once said, there must be such an insect. So 
there was. But the insect did not require the plant for its support. The germs of the plant would have aied out without the insect. But neither of them was especially designed for the other. The probable fact is, that the form of flower on the plant was a variation produced by a natural cause that had no reference whatever to the existence of the insect with the long bill. But, the insect in its casual flight among the vegetation of the island, alighted on this new variety of flower, and in feasting on its sweets carried its pollen to another of the same variety, and thus started a growth which will continue as long as the soil and habitat produce both the flower, and the insect. The only parallel here is that both forms are adapted to each other to this extent, and that parallel is very unusual, and noticeable. It is precisely the same principle, that governs all evolutions. Variations are continually appearing in all hereditary forms, whose cause is rather obscure, and those that find the conditions as favorable as did that of the deep petaled orchid of Madagasear, in the means of fertilization and growth, in the long billed insect, live and spread. But those that fail to come in contact with such means, die out, and most of them are never noticed, as are those that live, especially in such a striking way as the above mentioned orchid. If there were any design in such evolution of life forms, would not the designer bring into existence only such forms as can survive with the means at hand, and not waste such an innumerable host of incipient organisms, as we see dying every year?

It seems there existed in the inorganic world after its evolution to a certain condition, four elementscarbon, nitrogen, oxygen, and hydrogen-which were so explosive, or unstable, that the inertness of a solid 
form could not hold them in its grip. Impelled by the radiating energy of the sun, the carbonic acid of the earth was forced to yield its carbon to a new substance which we now call chlorophyl. This also was enabled to fix the nitrogen of the air. But this double function seemed too onerous for the vegetable, thus primitive in its origin. So it seems to have transferred the fixation of nitrogen to the organisms called microbes. The microbe converts the ammoniacal compound into nitrous ones, and these again into nitrates. This splitting up of a tendency, primitively one, rendered the vegetable world the same kind of service that vegetables have rendered animals. The microbes which put the nitrates to the roots of the vegetables in shape of soil, served the vegetable kingdom, just as the latter did the animal kingdom, by furnishing to the animal kingdom both the carbon and the nitrogen, the two most important elements in the evolution of life. This vegetable life, which preceded animal life, would be impossible without the chlorophyllian function of regetation. This power of regetables, to fix the carbon in the inorganic kingdom, is at the root of organic life, and the necessary forerunner of all life evolution.

It is said that vegetables and animals represent two great divergent developments of life. They do this only in the sense of having some notable differences of characteristics, in outward form only. Intrinsically, the evolution is one. For, as shown above, there is a mutual dependence on each other, in such way, that the one could not exist without the other. The line, perhaps, cannot be demonstratively drawn, to show that the animal evolved directly from the vegetable, as the evolution of the vegetable cannot be shown directly, from the inorganic; but, there is such a vital connection 
running from the latter to the highest.organic form, that there could not be complete dissociation, without a fatal result to all evolution. Forms of evolution are divergent, only as a family kinship is divergent, in making, with its outgrowing, the form of a tree, and its branches. It is after all only a straight line of descent, with modifications in the members of it.

BErgson.-Some philosophers and scientific writers have opposed the method of evolution advocated by Darwin and Spencer. The most recent and radical of these is Henri Bergson, whose views have met with great favor in France, and with some thinkers in America, William James, for instance. Bergson admits that science is compelled by the nature of the intellect, to treat evolution according to the logic of mathematics, that is by measurements of matter. The intelligence, or intellect, acts only on matter. This is taking the products of evolution, with which to prove evolution. It is, says Bergson,, necessary to invoke intuition, growing out of intelligence, and instinct, in order to determine that all forms of extension are mere snapshots of the creative process, and represent the conflict going on between the flux of universal consciousness, and matter. Intuition dives into the flux of life which is guided by a "vital impetus," which, however, is not endowed with design. There is no teleology. Science, he says, is mathematical, theology is teleological, or finalistic. Neither is true in philosophy, which is metaphysical. He believes nature has been evolved, but not from without, by a continuous process of integration, but by discontinuity and division, from a center to a circumference. In doing this matter has impered it, and the material bodies are degradations. This is anti-intellectualism, and is partially parallel 
with the theological idea of finality, but does not, as does the latter, assume a final cause. It takes a peculiar idealistic form of brain to adopt the Bergson philosophy. Most people can better understand the inductions of the senses, rather than the intuitions of metaphysics. It is not likely that many men will ever be able to transcend intellect. What is beyond the reach of that, could not perhaps be useful to human requirements. Is it not therefore better to remain within the reasonable domain of our senses, than to try to cultivate mere imagination?

MENDELISM.-Numerous theories of variation have been advanced from time to time. Weissman advocated what he called amphimixis. This is the commingling of protoplasms from different parents having different hereditary tendencies. The crossing of two individuals, as far removed from each other in characteristics, as is possible, but not too far, to insure their hybridization, or breeding, would naturally result, one would think, in producing the most variation. Experiments have proved that, "in and in" breeding results in lack of variation in the offspring. except in the form of degeneration. It either degrades, or fixes a type similar to the parents.

In 1866 Gregor Johann Mendel, a naturalist, and an Austrian priest, published an account of his experiments in breeding garden peas. He crossed two races or varieties, to find what the result would be in several generations, in the distribution of the characters of the parents, to the offspring. He was evidently very careful, and able in his experiments. "He found that the cross bred plants raised from these seeds manifested only one of the characteristics, which he calls the dominant, to the total, or almost total, exclusion of the 
other, which he ealled recessive. The second generation produced from the cross bred plants, which were allowed to fertilize themselves, instead of being uniform, like their parents, broke into two original forms, in the average ratio of three dominants, to one recessive. The recessives are pure, and if allowed to fertilize themselves give rise to recessives only, for many generations. One-third of the dominants are also pure, while the other two-thirds produced descendants of which two-thirds are dominants, and one-third pure recessives. Each successive generation consists of dominants and recessives in the ratio, for each one hundred, of twenty-five dominants of pure blood, twenty-five recessives of pure blood, and fifty dominants, which produced descendants in the ratio of three dominants to one recessive."

Mendel reduced this principle to a mathematical formula. For a long time naturalists paid little attention to this law. But a few years ago it was revived by Bateson and De Vries.

The latest expression upon this law came from a practical breeder, Prof. Webber of Cornell University. He says : "No discovery in the field of breeding has had more effect, or is more far reaching, in its importance, than the discovery of what have now become to be known as Mendel's principles of heredity.

The law of segregation has shown us, that the splitting of characters follows a definite method, and that we can in general estimate the frequency of occurrence of a certain desired combination, if we know the characters concerned, to be simple unit characters. *** We can now study the characters presented by the different varieties of a plant, or of different species, which can be crossed with it, and definitely plan the com- 
bination of characters desired, in an ideal type, and can with considerable confidence estimate the number of plants it will be necessary to grow, to get this combination."

The great importance of this, in breeding varieties of grass and vegetables, for the use of man, and in determining the cause of variation in all organisms, is apparent from the statement itself. Mendel died in 1884 without knowing that his name has been immortalized, in that given to the principle,-Mendelism,and has been attached to a discovery that will revolutionize the ideas before held, as to causes and times of appearance of variations in heredity. The principles, he discovered, were rediscovered in 1900 by De Vries.

The hybird, resulting from the crossing first made by Mendel, although showing only the characteristics, of one of the parents-the dominant, yet contained, also the other, invisible-the recessive. Both characters are present within all the seeds. Castle, Davenport and others, experimented with animals. These tend to support the principle, and make it into a law. It is of great importance to establish a principle that germ cells remain pure however mixed, and transmitted, and that, as long as they are transmitted, their type of organism, from which they first came, will continue to live. The names of Weissman and Mendel stand high in the theories of heredity.

With plants, and a few animal forms, self fertilization is frequent. But there is no exclusive apparatus which prevents an occasional cross. In case of plants, their fixed locations necessitate a means of self fertilization. But being exposed to winds, and other natural mediums, for conveying pollen, an occasional cross occurs. These crosses are the probable source 
of variations, and therefore a general law, reaching every form of organic life. This is rendered more probable by the discovery by De Vries that variations appear periodically, and are then quite distinct.

DARWIN'S SAGACITY.-Scientists are now very much more amply equipped for the solution of the problems of evolution than Darwin was, but it is wonderful how his interpretation of his wealth of facts has stood the test for more than a half century of critical investigation by the ablest men of genius. The wealth of material now is incomparably greater than in his time. It is found that the principle of evolution becomes more firmly established, and that only here and there is his method, and an occasional inference therefrom, challenged.

Selenka's investigations of embryos, of different groups of monkeys, have filled up the blank in Darwin's proofs of the near kin of man, and anthropoid apes. Since Darwin, the Pithecanthropus has been found in the tertiary deposits of Java, which is probably a missing link. Other fossil forms found in other places, are thought by those most qualified to testify, to be additional proofs in paleontology, of the evolution of man from a lower order.

Experiments have been made in the mixing of the blood of man with mammals of different groups. The reactions, it is claimed, show that the anthropoid ape is nearer akin to man than any other animal.

The Utility of Investigation.-It might be asked by the reader who has not made a study of biology and physics, "Why is it desirable to have a great variety of species in the organic kingdom?" and "what difference to the human being is it, how the species arise?"

A sufficient answer to the first question is, that if all animals were of one species they would devour one kind of food only, and that food would soon become 
exhausted. The difference in species of both vegetable and animal kingroms is accompanied by their geographical distribution over land, and in water, in such a way, as to bring together the adapted organism, and its adapted food, for its preservation. Insects live upon a different form of sustentation from that required by vertebrates. By the evolution of different forms, having each its own digestive apparatus, adapted to a particular form of food, all are enabled to survive. This law of variation is therefore a necessary law, to preserve the process of life, which is also a part only, in the general scheme of the universe. All life is uniform in its method of preservation and perpetuation. Every organism, both vegetable and animal, draws from its environment its sustentation. But the organisms and their sustentation, are in as many different forms, as there are species, in the one, and combination of chemical elements in the other. In general terms where there is peculiar form of food, there will be found a species of organism to devour it. Life would be impossible without this reciprocal adaptation.

The second question can be answered, by saying, that knowledge consists, in being aware of the truth of phenomena. The real advancement of man, from the lower order of animals, has been the evolution of the power to know, more and more. of his environment. One of the most important things is his own real relation to other forms of life. This includes a knowledge of species, and how they arise. The breeding of vegetables and animals, for food, which has become the principal source of human supply in civilization, is immensely assisted by a knowledge of how nature forms new species. It is thus a utilitarian question of great importance. 


\section{CHAPTER IV}

\section{MENTAL AND SOCIAL EVOLUTION}

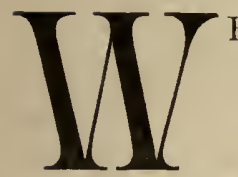

HIIE the principle of evolution is quite apparent in the physical life of organisms, and of man. it is more difficult to perceive it in the psychical life. With man there is a higher degree of mentality than in any other organism, which must be considered as a function of the physical. This gives him a much wider and more complex environment, with which he is in correspondence. But, as there is a comparative anatomy and physiology, so there is a comparative mentality, in the organic kingdom. Especially is this so in the animal class. It will be seen that the increase of mentality in the animal class is parallel with the development of a specialized structure; and while it seems essential to the study of the evolution of organisms, to divide the psychical from the physical, yet in reality they are one, genetically. They are distinctive only in their manifestations.

Distinctive Features of Life.-Living tissue, wherever found, from the lowest to the highest organism, has a certain peculiar movement, which characterizes it, as different from inorganic matter. This movement is its correspondence with inorganic matter. From the latter, it is constantly drawing, and appropriating certain elements. When this process, or movement ceases in the living tissue, it becomes at once, only inorganic matter. It seems therefore to be a medium only for transferring inorganic matter into living matter, and back again to its source. An organ- 
ism draws its sustentation, not only from the earth, but from the air and water. These sources of its sustentation are called its environment. Its correspondence with environment, or the movements made in keeping up this correspondence, are its mind, or psychical part, while the body tissue, which makes the movements, is its physical part. A study of the vegetable, and lowest animal organisms, reveals the fact that the tissue of their bodies is of one kind only ; that is, it is uniform in structure. Its basis is protoplasm in the form of minute cells. The body is formed by a multiplication of these cells, from one cell, by a process called fission, or division. Although the different parts of the body take different forms, yet the wlole is composed of tissues, homogeneous in structure: Such a uniform organism responds to its environment by a very sluggish movement. Its mind, therefore, is of a very low order. All vegetation is thus characterized. Animals are differentiated from vegetables by a greater response to their environment, and therefore more movement. Vegetables are fixed by their roots to one spot, while animals move from place to place. This fact gives. to the animal, the larger mind.

Nervous MATTER.-Those animals having a variation of structure called nerve matter, a white mobile tissue in the form of fibres; imbedded in the muscular tissue, and running from a knot of the same tissue, located in the anterior end of the body, to other parts, but forming a continuous thread, are characterized by a more noticeable active movement, and consequently greater mind. As animals rise higher, and more complex in structure, the complexity of the nervous system increases correspondingly. It is known by anatomists, physiologists, and psychologists that the behavior of an animal 
having a nervous system is controlled by that system. The function of this system is ealled psychical, to distinguish it from the function of the muscular system, which is termed plysical. But there is no real difference in kind. It is one of degree only. The nerve matter is composed of similar cells, which make up the other tissues of the body. It will be seen, at once, that if the control of behavior in the animal, is in the function of the nervous system, therefore, the principle of evolution applied to this structure in the same manner, it is applied in the preceding chapter, to the inorganic and organic realms, will show how mind is subject to the same laws of natural selection. It is not necessary to consider in detail, in the following pages, the mentality of animals lower than man, except by allusion here and there. Man is seen to be only a family in the order of mammalia, that is, he is classified as an animal. What is peculiar to him in the way of mentality is also characteristic of all other animals, in less degree.

The Nervous System.-Physiological Psychologists find that the mentality of the human organism is produced by a nervous system, containing about $3,000,000,000$ nerves, permeating the whole body, having its external terminations so arranged as to carry with much more rapidity than the other structure of the body can do, certain objective sensations from the outside of the body, and also from those parts of the body, objective to the senses, from within it, that is, from all its objective organs, and functions, to certain internal terminations of this nervous system, called ganglia, or neural centers. The largest ganglion of this system is the encephalon, or central organ, or brain; and is made up of innumerable strands of nerves, so interwoven, as to appear a solid mass of 
nervous matter. By reason of its extreme mobility this great mass of nerve tissue, permeating every point of the organism, is in perpetual motion. This isomeric molecular motion constitutes the consciousness of the individual, keeping it in perpetual unity, with the same energy, or force, which produces molar motion, in the environment-the two being differentiated phases of the persistence of force.

Whenever there is an impression made on any of the organs of the senses, - of touch, sight, hearing, smelling, or tasting,-it is conveyed inwardly, along the receptive nerves, by what is called isomeric molecular motion; that is, there is a re-arrangement, and more or less destruction, of the little invisible particles called molecules, which make up the substance of the nerve, through its whole length, or through a sufficient length, to convey the impression to one of the ganglia. These ganglia, composed of yet more mobile matter than the nerve threads of conveyance, add to, coordinate, and discharge the motion along effector, or motor nerves, and thus produce the phenomena of bodily motion, and all the phenomena called psychical. The ganglia acting, apparently, like galvanic batteries of electrical energy, send the impression, if need be, by the molecular motion of motor nerves, to exhaust themselves in muscular action. But, if the sensations are of a nature to require brain action instead of muscular action, then the sensory energy, coming from the environment, is conveyed to the central nervous organ, called the brain, and there by molecular and chemical process, it is co-ordinated into one of the phases of psychic phenomena, called perception, image, emotion, conception, reason, memory, or will. The individual sensations are co-ordinated with each other, 
by the patterns of nerves in the brain, and this produces generalizations and abstractions. It, also, in its normal condition, produces effective co-operation in all the movements of the muscles. When there is a lack of proper co-ordination for any cause, such as lesion of the brain, there results that condition we call abnormal mentality, in its different forms, or insanity. This coordination is prevented, also, by intoxication, or by any pathological effect on the tissue. The whole is physiological in process, while the result is impressions, coming from the environment, by way of the senses, into the nervous structure, and then further producing a resulting molecular motion, which is the psychical phenomena. It is all the result of natural force, the "persistence of force" acting along the line of least resistence.

The structural neural centers furnish fixed nodi, in which functions operate in a very variable and unstable way. The processes, while of course determined by what are termed material structures, are so modified physiologically, by the association fibres of conduction, crossing and mediating the sensory, and motor centers, permeating every part of the brain structure, that they must not be considered localized in the sense of the old phrenology. It is probable that the higher in the brain is the locality of neural function, the more universal are the contributions, by all parts of the conduction paths, beginning at the periphery of the body, running through the ganglia, the myel, the oblongata, mesencephalon, diencephalon, the cerebrum, and ending in the various association centers of the prosencephalon. Psychological abstraction, and generalization evidently occur in these higher parts, and they are the effects of the most complex functions, of 
parts of the brain structure, centering in the cerebrum, by the cross association fibres.

Reflex Arcs.-The unit of mechanism, in the nervous system, is the reflex. The simplest reflex arc consists of a receptive nerve running from a receptive organ, the eye, for instance, to the appropriate brain center of such organ, and from there to the appropriate muscle. In animals of very low structure the nerve current is made directly over a single reflex are and the reaction follows the sensation immediately. But in animals of complex structure, having large ganglia called brains, the reflex ares are compounded and multiplied. In man, this complexity is capable of controlling the action of the sensation, so that there is deliberation, hesitation, and calculation, before any muscle movement is made. A characteristic of the system is, that the chain of nerves forming the reflexes are joined together. in such a way, that the sensations received at the peripheral, can be conducted only toward the ganglion to which the nerve runs. This receptive nerve, however, receives impulses generated in various places in the body, and from other nerves near it. In this way, a muscle can receive impulses from many reflex arcs. In this way, a stimulation received through any one sense organ arouses the expectation of all the muscles of the body, if it happen to be of such nature as to demand it. It is thus that a soldier marching toward a field of battle, and liearing the boom of artillery, ahead of him, has all his senses aroused through the single sense of hearing. The muscles of his whole body are excited, by the expectancy of battle. A limb muscle is the terminus of nervous ares arising in everyone of the organs of sense, the eye, the ear, the nose, the skin, and the mouth. In the works of Edinger and Exner 


\section{MENTAL AND SOCIAL EVOLUTION 111}

diagrams are given, showing the patterns of nerves in the brain. Max Meyer has done the same thing in "Fundamental Law of Human Behavior." Such diagrammatic analyses of nerve physiology are of great value to students of mental phenomena.

IMAGES.-The patterns made by the movements of the molecules of the nervous matter on the brain, inangurated by objective stimulation, such as light, reflected from a solid body, to the retina, and thence conveyed, by a movement of the molecules, to the brain center of vision, are the images of the objective body. These patterns are constantly changing, and forming new images, corresponding to the innumerable things seen in the environment, from moment to moment. The stimulations frequently come from within the body. What is called ideation is thus produced; and memory is a pattern of a former external sensation, reproduced by molecular motion, initiated in the conducting fibres of the system, by an objective sensation, on its way to the brain. Our consciousness is the working of this psychic machine in its pattern making on the brain. A system of conductivity so elaborate, formed of matter so mobile, as to be in constant flux, the atoms of which are composed of that cosmic energy which is moving the innumerable globes of the universe, and which atoms respond so eagerly, and accurately, to the slightest, as well as to the greatest of objective phenomena, is capable of producing all the psychic effects which we feel in our bodies, and perceive, by their outward marks, in the bodies of others. The nerve cells in the brain are said to be fixed in number during life. But they seem to be exceedingly mobile and sensitive to excitation. They throw out new threads of connection by repeated stimulation of the 
organs, and thus increase the associative complex. The greatest benefit of school education is the effect that its repeated exercises have upon the multiplication of cross cut nerve threads, and the forming of complexes of these. In reading, music, painting, writing, the advance from painful effort toward automatism, means the gradual formation, in the brain, of short circuits from sense organ, to motor muscle. The perfection of all human effort, and behavior, is parallel with the like perfection of the flow of sensation through the plexuses of the human brain. Frequent repetition makes the effort less conscious, because it clears away in the brain any resistance to the chemical action, or molecular motion; and this is done, if Max Meyer is correct, just as the variations of sensory paths increase in number and power. He says the progress is by steps to a first level of accomplishment, and thence to higher levels, stopping for a time at each level.

It seems that these halts are due to the necessity for the growth of new fibres from the old unused cells, in reaching the ligher ares in the brain.

The growth of new variations in the neural paths depends upon (1) the intensity of the sensations and (2) the continuity of them. Forgetting is the negative susceptibility of the nervous paths. By non-use they lose their power. They are kept up only by continual use.

In discussing the effect of the nervous system of moths, Meyer concludes that the excitation of the eyes of the moth, by which the wings are set in motion, toward the light, is of great benefit to the moth family, notwithstanding that millions of them are destroyed by artificial lights. The moth evidently obtains his food by his instinct of flying toward the light, and the lights of nature do not injure him. 
Reflexes and groups of reflexes, called instincts, are hereditary. He calls them hereditary activities. 'They are so, because the characteristic response to stimulation of the nerves producing these activities, is produced by the anatomy of the nervous system. They are in no sense shaped by individual training, only improved.

Sometime before birth man has as many brain cells as he will ever have. But at that time, they are mere balls ready for unwinding, when excitations from the sense organs are sufficiently intense. These unwind into threads of conduction during life, it is to be presumed, as the "mind" becomes more and more vigorous, intelligent, and its psychic phenomena more automatic. They, perhaps, are not at any time of life all unwound. Thus man never ceases, during life to develop mentally, and in old age, intelligence is still enlarging, because unused cells ever remain, for forming new avenues of thought, in his brain. It would seem, that a life time is too short for the development of so many, just as it would take more than a life time to count them. The somatic cells cease to multiply in later life. So if a piece of the brain is destroyed it does not grow again, but is filled in, with supporting tissue. But as long as we live, the innumerable nerve cells existing in the brain are capable of throwing out new fibres which connect with other fibres, and thus form new short cut channels for the passage of excitations from sensory points to motor muscles. The short cuts from one ganglia to another enable man to acquire new habits that in time become automatic. They quicken thought, and multiply the avenues for human activity.

"It is possible, even highly probable, that a special 
talent means merely a special form of interconnection of the fundamental reflexes, common to all." (Meyer.)

This looks very plausible. It is in support of the theory that thought is the chemical and molecular action of the nervous system. A genius who shows a specialty in any direction, is simply pushing, by the exercise of his special mentality, the formation of new connections of the motor nerve ends, which will greatly facilitate the movements necessary to accomplish extraordinary achievements. If he should be an artist, then the sensory nerves aroused by sight, excite intensely the motor nerves of the hand, in movements adapted to the imitation on the canvas of things, seen by the eye. The intensity of the flux, along the fibres running from the eye to the muscles of the hand, meet with resistance by those nervous cells yet undeveloped, and these throw out short circuit fibres, under the intense repeated pressure, which connect with other nearby fibres, and thus excite to motor action, of great co-ordinating power, all the muscles necessary to draw, and paint a great picture. If the genius is gifted in oratory, the principle is the same. The special connections of speech nerves, at their terminals, both in the excited sensory end, and the motor end, whether the sensory end lies in the interior of the brain, or in any of the peripheral sense organs, or in any part of the body, yet, the peculiar material interconnections of nerve plexuses produce the oratory, which rises in grandeur in proportion to the profundity of the interconnections, which produce also the special associations between ideas just arising and previous ideas acquired from experience or learning. All the mental activities depend upon these nervous connections, and are extraordinary in proportion to the completeness of the interconnections. 
Man is right handed as a rule, while animals are both right and left, for legs, indiscriminately. The two hemispheres of the brain function differently. The center of speech, and that of the motor muscles of the right arm, lie in the left hemisphere. The interconnections, between the two centers are close and profuse. Therefore when speech must be emphasized, by pointing to a place indicated in the speech, or in any other manner, it is natural to do it with the right arm or hand, which is stimulated by excitation, near the speech centers. Meyer had said previously, that all babies are left handed, during the first three months of life, and afterwards right handed for the reason of the growing exercise of speech. It may be therefore that the men who are left landed may be found to have been backward in speech when babies, and that the habitual left handedness as babies, continued with these left handed men, until it became a habit through life. It may be that what they did say in early life, needed no emphasizing, by gesture of the hand.

As to the evolution of what is called altruism, Max Meyer, while he does not consider the question directly, yet he shows that all generalizations and abstractions are impossible without speech, and that speech depends upon the developed nervous system of man. This nervous system has been evolved with the rest of the body. All human behavior is the direct effect of nervous action, and altruism is one of them-a very compound and intricate one. Of course it may be difficult to demonstrate the survival value of pure altruism, as the direct result of natural selection. But it must be treated at least as a secondary effect, growing out of a complex of nerve tissue in the brain, which is the product of natural selection, or survival of the fittest. Altruism would be impossible 
without the nerve complexity of which it is a result. In practicing altruism we are only following nature, which does everything for others, and thus best serves herself, because all others are parts of herself. Man is a part of nature, and when he nurtures others, he is indirectly doing that which sustains himself. When he helps another, he is teaching it, how to do the same to him. The simplest reflex action, and highest mental abstraction, are equally dependent on material nerve matter. The former is done by a simple reflex arc, consisting of a sensory, and a motor fibre, connected by what is called a ganglion. The latter is the passing of the excitation, either sensory or initiated in the brain, through several reflex ares, through higher, that is, more complex nerve centers. When an instrument shall be invented which will enable man to measure the process in the higher nerve centers. all mentality will be demonstrated as the action of nerve plexuses. The endeavor to discourse or reason on the "states of consciousness," "sub-consciousness," "subjective states" or "consciousness being a self, conscious of itself," without showing objectively the nervous process which constitutes these conditions, is without any convincing effect.

$\mathrm{By}$ observing the gradations of complexity, and definiteness in the nervous system of animals, from the lowest to the highest, it is plain that intellect, and intelligence, depend upon the correspondence that these systems give the body, with the relation of things in the environment. In other words, the psychology of an animal is the degree of perfection of this correspondence. The lowest animal life is without nerves. It has only the sense of touch, and that very feeble. In this regard, it is very different from a human being 
deprived of all senses except touch. Such a human being is possessed of a nervous structure. constituting the nerve centers of the other senses; and by the associative conductive paths crossing in great numbers, every part of the brain, and connecting all the sense centers, these centers of the other senses are excited to the vicarious performance of the psychical functions of each other. So that the sensations, coming through the sense of touch alone to such a brain structure, produce more slowly, only, nearly as much mentality, after repeated practice or experience, as if the outward sense organs were all in normal working order. The reaction of its muscles to the sensation of touch is slow in the animal without nerves. Such animal life is sustained by the absorption of whatever suitable matter comes casually in contact with its surface. It is without other intelligence than sustentation and procreation. It has no correspondence with spacial environment, and none with the time sense. The difference between it and the most intellectual man, is the difference of complexity in physical structure, which, of course, includes nervous structure, corresponding with a like complexity in the not-self, or environment.

INSTINCTS.-The connections between the peripheral sense organs and the motor muscles in lower animals, are the instincts of those animals. The same connections in the higher order of animals and man are the instincts of that order. But, as the complexity increases, many instincts necessary to the low orders become unnecessary to the higher. Especially is this true of man. But the instincts of self-preservation and race perpetuation remain all through the series, from the lowest to the highest. These are love, fear, anger, and the sexual feelings, and are characteristic of all animal 
life. The vegetable which has the power of drawing its sustentation directly from inorganic substance, has no need of locomotion, because its source of food is so universal that wherever it has originated there is sustentation, from which it is supplied with little effort on its part. Of course, such an organism never rises to actual consciousness. There is but one choice on its part. It takes what comes to it, through the natural elements of the earth, the soil, water and air, and it cannot move in search of more somewhere else. In this way the vegetable kingdom stores up in its fibres, not only the simple elements necessary to its own growth and preservation, but in the only form in which the animal kingdom can assimilate them. Therefore the vegetable preceded the animal in its appearance on the globe. The animal in seeking its food, had to have the power of locomotion. It could not be confined to one spot; although in the ocean, which is, itself, in constant motion, some crustaceans remain fastened to the rocks. Their food is brought to them by the motion of the water. The vegetable has no nervous system, yet the sensitiveness of the "Venus fly Trap" would indicate that the reflex action of some vegetables is scarcely distinguishable from that of many animals. But, in a technical sense, at least. we can say that vegetables and the very lowest animals have no distinct nervous system. But the nerves, as differentiated tissue, begin to appear in very low forms, the earth worms, for example, having a distinct nervous system. From these to man, precisely the same chemical and protoplasmic elements, enter into the composition of not only the somatic cells, but those of the nerves as well. Not only this, but the same general plan, or system, outlines the body nerves of all animals, from 
the lowest to the highest. This system is adapted, in each animal, to the support of such reflex action in the lowest, as may be necessary to maintain its existence and perpetuate its species; and in the highest, in addition, to give it choice in the maintenance of all its complex environment. This increase of choices constitutes consciousness. In every animal there is a central organ to the neural system to which every fibre runs, either directly or indirectly. The complexity of this central organ is in proportion to the number of fibres, and small centers in the body, and its function is the determination of the responses necessary to be made to the most important sensations received. But always there is. in the simplest organism, at least, a reflex arc consisting of a fibre running from every point of the body contiguous with objectivity, or environment, to a center and from that center to the muscle tissue, best adapted to make the movement,- to avoid an object, or respond to the sensation. For example, hunger is the sensation of an absence of the substance necessary to maintenance of life. This sensation is carried by the reflex are to the central organ, and that sends it to the motor muscles, putting them in proper motion to procure the food that will allay the sensation. Most animals, being supplied with organic tools only, that is, not being able to manufacture artificial tools, as man is, have no choice except to use the tools nature has provided. These have a system of nerves simple and adapted to the instructive control of these natural tools. Their tools, such as wings, legs, teeth, claws, beaks, etc., remaining unchangeable in their shape and power during their lives, compel them to do whatever work they perform in only one and the same way during life. Therefore they have a nervous 
sy'stem, in control of their mechanism, in like simplicity. The complexity of the nervous system corresponds with that of the mechanisn of the organism. This correspondence produces a uniform result, and that result is always produced in only one manner. This is called instinct. Now, as soon as there came into being an animal with the manifest power of another choice as to the mode of responding to his environment, possessed of the additional tool, or the ability to make a tool to aid his natural tools, or who could make a fire, and thus work in a way before unknown, that variety of animal, we now call man, and his ability to choose his mode of acting on matter or environment, is called intelligence. Investigation discovered that this man and this intelligence possessed a more complicated nervous system than the animals whose work is instinct; but that the complexity of his nervous system is made up of the expansion by growth of the same nervous matter of the instinctive animals. and not matter of a different kind.

It is a well known fact, that in the decline of vitality accompanying old age of man, the functions last developed in life, are the earliest lost. The term "second childhood" is the popular recognition of a profound psychological truth. The highest intellectual functions soonest fade, while the instincts and emotions, which existed almost at birth, remain to the latest breath. Those phenomena, which accompany normal senile decay in man, are strikingly similar to those which the vivisectionist is able to produce with his knife.

Remove the cerebral hemisphere of a pigeon, and it returns to a condition closely resembling that of the newly hatched bird,-it will swallow food placed in its mouth, and if you turn it on its back it will regain its 
normal position. But it cannot pick up food for itself, it cannot avoid danger,-indeed it does not recognize danger,-it cannot fly. These powers depend on the co-ordinate action of its higher brain cells, and the removal of these cells reduces its activities to the condition of a lower order, from which it sprang. No one has been able to carry on similar experiments with the higher mammals, because of the resulting shock, and the uncontrolable hemorrhage; and of course experiments on human beings are out of the question. But, there is good reason to believe, that if these normal and technical difficulties could be eliminated, the trained physiologist could carry a man back, by the successive steps of his evolution, from lower orders, first, in the scale of civilization, and then in that of organic life, by simply destroying, in succession, the physical centers of the brain, from the highest to the lowest. There are many eases, in medical literature, of insanity resulting from injury to the brain, and disappearing when the injury was cured. In some of these cases the injured person, while retaining nearly complete control of his mental faculties, lost all sense of moral accountability, and committed grave offenses. Certain diseases, especially paretic dementia, produce the same effect, and these diseases have for their constant lesions, the destruction of the brain tissue.

The phenomena of anaesthesia furnish similar evidence. Physically the person going under chloroform, or ether, loses first conscious sensibility, then unconscious sensibility in the voluntary muscles, then the peristaltic action of the involuntary muscles of the coats of the intestines stops, and finally, if the anaesthetic is pushed, the heart ceases to beat. Mentally, the same order is followed,-the reverse order of development. The pa- 
tient loses first his judgment and self-control, his ethical, instinctive, and carefully taught manners disappear, and he laughs, eries, or swears, in utter abandon, long before he has ceased to be able to repeat, parrot-wise, the monotonous counting of the anaesthetist. The qualities latest acquired, which can best be spared, go first. Judged by this grimly practical test, our mentality depends upon the physical development, at the time, and must have been an evolution from lower forms of mentality.

Mental Evolution, Materialistic.-The principle of organic evolution, being once established, necessarily carries with it mental evolution. This is especially so, upon the theory of the materialist, that "mind" is the function of specialized matter. But, even if that of the parallelist, is taken as true, there is such an intimate connection between the molecular pulsation, and the physical effect, that the evolution of both simultaneously, would seem to be the only conclusion. Such great advancement has been made, in late years, in the science of brain physiology, and in physiological psychology, that-the study of "mind" must now be made through physiology. The result is, that the new definitions of psychic elements, and mental phenomena are material. For example, Max Meyer's definition of instinct, is that it is the connection of a receptive nerve, by a reflex arc, through the brain, to a motor muscle. Bergson calls it, an animal mode of doing a thing, because it has but one choice. A brook trout darts away upon sight of a moving object, on the shore of the stream, because its sense of sight is exceedingly keen, by having its eye connected, by a large nerve to the very large brain center of vision, and by other nerves running from these to the motor. muscles of tail and fins. The lobe of a trout's brain, containing the center of vision, is very large in 
proportion to its entire brain. This knowledge is important to the fisherman, easting the fly in the trout stream. For, if the trout gets a sight of him, before it is hooked, it escapes; and after a good sized trout is hooked, upon delicate tackle, a good fisherman will not move a muscle, except that necessary to operate the reel. The motion of a finger will sometimes cause the trout to make remarkable struggles to relieve himself of the hook. No one attributes these traits of the trout to any other cause, than that of his nervous system. Then, why should the behavior of man be attributed to any other cause than the control his brain is shown to have over his motor muscles?

Mental traits are inherited, because they depend. upon the peculiar structure of the brain, and structure is inherited. Aptitude and genius often run in families; so does insanity. Every breeder of animals knows how temperaments, and tendencies, peculiarities of behavior, are handed down from generation to generation. This is so, because the peculiar structure of the brain is inheritable, and the brain controls the behavior of both man and animals. Natural selection as said before, does not confine its operation to physical traits, anymore than it does to mental traits in animals. Man, the weakest of animals, is the best adapted, and therefore dominates, and survives all others, as a class, because of his mental power, to contrive, construct, to manufacture, and to farm the soil. He annihilates other animals, selecting those best suited to his needs for domestication. Other animals are selected, by this law of survival, on account of their superior mental traits, by which they overcome their enemies by cunning and subterfuge. Beside, the "minds" of animals have been evolved by domesticating them. The dog, the 
horse, and the cow are all descended from wild species, whose temperaments and intelligence were very low. By artificial breeding and selection, they have evolved into most useful, and intellectual servants of man. The most intelligent is selected to survive. The evolution of man himself from a lower, vicious, and savage ancestry, is parallel with that of the dog. The evolution of his brain has been accompanied by that of his intelligence,- -his mind. If, when he was a lower animal, his brain was operated, by an entity distinct from its function, that separate power must have evolved also, parallel with the evolution of his brain. Otherwise, how can his advancement in psychical power be accounted for. But that dilemma is avoided, by the theory, that his mental powers are the functions of his brain, and, evolution being conceded in structure, it naturally follows in function.

The evolution of the Collie from a wolf, or a canine, equally savage and vicious, is a remarkable transformation. Its intelligence, faithfulness, and sympathy when trained as a sheep dog, in herding and caring for a flock, are equal to these same traits in man. In the early days in Colorado and New Mexico sheep were herded on the public lands. The herders were generally Mexicans accompanied by dogs. A flock of two thousand was stolen in Northern New Mexico. The thieves, the herders themselves, drove it into Colorado, and finally to the north side of the Arkansas River, near Las Animas, Colorado. Here they abandoned the flock fearing capture, for the owners were on their track. But the dog remained with the flock. One morning a ranchman on the river heard a scratching on the door of his kitchen. On opening the door, he saw this sheep dog, evidently half starved. The dog had put the 
herd in the corral, and then came to the door, for something to eat. After being fed, he took the sheep out of the corral, and onto the range for feeding, bringing them in each evening, watering them in the river, and repeating this service each day, until the sheep were found by the owners. Innumerable instances might be given of equal intelligence in dogs.

SleEP.-Even sleep, which is the period of rest, to the functions of the nervous system, is caused by the contraction of the blood vessels of the brain, and the enlargement of the peripheral termination of the circulatory system, thus lessening the activity of the molecular motion which sustains psychic phenomena. The resulting inactivity of the senses, is sleep. It is often asserted that the mind, as some call the functions of the nerve tissue, never sleeps. One proof of this is the supposed mystery of dreams. The memory images can only be true to the absent object, whose representation constitutes the content of memory, when the organs are fully awake and working normally. In sleep, the vascular system is greatly modified. The molecular motion of the brain depends on the constant renewal of the physiological units, as they become exliausted in the psychical process. But sleep is the anemia of the brain. Hence dreams are always abnormal presentations in the brain. Very few of them have any sane cohesion, and can seldom be entirely recalled. They are like half taken photographs, when the plates are not properly prepared. The brain centers lack in sleep the physical elements necessary to a normal image.

The objective thing, or rather nature as a whole, especially the inorganic, is that to which the organism has adjusted itself during its whole evolution. Psychic- 
ally it continues this adjustment, in meeting new situations; but the limitation of this correspondence is determined by the limitation of the structure. Within its limitations the psychic device, in various ways, modifies the image by its pliability in adaptation, such as changing the point of view, and also by all grades of attention, and inattention. The pathological condition of the psychic device greatly modifies all sensations and images. Dreams are modified forms of memory.

Dreams.-Dreams do not come in profound sleep, -that is, when the molecules of the nerve tissues, which produce the psychical phenomena are at rest. It is probable, that those nerves that sustain the physiological function, of replacing the destroyed molecules of nerve structure, may be as active in profound sleep, as during the waking hours. But not those which produce the images, and patterns of ideas, or which recall by the associative fibres former impressions, as is the case in dreaming. Dreams seem to be produced during the decreasing activity of the molecular motion of the psychical patterns of the brain, in process of going to sleep, or, by the nascent motion of the same molecules, in the process of waking. At these two opposite periods, the sensations coming from the environment are not operative, but the faint and imperfect representations of former sensations are produced, by the feeble movements of the molecules, not vigorous, and true, as when first presented, in the waking hours, but modified, and never an exact copy of the original. Thus dreams seem to be of different degrees of truthfulness. As the brain approaches sleep, the first dreams are likely to be the most vivid, and representative; but as sense activity gradually declines, 
they become fainter and more fantastic, and at last incoherent. This order is reversed, in the period of waking, the last dreams, that precede the final opening of the avenues of real sensations, coming from real objects in the realm outside of the brain, being more definite, and true to the reality, than those preceding. In this sense, dreams are in line with other psychical phenomena, having physiological marks. Profound sleep may be prevented, by various abnormalities acting on the senses, such as indigestible food in the stomach, aromas coming in excess to the nostrils, or unusual pressure on any part of the body. In such cases, there is not profound sleep, and the molecular nervous motions are more or less active, producing corresponding representations of modified forms of previous sensations and ideas, or dreams.

Reason Is LIMITED.-The higher the mentality, with reference, of course, to the maintenance of a higher adaptation of the organism to the material environment, the more readily will natural selection operate in its perpetuation. Such a mentality is based upon its emanation from and genetic connection with a material environment. But, if that higher mentality is what is termed merely a sentimental one, impractical, artificial, and in correspondence only with a fantastic and immaterial environment, it would be unfit for the preservation of physical life, and therefore of its own life. This condition arises from a diseased condition of the nerve tissue. Man is so heterogeneous, especially in his mental functions and social relations, that the action of the principle is much less easy to trace. Yet, the more the principle is studied, the stronger becomes the evidence, that natural selection is operating just as powerfully in man, and in all aggregations of men; 
in society, in governments, in churches, in barbarism, or in civilization, as in any animal organism. The principle seems to be the essential method in all phases of organic life. It is true, that man seems to have a larger degree of control of his functions than do the lower animals. Consciousness and reflection, in the form of so-called memory, reason and will, seem to partially supersede natural selection. But this is only apparent, and certainly not efficient, to prevent the natural survival of the fittest in all organisms and methods; not such as man himself would select as the fittest, but what the persistence of force may determine by actual test to be so.

It is frequently asserted that psychological, sociological and ethical evolution has been superseded and arrested by the evolution of reason.

Reason as defined by such writers means the power of the organism to control its own development, and its own functions. It means further, according to these, the ability to organize mankind socially and morally, and in that way to arrest the principle of natural selection and introduce design where none existed before. This seems to be viewing reason as a creative entity, dissociated from the structure and function of the braill. But the fact is, reason is nothing more than one phase of the psychical aspect of the physiology of the brain, and can only be a result of physical molecular motion, in certain centers of the brain tissue, and that is the product of biological evolution. There is a social evolution which, of course, is accomplished through the psychical power of mau. But as man's psychical power comes only through a natural adaptation or adjustment to environment, the resulting social evolution while seemingly under the control of man's "free-will" is 
determined by the laws of physics,- -which hold man's "will" within the bounds of economical adjustment. All rcason is determined the same way. That is, man is compelled to reason within natural law.

Alfred Binet says "Reason is a synthesis of images." It is a coalescense of images. It is sense impression, arrested in its ordinary neural path, and sent over a new one, where it meets with some resistance, because the new path has not been worn smooth by long use. It is like a ship bound for the East Indies from London. Its natural route would be, via Cape of Good Hope. By this route it would sail easily, and almost automatically, to its destination. But the Suez canal has canalized a new short cut, via the Strait of Gibraltar, Mediterranean sea, and the Red sea. But the latter is not only a change of direction, but that part of it through the canal is slow, and requires new methods. It is not so automatic, but in the aggregate is quicker. It is not reflex action, but a deliberate, studied movement, requiring intelligence, more than instinct.

The conscious psychical effect, of this arrested reflex, is called memory, reason, or imagination, according to the particular center of the cerebrum excited; and the final manifestation of the energy thus aroused, in nervous activity resulting in muscular movement, is called will. The anatomical fact that, in some way unknown, a variation occasionally occurs in the way of added convolution of nerve matter, or facility of molecular motion, in the cortex of the brain, gives the organism, so favored, new power in co-ordinating sense impression. Or, if Meyer is correct, these variations are new nerve threads forming new short cut connections in the brain. The human brain has evolved by reason of these biological variations, and not by its own "will." 
Binet further says, "We reason because we have in our brain a machine for reasoning. * * * In reasoning the primary roll belongs to the images." (That is, the images that objectivity makes on the brain.) "It is they, which spontaneously form, to our external sight, the picture of the external world. *** Just as erystalization, in its oddest eccentricities, always observes a certain angular value, so reasoning true, false, or insane, always obeys the laws of resemblance and continuity. * * * It would be an error to believe that this process belongs specially to reasoning. We meet it in all intellectual operations. *** * The highest science is epitomized in these simple words"to see."

Difference in Brains.-The real difference between two brains, whose anatomy is apparently alike, is very obscure. Why the cognitive centers will develop so much more rapidly, and become so much more powerful, in one, than in another, with an equal environment, and practice, is a difficult problem. The difference in function does not seem to depend entirely upon the weight and size of the organs. The real difference between two brains is rather that of quality, or at least, the quality of the nerve matter, or the perfection of the cross association system, in its adaptation to the all important function of co-ordination, and inhibition. The greater activity of the one brain, in producing that psychic effect popularly called "will," impresses the observer as being the result of the will reacting as a governing power, over the molecular motions, and thus molding them by "will power." All the psychic phenomena, beginning with the simple emotions, which perhaps at a very early period of the evolution of mind, were as difficult to express, as is now the highest thought, 
or reasoning in man, have been evolved, by reason of those variations, or differentiations. It is also likely, that when man's present memory, reason, and will, shall have been in use a sufficient time, they will become as automatic, as are now the emotions and instincts. Then the new born infant will have them as he now has fear, love, and hatred. Then higher, more abstruse, more complex,psychic phenomena will gradually appear in the mature human organism. This should come only with the growth of brain, in, or above the cerebrum, with new reflex ares connecting it with all the other parts of the nervous system. But Meyer has placed this whole question upon a new basis. If, as he contends, the innumerable cells, are like little balls at first, which unwind, as mental experience, and practice works upon them, then the strenuous excitation, which the will-to-think-and-do, exerts upon these little potential reflex connections, unwinding them, and throwing out new short cuts, to brain centers, reached before, by only long reflex ares, then, that will account for the superiority of some brains over others. Yet there are brains originally superior to others. 


\section{CHAPTER V}

\section{MENTAL AND SOCIAL EVOLUTION Continued}

PHE Advantage of Civilized Environment. As said by Romanes, civilized man enjoys advantages over savage man, far in advance even of those which arise from a settled state of society. Whether we agree with Lamarck concerning the heredity of acquired characters or not, there is a very noticeable difference between the hereditary traits of a civilized man, and those of an uncivilized one. In one sense they both inherit their environments. There is a transmittal of intellect, when once acquired; and it is not inherited, until it is acquired by some organism. It may have required many generations of variations, which an environment of refining education would give, before the barbarous habits, and instincts, were finally extinct in offspring; but such change certainly must have been made, at some time in the evolution of a race, from a low condition, to a higher one. The evolution of the Anglo-Saxon race, from the condition it was in, when it first settled in England, to its present condition, is a very remarkable instance of such evolution.

Refined parents, of the present Anglo-Saxon race, hand down to their children such traits, of structure and function, as would distinguish them, were they brought up in a savage tribe. While it required a thousand, or more, years of advancement to make the Anglo-Saxon what he is, yet it would perhaps require the same length of time to degrade him to his former condition. All society has been evolved by the com- 
bination of innate tendencies, external influences, and effort, both physical and mental, by the individuals composing it. And until the society had made great advances, by the arising of variations in its form and function, and the operation of natural selection, in the survival of the fittest, the productions of genius in literature, art, and mechanics were impossible. A Bacon, a Newton, a Darwin would be impossible in savagery, or barbarism.

"There is a transmutation of habits, quite as much as of structure, and the former is probably initiative of the latter." (Montgomery.) That statement is decidedly Lamarkian. It means that acquired characters are inheritable. It is, also, in line with Meyer's statement heretofore referred to, that man's will-to-do, or mental effort, will form new nerve fibres, thrown out by the ganglia, and that the connection of these with other fibres, and brain centers, produce new mental power. At least, the new power given by these new nerves, whether in the form of reason, imagination, or will, by reason of their new channels, is flowing along the line of least resistance. Its effort then becomes so automatic, that it gives one a feeling that it is the effort, that is, the reason, that has produced its own cause.

Line of Least Resistance.-The question of line of least resistance, as well as the attraction of gravitation, is, at large, the question of the general diffusion of matter; while the method, or process of such diffusion, is that of the nature of motion. Matter perhaps was never wholly quiescent. In that condition of it in the nebula, when it was most homogeneous, we assume its natural tendency to condense, and the theory of evolution requires, that since then, it has 
been in perpetual process of integration, and dissipation. This means, that "substance," a term applied indiseriminately to matter in all forms, is a combination of matter and motion. It is in constant change, and when we say that it always follows the line of least resistance, we mean that it is moving from a location, where it is, to another, where it is not, and that this results in what is a change of form, more adapted than the preceding one. This change is sometimes said to produce an equilibrium. This it does not do, except in the sense of more or less persistance. Substance is not long persistent in any one form.

But, in fact, there is no equilibrium, except in the homogeneity of a nebula, where all the particles, in theory, are equally distributed, and of this we can have, with our limited senses, no conception. The line, that matter and motion, always take, in making and unmaking the forms of things, is the line of least resistance. The line of least resistance, in the psychical device of man, is the tendency of "mind" always to maintain the life of the organism, and perpetuate it by heredity. This is done by sensations taking the paths marked out for them in the nervous tissue. Otherwise, its correspondence with objective environment would soon be severed, and all life would soon end.

The process called reason is modified very largely by the simple emotions of fear, anger, the affections, the sexual emotion, and sense of possession; and by the multitudinous combinations of these in complex, and secondary emotions, which existed in the organism long before reason was developed. The common necessity of sustentation of the body, and defense of life, nearly always determines the final channels of 
sensations, or feelings. Sustentation is transfer of substance from where it is to where it is not, and a change during the process to a new form; and fear, or defense of life, is the change of the line of motion of substance, from where there is resistance, to a line where there is little. In all cases, the final decision of so-called reason, i. e., the course the molecular process producing the mental hesitation will take, depends upon some motive outside of the so-called mind itself, operating through the emotious, or instincts, generally through love or fear. For example, when a man unexpectedly confronts danger to his person, or to his family, the direction of his motor action, or "will power" is entirely governed by the emotion of fear suddenly aroused. He meets it by doing that which his judgment dictates, as the most effective, for avoiding the danger. The sensation terminates, in the motor action, which the peculiar form of his brain compels him to take. It is the preservation of limself, or his race, that produces the reason and the "will," or, as said above, the transfer of motor actions, from the line of resistance, to one of lesser resistance. Thus, in reality, what is called the mind of the organism, which is nothing but the aggregation of natural feelings, induced by molecular, or chemical motion, initiated by objectivity, has no control whatever in forcing this molecular power of the brain into any but natural channels, and only into such channels, as make for the physical welfare of the individual and his race. It is along this line only that his brain has developed.

Any departure from this principle simply ends in calamity to the individual. The world is strewn with the wrecks of lives because the reason of man has 
often become insane upon this proposition. Nations and civilizations have failed because their measures have departed from the natural, and physical welfare of man, and society, into the realm of fantasy and imagination. The French kings, who, by their acts, brought on the French Revolution; and George III, who lost to England her most valuable colonial possession in America, are vivid examples of brains, that ignored the law of natural cause and effect. It is so, with every individual, who ignores the physiology of his body by living intemperately, or who does any act, inimical to his health, or morals. There are certain channels, in which reason must operate, if it is to be effective. Disaster comes sooner or later, if it neglect these for others, not regulated by the law of fitness, viz., the survival of the fittest. Said James A. Froude, in his lecture on "Science of History," "Men have gone on, for centuries, trying to regulate trade on moral principles. They would fix wages according to some imaginary rule of fairness; they would fix prices, by what they consider things ought to cost; they encouraged one trade, or discouraged another for moral reasons. They might as well have tried to work a steam-engine on moral reasons. The great statesmen, whose names are connected with these enterprises, might have as well legislated that water should run up hill."

The reason of man is like the government stamp on the gold coin. It is very limited in its scope. It guarantees the purity and weight according to a law arbitrarily adopted by the Government itself. That is, according to the reasoning of man. It does not and cannot guarantee the fixity of its exchangeable value for the products of the world. The natural law of supp? $y$ and demand, and all economical laws, are made 


\section{MENTAL AND SOCIAL EVOLUTION 137}

by the interaction of natural readjustments, on the same principle that the law of evolution operates. The reason of man can advance to the point of establishing a currency, uniform in weight and purity; but its real value as currency in the purchase and sale of commodities is beyond the reach of legislation. Fifteen years ago it would buy fifty per cent. more of wheat, bacon, butter and eggs than it will now (1912). Then it was a dollar in the market. Now it is about sixty cents. So it is with everything man reasons out. If it is in accordance with the natural law of evolution -that is, the law of rhythm of motion, and consequent readjustments constantly going on, not only in the inorganic, but in the organic universe, it is righteous; otherwise it is unrighteous, and must be readjusted. Man is very gradually growing, as the ages elapse, into closer harmony with the natural laws of the universe. The method of development and constant effort, is the law of life itself; which likely is all there is of life. When it ceases, there is no more life, but a stillness or want of motion similar to or the same as that condition which we now call death.

All Evolution Alike.-The method of man's evolution has been the same as cosmic evolution, the struggle for existence, and the survival of the fittest. When he came to aggregate with his fellows into a society for better protection and mutual enjoyment, the savage elements of his former "tiger and ape" methods still clung to him. It was difficult for him to rise to the requirements of civilized life, and in doing so the old habits to a certain degree, such as indifference to the cries of the weak, clung to him. These relics of the past condition are called by the present average of men, sins. They do not know that they are naturally 
inherited from our ancestors. "He (man) punishes many of the acts which flow from them as crimes; and in extreme cases he does his best to put an end to the survival of the fittest of former lays, by axe and rope." (Huxley).

The difficulty is to put into practice the golden rule ethics, in opposition to the continued struggle for existence. The two principles, that of altruism and that of the survival of the fittest, are struggling with each other in human society. At their extremes they both seem to be destructive of the bonds of society. Therefore both must be kept within bounds. Altruism must not be allowed to weaken the race by the perpetuation of the mentally, morally or physically weak. Neitier should death be courted too much in favor of those who may think themselves the fittest. Man, with his present limited comprehension of the cosmic method, is very apt to blunder in his social laws. Hence the failure of nations and civilizations in their permanency. "If this world is full of pain and sorrow; if grief and evil fall like rain upon both the just and unjust; it is because, like the rain, they are links in the endless chain of natural causation by which past, present and future are indissolubly connected; and there is no more injustice in the one case than in the other." (Huxley). Says Karl Marx, "The mode of production in material life determines the general character of the social, political and spiritual processes of life. It is not the consciousness of men that determines their existence; but, on the contrary, their social existence determines their consciousness.' Suppose we make a somewhat different statement of this principle: The consciousness of man is the product of his total environment. This environment is a very complex one, but is wholly 
physical, or material. The two obvious factors are the inorganic and the organic. The latter includes "social existence" as mentioned by Marx. As this "social existence" includes the psychical phenomena of mankind, by which society in all its forms is created and sustained, it is, in the latter evolution of man, the predominant factor. But consciousness is the transforned image in the brain of man, of his entire environment.

Mrsconceptions.- The misconceptions of the principle of the survival of the fittest in all nature, and its application to society by the writers of current periodical literature, is most astonishing; in many instances. For instance, says one "Here" (in human society) "it means that the mass of men must consent. in the interests of progress, to be driven to the wall, in order that a few more excellent individuals may be selected to rule society and keep it at the maximum of efficiency." This is a misconception of the principle. It does not require the assent of man in any respect; but of course, the mell who are "driven to the wall" because they are not fit, would never consent to such a procerture, and the working of natural selection does not wait for them to either assent or dissent. Evidently the writer of the above quotation does not believe that natural selection operates in society. Then why do so many forms of society "go to the wall?" Because, he may say, the reason of man, which makes society, fails to work out the proper organization. But then, in that case, it is the working of natural selection in letting them fail. That psychic function called reason. as said before, is simply the result of the fusion of certain images in the brain cortex, by which something un- 
known before, becomes known. The value of these results, or lessons, depends upon their persistence in the lives of men. Those that prove of value to the individual, or the race, survive and the others die. This species of natural selection is going on all the time, in the brains of men. There are a thousand reasonings, which die, where one of real value survives. The responses, that man's brain makes to environment, are limited to the capacity of the five senses. These senses and their capacity, of functions, are biological evolutions according to the law of the survival of the fittest, and are limited to like material things in the environment. These things are those forces that contribute to the support of the physical and psychic life of man. Esthetics and altruism are further biological evolutions of the power of the brain to contribute to the pleasure, and therefore to the life of the individual. and the race. The latter evolve co-ordinately with intellect, that is the art, and the ethics of savagery and barbarism, evolve into the art and ethics of what are called civilization, just as the "mind" of the former becomes unadapted to the customs of that form of society, and evolves into the customs, that make up civilization. This evolution is not a struggle, or competition between the individuals, who make up savage or barbarous tribes, not a conscious struggle. But it may be a struggle, between tribes, and between such tribes, and civilized colonies, or nations. For example, the evolution of the United States required, that the native Indian tribes should be constantly pushed back, as the white people advanced, to occupy the country. But the units of the tribes, and the units of the colonies gave "mutual aid" to each other in this struggle of tribe with colony. The colonies survived 
in the struggle, by the principle of natural selection, and the survival of the fittest. Just as the organic units,-cells,--that make up the organic body must work in harmony with each other, give "mutual aid" in building up the growing body, and in keeping it a living organism, after it is built up; so must the individuals forming a body politic work together in forming and supporting, the social organism. At the same time, there is a certain unconscious natural selection, constantly going on, even among the individuals, which the aggregate reason of the society does not seem to control, and this natural selection does not interfere at all, with the "mutual aid" necessary to preserve the unity of the society, in its natural struggle for existence, as a society. Neither is this individual natural selection, or struggle for survival, a conscious one, in the sense that the mass of men must consent, in the interests of progress, to be driven to the wall, in order that a few more excellent individuals may be selected to rule society. Nor does society itself select those who rule it. This is done by natural selection, as the ultimate cause. That is, certain individuals are possessed of superior ability to govern. If these are selected, also, by the individuals of the society, in the exercise of their reason, then the selection is wise. But if the unfit are selected to rule, it is unwise, because society suffers. The consent of men, as to the fit or unfit, as to "those who go to the wall" or "those who rule" in society, can only be governed by what nature has already done to determine such matters.

The breeder of domestic animals practices conscious artificial selection with a purpose, and that is, to form the animal for the most economic use of man. But natural selection among human beings in society, by 
which some are better adapted to their environment than others, who are more efficient in building and keeping society, to a high state of efficiency, and who, by the consent of the units, are thus selected, is not controlled by reason, but by evolution. The term "struggle for existence," as used by evolutionists, is not a conscious fight to the death, such as a battle between two opposite armies. It does not require that any one shall "consent to be driven to the wall." But we all know, that a certain number of individuals and societies of all kinds born, die in infancy, others are dying at all times of life, for the want of some power within them to withstand what others, who live and thrive, have the power to do. Reason does not seem to control it, and no "mutual aid" can control these survivals of the fittest. It is true, the survivals often do not seem to us the best, but would they not seem so, if reason really controlled it? But, as they survive, nature must have thought them the best. They are certainly the adapted, or they would not survive. It is so, with the forms of society. Those that survive must be the fittest, but they are not what our reason would select in all instances. The real fact seems to be, that nature pays no attention to the reason, or desires, or the efforts of man. Man's evolution of brain power, including reason, must be along the line of natural laws, or it does not avail. If evolution by natural selection is the law of development, then reason is confined to discovering man's relation to this law, and his conforming his human law to that. He seems to have yet made but little progress in that relationship, and there is no way to make further progress except by trial and repeated failure. Life consists of such effort, to find a solution to this problem, and when 
found, that is the end of organic life. No one can reasonably conclude, that the inequalities in the individuals who make up society, form a desirable condition. We never can be satisfied to have a large number" "constantly pushed to the wall" by power of greed, and selfishness. If there is a way to prevent this, that will be successful, the great majority of mankind would certainly be glad to adopt it. But, as yet, neither religion, nor reason, has been equal to the task, and they both have been tried for centuries. There is no doubt it is a problem that man himself must work out, for if there is other power, personal, or abstract, with that purpose in view, it certainly would have solved it before this. If natural selection, in the survival of the fittest, can do it, or if it is designed for this purpose, then Darwin is nearer in his contention of the slowness of the process, than DeVries is in its quickness of mutation.

Reason, a Product of Evolution.-Reason itself, being an evolution, whatever it is able to accomplish, must be in accordance with the laws of evolution. It is not likely that reason is a creative, but a directive power. It may be able, in -a limited way, to direct further human sociological evolution, along the natural lines that all evolution has so far taken, but not outside of these lines. Those methods have been by a change of forms; by dissolution, of tried and unadapted forms, and the integration of those better adapted. Has reason so far invented a better process, or can it do so? If the present form of society is unadapted, what can reason do to improve it, except to change its form to one better adapted to man's natural place in nature? It could not be a change to an unnatural place in nature. This is what 
natural selection, or the survival of the fittest, in the struggle for existence, is, and it is never done "in the interest of a few superiors," but in the interest of the increased power, or struggle of the whole cosmos, including man, who seems to be only one passing phase of it.

"The orderly and beautiful world which we see around us" has been thus orderly and beautiful ever since life began on the globe. What is ealled "the struggle for existence" in all animal and vegetable life is as muclı a struggle now as it ever was. It is not a conflict of arms with great turmoil and personal war. It is a silent natural process, unconscious to the contestants, and without apparent design. Natural selection is a negative, not a positive force, and Darwin said that he was unfortunate in ealling it by the name "natural selection." Perhaps the better term is the "survival of the fittest." The unfit naturally and quietly die, while the fit survive, not by their own consent or effort, but by a law beyond the control of either. This is so. not only with individuals, but with all forms of social aggregations. The struggles constantly going on in commercialism, for instance, ealled competition among men, while designed by the men themselves, are subject to the same law. Over ninety per cent. of business units succumb because their methods are unfit. Tribes, societies, nations, come and go, by the same law. This is no argument against the use of reason by men. But that reason must be used for the purpose of conforming man's and society's efforts, to discovering what is fit, and therefore enduring. The reason cannot change the law. It may eventually be able to bring society in proper relation to it, but it has not done so yet. The small per cent. of individuals in society who are in 
control, and seem to be satisfied now, are not going to initiate a change, and those who are being "pushed to the wall," being to that extent the unfit, have not the power to do so. There is a constant interchange of units from the latter class to the former, and as mankind is evidently increasing in reasoning power from generation to generation, in those countries where reason is most in use,- that is, where scientific education is persistently invoked, there is a prospect that a solution for the seeming injustices now existing may event. ually be found. Everybody must acknowledge that this is but a slow evolution of reason, and that it would be most desirable if it could come by a mutation per saltum; but so far it has not come that way. The earnest and able discussion of the methods of economical reform now going on should greatly hasten the accomplishing of it, and every right-minded person should desire and aid to the extent of his ability in its consummation. In the United States there is the fairest, the most favorable field, for the exercise of the franchise, by a majority of the votes, by electing those who represent their reason in the matter and actually putting in force the principle-that reason governs the evolution of society. They would then soon show whether reason, as now evolved, will do this, in spite of or in accordance with the natural law of natural selection, or the survival of the fittest. If, in accordance with the natural law, it will likely be permanent. Of course, if natural selection is not the law of evolution in society, but "mutual aid" is, then reason must conform to that law. To be at all effective, reason can only evolve, and operate, along the lines of the natural law whatever it is.

Forms of SocIETY.-The evolution of the gens, the 
phratry, the family, the tribe, and the state, all forms of society ever since man became a social being, has occurred hy the same method as the evolution of the individual; viz., by natural selection, and the survival of the fittest. The existence of each aggregate was necessarily adapted to the physical necessities at the time; and whatever laws or customs grew out of the conditions were, at the time and under all the circumstances, those conducive to the real happiness and welfare of the social organization. Otherwise the social organism would not have survived. A study of many of them shows that the nuatter of sustentation, and its necessary mode of production of food and shelter, were the ruling factors in compelling the individuals of each social community in determining the form of government and the morals of its members. The form of marriage called the group, or afterwards, the pairing, in which the lineage was traced through the mother, and during which the little property was owned in common in the gens, or tribe, as existed among the American Indians, was universal throughout the world, at the same stage of what is called savagery, or in the lower forms of harbarism. It is as true of the Greeks. Romans or Germans in the same stage of evolution as it was with the Celt and the Indian. Monogamy became a custom only when private property came to be recognized and protected; and the monogamous family heralded our present form of civilization, in which the lineage is traced through the father. because he is the producer of commodities and the holder of the wealth. These changes necessitated new forms of society, or community governed by new laws. This relegated woman to the inferior position of a domestic care-taker: whereas, in barbarism and savagery, she 
was the real head of the gens or kin. The evolution of society, at every step, was not controlled by sentiment, or idealism, or by a priori reasoning, but by purely materialistic conditions; or, in other words, by economies; and this was always determined solely by the principle of natural selection, the adaptation of the fittest to the physical welfare of the social unit.

Captain Fitz-Roy, of the good ship Beagle, carrying Professor Darwin round the world, brought also from England, a young Fuegian, who had been taken to that country two years before. This boy was returning to his people in the territory adjoining Magellan's Straits, at the south end of South America. He was dressed in eivilizer costume, could talk broken English, and took with him several articles of English manufacture. He was left on shore, as the vessel passed through the Straits toward the Pacific Ocean. When the ship returned some months, or years later, the Captain Janded and hunted up the boy. The first day; he did not find him. But the next morning, "a canoe," says Darwin, "with a little flag flying, was seen approaching, with one of the men in it, washing the paint off his face. This man was poor Jemmy,-now a thin, haggard savage with long, disordered hair, and naked, except a bit of blanket round his waist. *'** We had left him plump, fat, clean, and well-dressed; I never saw so complete and grieveous a change." (It was grieveous to Darwin, but not to Jemmy). * * * "He told us he had enough to eat, that he was not cold, that his relatives were very good people, and that he did not wish to go back to England." Darwin goes on to say, "I do not doubt now, that he will be as happy as, perhaps happier than, if he had never left his own country. Everyone must sincerely hope that Captain 
Fitz-Roy's noble hope may be fulfilled, of being rewarded for the many generous sacrifices which he made for these Fuegians, by some shipwrecked sailor being protected by the descendants of Jeminy Button and his tribe."

The chief of the tribe, and its customs, in thus compelling "Jemmy" to revert to the habits of barbarism, seem cruel to the civilized man only. But not to "Jemmy," who had experienced both. The "reasoning" of the tribe necessarily took that line, and form, which meant the preservation of the tribe's necessary correspondence with its wild and savage environment, commensurate with the limited intelligence of the individuals; while the sympathy of the civilians on board the "Beagle" took also, that line and form, which would preserve the correspondence of "Jemmy" with English civilization, or environment, and therefore was unfit in the environment upon which "Jemmy" was then entering. It is evident that "Jemmy" was wise in remaining with his race. His reasoning, in the matter, was wholly determined by his environment, acting upon what brain he had. It is the same with the American Indian. When one is taken away from his tribe, and educated in a civilized school. then returned, he doffs the civilian's clothes, and dons the blanket. The perfect equality of the individuals, making up the communities in savagery, or barbarism, makes the possession of clothes, or anything else, by one individual, not common to the tribe, an impossibility. This law keeps the peace, subdues passions, hatreds. mean ambitions, and prevents strife and war. It is these facts, that compel the reason of the returned Indian to again conform to the customs of his tribe, which he had discarded while in the white man's college, or country, 
where his reasoning took an entirely different form. The right of private property, barter and sale of production, characteristic of our civilization, but unknown in savagery, have brought with them the crimes peculiar to them, and changed the reason of its personal units into a channel conformed to the support of these economical conditions. Whether we could have the evident advantages of civilization, without the crimes is doubtful, and yet civilization could not revert to savagery, for the sake of its equality of individuals.

Commiseration of the conditions in savagery is wasted, because such conditions are perfectly compatible with its mental and physical development, and perhaps contain as few proportionate necessary evils, as does our civilization. The freedom and equality of savage tribes have never been maintained, when the brain development advanced such tribes, to a civilized condition. Tribal governments are almost pure democracies. So that "Jemmy," by rejoining his tribe, became an equal with his associates, socially and politically, and this fact undoubtedly determined him not to return to England. It is not necessary to mention, what his social and political status would have been had he chosen to remain in England, to which he was wholly unadapted.

There was no slavery in the clans, gentes, tribes of the Indians; nor of any people at that stage of their evolution, because production was enjoyed in common, and was not a commodity. As soon as private property came to be protected, commercialism, and slavery arose. These needed stronger protection, than the tribe could, or would give them. Hence, the state was formed with police power, and militarism, under which, the exploitation of the weak by the strong, was legal- 
ized. But, when this immense and significant change came about, the numbers of the people had so largely increased, as to outgrow the possibility of the gentile, the tribal powers, and customs. These needed that each member of the tribe should be personally known to almost every other member. We are, therefore, compelled to assume that the state, which was evolved from these natural conditions, - our own civilization,- -was that form of society best adapted to the material conditions out of which they so evidently grew. It is, surely, not an ideal civilization, nor such as the sentiment, or the reason of men, in the aggregate, could they control it, would select, or make, and the present form of society will not endure. Society is in constant process of transformation, caused by material, not sentimental motives, beyond the real control of men. Therefore, reason has had little to do with it, except to follow the impulses given it, by material conditions. It is an evolution through, not by, psychical processes, called ideas, and the ideas were formed by sensations, from the objective environment.

"Natural selection" determines, in the last resort, which nations shall survive, what groupings of mankind are most vigorous, and what organizations are most successful."' (Prof. Ritchie.) What is it, therefore, but a physical, or biological evolution?

Man Still Evolving.-Man then, as a social and reasoning organism, is still evolving, both biologically, and psychologically. He can never hope to free himself from the biological laws of natural selection now, nor at any future period of his evolution.

Alfred Russell Wallace has argued, that after the development of those intellectual and moral faculties 
in man, which distinguish him from the lower animals, he would be little liable to change in bodily modifications through natural selection, or any other means. That is, man through his mental faculties is enabled to keep in harmony with the changing universe, with an unchanged body. Following this essay, by Wallace, or perhaps before, or simultaneously, many opponents of the evolution theory, took heart, and began to assert that the evolution of reason in man gave him control of his own development, and as to him, natural selection did not apply. There is no doubt that man has great power of adapting his habits to new conditions in life. His inventive genius enables him to make tools and implements to aid him in his correspondence with a more complex environment, far beyond the power of the lower animals. These inventions enable him to get into touch with more productive sources of natural law, but not to change those laws for his own benefit. This increased mental power comes to him only, as his nervous structure increases, so as to bear a larger ratio to his total body, or at least by largely increasing the complexity of his nervous system. While this ean be done, perhaps, without very greatly changing his outward bodily form, yet it is a change of bodily form internally, and this change is, undoubtedly, continually modifying the whole bodily structure. By comparing the head, and facial expression, of an intellectual white man, with a red savage Indian, one can readily comprehend this fact. Every change, in the mental capacity, is imaged in the external physical marks of the body.

Man ean never be entirely freed from the control of biological evolution by reason of an increase of his psychology, which means his correspondence with his 
environment. The very fact, mentioned by Wallace, that man must keep in harmony with the changing universe, means that, as the universe changes man's perception and conception change, and this means a change or modification of his brain structure, which is a part of his body.

Survival of Human Iaws.-We know from our own observation upon which we base human law, that whatever seems wisest and best in social custom, even to ourselves, eventually survives; and whatever is wisest and best, humanly speaking, should be the fittest. But remember at the same time that our human ideas of the best and the fittest are not always the same as the wide reaching methods of cosmic forces. As one instance of the operation of natural selection, in the survival of the best in human institutions; but beyond the control of human design, except as a design, may be shown in repeated experiment, to be an effort toward the natural law governing society; take the illustration of the celebrated lawyer who, in commenting on the evolution of the common law of England: in its wonderful adaptation to the preservation of the interests of man, in his governmental relations, with that form of government peculiar to England. said that if all the criminals who had been condemned by the law, could be placed on a lone island in mid-ocean and left to their own control, they would, as a matter of self-preservation, be compelled to adopt the very code of laws by which they had been condemned. This might not occur until a large number has been annihilated, through ignorance, by a violation of the natural laws of sociology and obedience to an unfit criminal code. Then, a statute law, found best fitted to preserve the natural laws, would be necessarily 
adopted. That is, those who have a variation of brain structure, enabling them to keep in harmony with natural and social law, survive, and those who do not, die. Man's artificial selection of customs, or habits, must be in conformity with the natural selection of cosmic law. England's common law was strong and sufficing only as it coordinated with natural law, and that condition was not evolved until many laws had been tried and discarded. The common law of England is the result of a thousand years of social evolution, and yet its theory still abides, that every interest rests in a king, which shows that English government is in a state of further evolution. These castaways on an island would. of course, not be compelled to choose a king; but, for self-protection, do the reverse. Under penalty of ultimate extinction, otherwise, they would be forced to adopt those laws, viz., customs, that all human experience has shown to be necessary for the support of society. While codes could be adopted that might, in very many particulars differ from the common law of England, especially in regard to royalty and state church, and in the penalties attached to crimes and misdemeanors, yet the rights of man and the rights of property, would have to be protected in practically the same way that these were in the laws under which these criminals were condemned. The whole social evolution has been, as far as man had anything to do with it, trial, failure, and continually a repetition of trial in different forms and directions, never quite solving the final problem. Perfection has not yet been reached, and perhaps never will be.

If all conventional human laws could be erased, and men left to protect society by those customs, which experience would compel, it would be found that there 
is a natural law by which alone the social bond could be preserved. This is the law to which all conventional laws, all written constitutions, and statutes must conforn, under penalty of social and individual extinction for violations. The Stoies first gave distinctive expression to this principle-the conception of an ethical irleal, abiding above the will of legislators. Plato undertook to prove that this principle rested on the constitution of man, and of human society. Aristotle recognized that there was an ideal standard more fundamental than the written or unwritten law of eustom. Thus Greece and Rome gave to mankind a natural ethic, viz., that natural law is the fundamental morality, independent of convention, and superior to enactment of kings. This is really the law of evolution in its broadest sense. If the law of evolution by natural selection is really the natural law it seems to be, then it is the principle that the reason of man must conform to, which is independent of convention and superior to enactment of kings or parliaments. Man's reason will therefore, eventually grow to fit into it.

In the British Museum, among the great number of valuable ancient manuscripts, is one of 1419 , attributed to Henry 5th, King of England. There is another manuscript letter of Queen Victoria's dated March 16, 1885. Henry's was written before the art of printing was invented in Europe. There is a period of 466 years between the two dates, which represent a wonderful evolution in the methods of ruling the people. the constitution of laws, the manners and customs of the English people. But what is to be noticed here is the difference between these two manuscripts, in the chirography, the spelling, the grammar, and the ideas expressed. There would naturally be much difference 
between the penmanship of the two sovereigns, one a male and the other a fernale, but the formation of the letters of the period of Henry 5th is very primitive. The word "brother" is used in both letters. Henry writes it "bjuthe," Queen Victoria writes it "Brother," with a capital B. Henry says, "Wherefore I wolle that the Duc of Orliance be kept st(i)lle within the castil of Pontfret," and the letter refers to the care with which he desires his prisoners of war to be kept. The queen's letter is in acknowledgment of a gift from Miss Gordon of General C. G. Gordon's bible. The two manuscripts are fine examples of the evolution. in four centuries of language, chirography, and expression; but, also, of the remarkable evolution, during that period, of the functions of the Kingly office. as expressed in the subjects of the two letters; in Henry's time, war, oppression, the support of Kingly power, imprisonment. In the Queen's reign, these thoughts had been turned to social duties, and the sympathetic functions. In this letter, she speaks of the "bible," a "dear brother," and the erection of works of art.

All such relics of important characters, in the world's history, exhibit the mental condition of the people at the time, and in many instances the moral condition also. They display these much more surely than do the pages of history. The letters of Henry and Victoria do this more certainly than would the manuscripts of Chaucer for instance, who wrote his poetry in the 14th century, and was a learned scholar, and of Longfellow of the 19th century. For these two were literary, and better educated, in language and literature, at least, than the society of their times. But, we cannot say as much of royal personages. Their education is limited to certain things. In real attain- 
ments they are little above the average of their people. The object of this comparison of the manuscripts of King and Queen, is to illustrate the evolution of mind, and its attributes and products, in the short time of four centuries. This evolution is shown as much, in what man has abandoned, as in what he has acquired. The customs that he has dropped, mean an advancement in mental habit. The change, marking the beginning of the 20th century, in the manner in which international questions shall be met, means the abandonment of war, and the resort to courts of arbitration instead. These changes all occur through the principal of natural selection, and the survival of the fittest. It is so in the forms of government, when republics follow monarchies. It is a constant readjustment, until an adapted form is reached, and that may undergo modifications for a very long period, before a desirable form shall be reached. 


\section{CHAPTER VI}

\section{MIND IS FUNCTION}

7 HERE are two theories of the method of consciousness and thought. One is that thought is produced through the mechanism of the brain by an indefinable, but independent force." Another is, that the brain and nervous system, in its molecular motion, its metabolism, produces the thought and consciousness. The molecular motion of the brain, as, of all the tissues of the body, is a specialized form of cosmic energy, and is as natural and material as any other movement. The nervous fiber is a specialized form of protoplasm, made so by its constituent elements. Its composition is exceedingly mobile, and therefore extremely sensitive, to incident forces. It is so placed in the body, as to receive impressions of the phenomena outside of itself, which have any bearing whatever upon its own preservation. This is its correspondence with environment; and its reaction to this correspondence is its physical, as well as its psychical life. This reaction, of the nerve tissue, is its molecular motion, and controls, or inhibits, the constant momentary movements of the organism in all its parts, including that aggregation of its feelings called its "mind." Those who profess to believe in the independence of thought, from this physical pulsation, acknowledge the molecular movement, but dismiss it with the expression, that it is parallel only with the thought. The materialist says it is the thought.

Nature of Molecular Motion.-It is well to state, in this connection, that molecular motion of nerve mat- 
ter, is not merely mechanical movement, by change of position, of many round atoms of substance. It is the function of the structure. The molecules of matter that makes up the tissues of living bodies. are the storage batteries of energy, transformed from the animal and vegetable food, taken into the digestive apparatus; and molecular motion in the nerve tissue means that this energy is being released by catabolism, in the form of psychic phenomena; that is, transformed into thought and ideas. Materialists call this a physical process, while idealists call it an independent process. Idealists contend that the result,thought, or ideas,-is the cause of the plienomenon, while realists assert that the physiology of the living matter produces the phenomenon. It is really the escape, by the destruction of the proteid molecule, or cell, of the stored energy, or retained motion, which has been metamorphosed from other animals or vegetables, in the form of food, by the human being. This destruction of nerve tissues is followed, or accompanied by, an observed psychical phenomenon, which is variably called thought, idea, image, conception, imagination, or memory. Those molecules of matter thus destroyed, are quickly replaced in the living organism, from the blood, by a process called anabolism,--the whole process, of destruction and construction, is metabolism. As said elsewhere, the body is a maelstrom of active energy, the explosions of atoms, or centers of energy giving the effects. All the mental and physical activity of the organism depends upon this physiological process, and ceases entirely when, the metabolism stops.

Hnxley, in commenting on Hume's contention, that thought is produced by the physiology of the brain, 
says, "Surely no one, who is cognizant of the facts of the case, nowadays doubts that the roots of psychology lie in the physiology of the nervous system. What we eall the operations of the mind are the functions of the brain, and the materials of consciousness are products of cerebral activity." The strict line of demarcation between the physiology of metabolism and the psychology of the thought, or idea, can well be maintained, if we interpret thought as caused by molecular motion. All the psychic effects, by which the organisin maintains its correspondence with environment, are the elements of psychology, and the molecular motion is the physiology.

There cannot be two separate independent forces operating in the realm of what is called nature,- the one called natural, and therefore evolutionary; and the other, something undefined and not subject to the laws of evolution, nor the result of it. All phenomena, usually called psychical, are one in natural cause, with other interchanges of matter and motion and matter and motion are one in reality,- - the unity of phenomena having the dual aspect only, of structure and function. Psychical phenomena cease when that interchange of matter and motion ceases. They exist only in connection with nerve molecular motion. Each brain produces its peculiar manifestations for that brain only. These peculiar manifestations or functions are not produced elsewhere nor continued after the disintegration of the brain, unless by an equivalent quantity and quality of living brain tissue.

Spencer's definition of an idea is: "A wave of molecular motion diffused through them" ("an involved set of nervous plexuses"), "will produce, as its psychical correlative, the components of the conception in due 
order and degree. The idea lasts while the waves of molecular motion last, ceasing when they cease; but that which remains is the set of plexuses." This means that the nervous structure in the brain, which has been evolved biologically, is the permanent determinant of ideas. Therefore the laws of evolution apply to psychical, as well as to physical phenomena.

Organic Preservation.-Every so-called action of the will, and every psychical action, e. g., every thought, is determined either by the preservation of self or of the race.

This is the meaning of life. It is an aljustment of the organism to the source of its preservation, viz.. its physical environment. Therefore, the law of evolution in physical biology, which is the preservation of the individual and the race, must apply to all forms of psychical phenomena.

As SAID BY RrBot: "Sensation" (which produces the thought) "is a monitor, an aid, an instrument, a weapon, with only one aim,- -the preservation of the individual.

The nexus between the sensations, and the organic, and motor reaction is, therefore, innate." This means, it is function of matter. This sensation may come from within the organism, but that does not make it necessarily subjective, but objective. The molecular motion within the brain may be the sensation causing other forms of molecular motion in the same brain. or thought producing lhought, but it nevertheless has a physiological mark, the same as sensations coming from without the organism.

Advocates of IndePendence.-The advocates of independence do not tell us what it is that produces the thought, but seek to measure by instrument the 
sensation, and its reaction in the brain, in much the same manner, that the conversion, of heat into power is measured. Not finding any instrument delicate enough to do this, they declare for independence. It is most probable that thought being a condition is not thus measurable. This idea of independence has a parallel, in some former physiological superstitions. For example, in the sixteenth century physiologists held that "the blood which has come through the septum is mixed with the air thus drawn in," (into the left ventricle of the heart from the lungs), "and by the help of the heat, which is innate in the heart, which was placed there as the source of the heat of the body, by God, in the beginning of life, and which remains there until death, is imbued with further qualities, is laden with 'vital spirits' and so fitted for its higher duties." This conception of an "independence," separate from the physiological, in the production of thought, is not quite so crude, as the ignoring of the chemistry of heat, and considering it as the direct gift of God, because the chemists of that day had no "measurable" evidence that oxidation of the blood in the lungs produced the heat of the body. But, the ideas of "separate independence of molecular motion and psychical phenomena" is only less apparent as a superstition, than the former is now. It has always been that unknown causes were traced to a divine power by the majority of mankind. Van-Helmont, 1577-1644, held that "the food absorbed from the stomach and intestines is, in the liver, endued with natural spirits, and in the brain, the vital spirits are transformed into animal spirits." The various "independent powers" called "spirits" have all faded away, as the true knowledge of the human organism came, 
by the senses, to the intellect of man. It is not surprising that such ideas were evolved, prior to the advance lately made in chemistry, physiology, biology, and physics. But now, when the indestructibility of matter, the conservation of energy, the persistence of force, the evolution of all things, are so well established by scientific evidence, it seems almost incredible, that an able author of physiology and psychology can contend for independent causes for any of the activities of the human organism. Contrast the above extracts with the following extract from a late scientific treatise on physiology, viz., "The Nutrition of Man," by Russell $\mathrm{H}$. Chittenden, professor of physiological chemistry, in Yale University :

"The human body is a maelstrom of chemical changes; chemical decompositions are taking place continuously, at the expense of the proteids, fats, and carbohydrates of the tissues of the food, the stored up energy of these organic compounds, being thereby transformed into active, or 'kinetic' forms of heat and motion; while carbon-dioxide, water, urea, and some few other nitrogenous substances are being continually formed, as the normal waste products of these tissue changes. *** In other words, the body is in a perpetual condition of chemical oscillation, constantly consuming its own substance, rejecting the waste products which result, and giving off energy in the several forms characteristic of living beings." One of the forms of energy characteristic of living beings is thought, and so is any form of psychic phenomenon, and like the muscular activities of the body are caused by the chemical activities constantly taking place in the body.

The molecular motion, in the brain tissue, being psy- 
chical phenomena, both must be recognized as the same thing. The molecular motion is the psychical phenomena. No one can find a measurable test, scientifically, of the purely psychical phenomenon, because he is trying to measure something that does not exist, in a measurable form. But while the evidence cannot be thus reduced to the same scientific basis, as mechanical motion; yet, such constant connection, between such molecular mechanies of the nervous structure, and the phychical phenomena of the organism, made up largely of such structure, seem to be one and the same thing; just as molar motion is the attraction of gravitation. The three laws of Kepler from which attraction of gravitation was mathematically derived, are descriptions of the observed forms which such motion always takes. That motion produces the harmony, or "mentality" of the universe.

"We occasionally meet with the view, that in the exact natural sciences, nothing shall be the object of investigation, which cannot be measured, according to mass and number. This conception, destined to hinder the development of scientific knowledge, as the first step towards the explanation of many phenomena, can in most cases only be made by qualitative, and not quantitative investigation, although the ideal goal is mathematical demonstration of the processes, in living organisms, from which we are still far removed." (Max Verworm.)

There are very many mental conceptions in the practical affairs of men, whose boundaries cannot be measured by exact mathematical lines. Lord Macauley in discussing the revolution of 1688 in England said, "A good action is not distinguished from a bad action by marlis so plain as those which distinguish a hexagon 
from a square. There is a frontier where virtue and vice fade into each other. Who has ever been able to define the exact houndary between courage and rashness, between prudence and cowardice, between frugality and avarice, between liberality and prodigality?" This is so because the extreme mobility of our nervous action, and the intimate meshes of its conduction paths, the perpetual motion of its minute particles. make the psychical phenomena so blend that the subject fails to perceive the true line of demarcation. They cannot be measured mathematically. So it is with our collception of the unconscious process of thinking. It eludes the subtlest mathematical tests because the measurements cannot be applied to the material substance of the brain while it is in action, as it can to muscular tissue in a mere reflex action. If the brain is simply a bundle of nerves, however, to convey spirit, as copper wire carries electricity, then science should turn its attention to the study of "spirit," as it does to radio activity. But when it nndertakes to do that, it finds nothing but a blank, nothing is found except molecular motion, accompanied with explosions of energy, and that is measurable as such, in metabolism.

The division of the human organism into a duality, physical and psychical, and the treatment of the psychical, in the last few pages, as the product of evolution, is necessary only in view of the commonly accepted theory that the psychical is a distinct entity. But it is entirely unnecessary to the monist, who holds that the organism is a psycho-physical unit, the psychic being a function of the physical. The monist holds that the proof of the evolution of the body carries with it the proof of the evolution of all the manifestations of its structure. 
ENERGY.-One gramme of radium produces as much energy as the burning of one ton of coal. Where does this energy emanate? It is a natural element existing throughout the universe. Wherever there is motion, some of this energy is causing it. It is not independent of matter. In fact, if electricity is molecular in its composition, then it is matter. All matter is the aggregation of these corpuscles of radium and electricity. The brain matter is only a differentiated form of it. According to the researches of Sir J. J. Thompson, Rutherford, Professor Strutt, Joly, and others, ordinary matter contains immense stores of energy, and when by the inetabolic process in the human brain a molecule is disintegrated, and its energy is released, we can well believe that the psychic phenomenon resulting can be attributed to this canse alone; for, if at any time an appreciable fraction of the energy in ordinary matter, held in bounds by the corpuscle, were to get free, the earth would explode and become a gaseons nebula. The intense energy of the sun does the work of the world, and all the psychic phenomena of its inhabitants. It is stored up, not only in its coal, and its waterfalls, but in the food with which our bodies are built up and sustained. This energy of the sun transferred as carbon to the regetation, is transformed into the atoms of the brain, and released by metabolism into all its activities. It is thrown out from the sun, modified by our atmosphere, and stored in the soil and rocks of the solid body. We could not exist without all the meaiums of transference of energy, our bodies and brain receiving their life through the chain, and eventually giving back, in some form, either physical or mental, all that we receive. So that, as far as we can see, there is going on a process of transference of energy which had no begin- 
ning, is in process only, never finished, and therefore without end. This is what intellect discovers. Now. if there is any "aurora" around intellect, as said by Burgson, that ean by any method be utilized to disclose that the intellect at present is deluded, and that the eternal round of phenomena, now supposed, can have a further meaning, then let us strive toward such achievement.

Renewal of Tissue.-It has been urged by a parallelist that periodically (one has said every two years) a new brain results from the destruction of the old cells and the formation of new cells. Therefore, low could a continually renewed brain do the thinking? Because a movement called metabolism is constant in the body, that therefore a new body is being formed, and that, in any set time, a new organism results,different in function, is absurd. 'The multiplication of cells, by which the body is formed, is a division of the same cell handed down generation after generation with its mnemonic quality, which makes it the same, in every respect, as the former cell. "It is a continuation of the personality of every ovum in the chain of its ancestry, which ovum it actually is, quite as truly as the octogenarian is the same identity, with the ovum from which he has been developed. * * * We therefore prove, each of us, to be actually the primordial cell which never died, nor dies." Butler's "Life and Habit," p. 86. This view is approved by W. Bateson in his paper in ' Darwin and Modern Science.' But aside from this, the common sense of every individual teaches him the falsity of the idea. A human being is constantly aware that he is the identical organism, at 80 , or at any moment of his life, that he was at the first dawn of his awaking memory.

The brain from birth to death is made up, of exactly 
the same nerve tissue, formed of the same molecules, placed exactly the same way, with the same number of cells, all composed of the same elements, combined in the same proportions. Its waste, by the way of the venous system, and renewal by the arterial blood, is a slow and continuous process, during which the old and new atoms are constantly in physiological contact and accord. The molecular motion producing the images of immediate sensation, and associative memory, and the coalescing of these into ideas, is a continuous process. Thus, long before what is called above the "new brain" is formed, the experience of an old brain is constantly renewed, and there is nothing new and untried, or unknown, such as there would be, if every two years an entirely new brain was manufactured outright, from new material, which in the meantime, never had any psychic experience, and this new structure mechanically put into the skull, after the old one had been bodily removed.

We know that human consciousness is the manifestation made, apparently, by nerve tissue in the body, of which the brain is the largest, and most complex part. As long as the brain is active, these manifestations appear. Did any one ever see, or hear, or feel the manifestations, except in connection with the nerve structure? Whatever cells arise in the brain are identical, in structure and function, with the ones replaced, have the power of memory, of all the organism has done during its life, the same reason; in short, it has every identical feature of the cells replaced, each new cell being really the old cell, not a chemical substance even being changed, in the least particular. They act just as the body cells do. "The new cells keep up the peculiarities of the body shape, the physiognomy, the 
complexion, color of the eyes and hair, so that at each moment of life the personality is the same. It is not a process of cutting out an old cell and putting in a new one made outside. It is a process of metabolism.

The Psxchic Phenomena.-Science has never been able to discover in mental phenomena anything but the nerve structure, and its molecular motion. When the molecular motion ceases, there is no consciousness. Then, what is to be gained by assuming that there is something not apparent. Until there is something else apparent, it is logical to attribute to the structure and motion the resulting psychical manifestation.

It is not unthinkable that matter and motion, in the form of mobile nervous ganglia, charged with such marvelous energy, can directly'produce the thought of mankind, when we see them in other combinations and relations, produce tints of changing sunset, the rainbow, the solar spectrum, chemical attraction, the attraction of gravitation, and the evolution of all forms, or the production of the finest music by the "rasping of the hairs of a horse's tail, on the intestines of a cat." (Wm. James.)

The natural phenomena in the environment referred to above, are objective phenomena, that existed prior to any known psychical phenomena. Their connections with their real causes are as obscure, as are those of mental phenomena, with their real causes. They are all the results of particular combinations, and phases of energy, and our senses never perceive them except in these combinations. Thought is the reproduction of them by sensations and images, through the physical nervous structure. The mind is a spectrum of objective phenomena, produced by sensations coming through the eyes, ears, nose, skin, and mouth, and 
what is called self-feeling, or the kinaesthetic. There can be nothing in all phenomena, but what matter and motion, in the form of energy, produces. Fceling is the observation of the effect by the organism. This is consciousness, or awareness; or a relation between certain objects, the number being limited by the capacity, for impression, of the neural structure. Or consciousness is the power of choice of several methods or paths. "No state of conseiousness can be dissociated from its physical conditions." It does not appear to the ordinary observer that the energy exhibited by the daily and nightly phenomena of nature could be naturally produced. Of course, mental phenomena are still more mysterious to him, because they have an entirely differcnt relation to him from those in the inorganic kingdom. But after scientists adopted, by empirical observation, the theor'y that atoms are mere centers of cosmic energy, the same that runs the universe, there seems to be no difficulty in neglecting former mysterious cause for these effects; an angel, for instance, at each star to supnort it in position, was not a necessary assumption, after the discovery of the attraction of gravitation.

All human phenomena, pliysical or psychical, are a part of natural foree, called cosmic energy, or the persistence of force, a part of the physical universe, the same as matter. The peculiar phenomena called vital, and those vital phenomena called psychical, cannot be separated from the mental conception of the universal postulate. They are natural, and governed by natural laws only. The mind, or consciousness, of man, is impossible withont the neural structure, always accompanying it, and the neural structure without its function, or without its genetic correspondence with cosmic energy; in other words, without its excitation by the 
objective, is nothing more than any other functionless matter, it is inorganic.

If we interpret thought as a molecular process; that is, as images of objectivity, formed by the psychical device, we get rid of the dualism of thought and object. This is "immediate experience". In that, the object is the only thing; and that object is always an immediate reality; it is a phenomenon, either of things as we "know" them, or of an abnormal differentiation of such things in the diseased brain. In other words, if thinking is a part of substance, or matter, there is no necessity to discuss it as existing apart from substance or objectivity. The brain is that form of matter which produces what we distinguish from the physical form of phenomena, as psychical, and its correspondence with other forms of matter is analogous to the relations that all forms of matter hold to each other. "The sciences ultimately refuse to recognize dualism. The world is only intelligible by science, on the assumption that it forms one coherent system. A philosophy based on the special sciences cannot recognize anything outside the material universe." (David G. Ritchie). This is monism, and is both materialistic and idealistic. Huxley has shown that the two views lead scientifically to the same conclusions.

Human KNOWLEDGe.-Human knowing has as its essential elements two forms of being, or, more properly, one element polarized by mental analysis into two conditions, viz.: (1) an environment composed entirely of phenomena, which are manifestations of a creative evolution; and, (2) an organism controlled by a nervous system in correspondence with and responsive to such environment. Both elements are specialized parts of one universe, and are equally phenomenal, being 
manifestations of cosmic energy. The evolution of forms is the only creative force, and this is the working over dynamically of an existing limitation of energy, infinite to us, but to us, having no beginning and no end.

That phase of consciousness, having cognition, is the result of a correspondence between the nervous centers and an environment made up of natural phenomena,including psychical facts of all states of truth or falsehood. In this view, knowledge consists of pure experience, as we all have it, from day to day. To one individual, it may be largely delusion about an absolute. To the scientist everything would appear natural. The forms of matter visible to us are aggregates of certain attributes. The impressions made upon our brains are phenomenal only, but these impressions are real to us. There is never any doubt in the brain of the individual as to the reality of the impression; and to him water, air, earth, fire, are real things, although they may appear to the scientist as differentiated forms of energy. To the ordinary individual, they are existences objective to his perception, and without this existence he knows there would be no impression. He knows also that should the impressions made on his brain by these objective things cease, it would be the result not of the discontinuance of these objective forms, but his own cessation of the conditions of impressibility; or, in other words, a change in his own form which dissociates him from objective relationship. Therefore, the contention of the idealists that there is nothing but impressions, is not the common sense view. These impressions or sensations are received through the nervous system from those objectives into the organism, and there co-ordinated into feelings. Some of these feelings are 
again eo-ordinated into abstractions and generalizations by higher neural centers. The aggregate of these feelings is called the mind. Knowledge is the psychical phase, denoting the physiological wealth of associated and systematized nervous action in the encephalon. It is the culmination of sense impressions, acting by molecular and chemical motion, through the nervous structure, upon the motor centers of the cerebrum. We must understand that the resulting consciousness is of only the objective thing or fact or problem. As remarked before, late experiments and investigations tend toward proving that the functions of nerve matter and those of ordinary muscular tissue are in no way different in kind. The only advantage to the organism the nerve tissue gives, is the greater rapidity with which it conveys sensations and produces responses or reactions. It, of course, gives a wider and completer response to complex environment.

Mind, the Property of All Organisms.-The nerve tissue in the human individual is so large a part of the organism, that its activities include abstracting, discriminating and comparing the qualities, and the meaning of sensations in a very much larger degree than in any of the lower forms of life. But the animal, with or without nerves, and the members of the vegetable kingdom, have a degree of "mind." "The humblest organism is conscious, in proportion to its power to move freely." (Bergson.)

"I know of no test, by which, the reaction of the leaves of the Sundew, and of other plants, to stimuli, so fully and carefully studied by Mr. Darwin. can be distinguished from those acts of contraction, following upon stimuli, which are called 'reflex' in animals." (Huxley.) 
Psychological life begins with living protoplasm. The pseudopodia, therefore, have mind, although there is no trace of differentiated nerve structure. In this sense, mind is coextensive with life. Haeckel says it is not confined even to the organic. The original atoms, that make up the entire inorganic, as well as organic nature, themselves have the function of motion, attraction, and repulsion. To the extent, that these atoms respond to their environment, they have minds, and knowledge. In short, all such responsiveness, whether we call it attraction of gravitation, chemical affinity, molecular motion, or physical phenomena, is, in one sense, simply mind in different forms. This is the doctrine of continuity of consciousness. The degree, or intensity of it, depends upon the complexity of the aggregation of atoms producing the responsive motion. The atoms composing oxygen, when they leave their combination with hydrogen, and rush to embrace the atoms composing potassium, so impetuously as to produce fire, on the surface of water, is not a conscious process, in our conception of human consciousness, but the result,- - the phenomenon of incandescence, and the formation of a new compound, different from either of its constituent elements,-is clearly as wonderful, and as important, as the movement of similar atoms in the human brain, that result in only muscular motion, or what is called "will power." The two processes do not differ, in being the interaction of matter and motion; and that is all we can perceive mind to be. In only a less degree also, these chemical phenomena in the inorganic world, have their subjective, and objective phases. If there did not exist, in the inorganic world, these chemical responses to the requirements of the cosmic movement, chaos would 
abide. There would be no harmony of form and motion anywhere. The astronomical bodies would not be formed, and therefore life as we now see it, in the multiplication of effects, on the earth, would be impossible.

Units of inorganic substance, or of organic compounds, combining in the course of evolution, or disintegrating in the process of dissolution, appear to know, or to be conscious, to that degree, of the proper motion to make in harmony with the pending phenomenon. Teleology locates the consciousness of these movements outside of units of substance. But that is an assumption, not justified by the facts. This "mind" in atoms is their subjective side, and while it is very limited compared with our conception of the same phase in the human organism, yet we are compelled to recognize its existence. So, it is intelligence when the component parts of a star, brought by a ray of its light, pass through a lens, and form a spectrum, informing the astronomer of the composition, and conditions, of a far-off sun. These star components do this, whether there is any astronomer to interpret them or not. They did it millions of years prior to the birth of Fraunhofer and Kirchoff, who first properly conceived, and interpreted their meaning.

The term "psychical" has been limited to the activities of the human nervous system, and the analogous phenomena in the inorganic are termed physical. But the cause, and the effect, in both activities, are similar. If, at the moment of the discovery of a great truth, like the attraction of gravitation, in the brain of Newton, the bony covering of his cerebrum could be removed, and the most powerful microscope applied to the operation going on, nothing could be discovered, but the 
isomeric molecular motion of the units of matter composing the brain. All mental phenomena, however obscure, and however valuable, are simply the product, so far as experience teaches, of the interchange of matter and motion, going on in the nervous structure of the body. Particles of matter therein are constantly disintegrating, and other particles forming new units. This activity accompanies every thought.

"When movement ceases, consciousness dies away." That is the reason why parasites, both vegetable and animal, lose their power,-become inert. The plant is unconscious, but still some plants approach it very close. A plant shows it when it "bends the energy of the solar light, to aid it, in absorbing the carbon away from the oxygen in carbonic acid." "The same iunpetus that has led the animal to give itself nerves, and nerve centers, must liave ended in the plant, in the chlorophylian function." (Bergson).

The more rapid and intense the mental action, the quicker becomes the integration and disintegration of the molecules of the nervous system. When the matter ceases to act, the differentiated energy called mental process stops. No one has ever been able to show by induction that any human mental phenomena have been produced, except in the neural centers of the organisıns, following and seemingly the result of physical pulsations. The same motion of molecules, precisely, characterizes every chemical phenomenon in the organic. There is little doubt that if the two movements of the production of thought in the brain, and the formation of a crystal in inorganic matter, could be minutely compared by the microscopist, the only methodological difference observable would be in the time of the movements. 
There is no apparent line of demarcation between the physical and psychical, as there is none, also, between matter and motion. They are simply different forms of cosmice energy.

The mentality of living bodies below man is not different in kind, but in degree. If it were possible to dissect the nervons systems of a man, and of a lower animal, and exhibit them apart from the body upon manikins, so as to show them in all their ramifications, just as they lie in the organisms, they would show by comparison that the superior mentality of man results from the more complete and perfectly connected network of larger nerves, permeating every point of the human body, and all comnecting in the larger and more complex ganglion, called the brain; while the same system in lower animals is less complete and more disconnected at its reripheral and other terminations less complex, and of much smaller size in the encephelon compared with the size of the body; that the nerves and ganglionic centers, including the brain, are larger, more copious and complex, giving them higher quality just in proportion to the manifested mentality of the organism. This would be a natural and effective method of teaching psychology, and nerve physiology, if it were practicable.

When man is confronted with the unknown and desires to and can scientifically make it known to himself, his methor is the same as that of the animal. He simply makes repeated effort until he finds a solution. This refers to the manner of procedure only; not to the immensely larger number of higher problems man is capable of solving, of which the lesser mind of the animal is incapable. The difference is one of degree only. 


\section{CHAPTER VII \\ MIND IS FUNCTION \\ Continued}

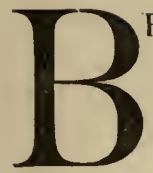

ERGSON asserts that the intelligence of man is different in kind from the instinct of the animal, but the difference seems to be one of quantity and quality only, man having more choices of method, because of his more complex nerve structure. The same method practically is adopted by both man and animal, under the same necessity, and this proves the homology of structure and function. That is, they have the same psychical device for accomplishing their necessities, the man's being greater in power and complexity only.

"It will be observed that Hume appears to contrast the 'inference of the animal' with the "process of argument, or reasoning in man.' But it would be a complete misapprehension of his intention, if we were to suppose that he thereby means to imply that there is any real difference between the two processes. The 'inference of the animal' is a potential belief of expectation; the process of argument, or reasoning, in man is based upon potential beliefs of expectations, which are found in the man, exactly in the same way, as in the animal. But in man endowed with speech, the mental state, which constitutes the potential belief, is represented by a verbal proposition, and thus becomes what all the world recognizes as a belief.'

(Huxley.)

Bergson compares consciousness to a sharp knife. "The brain is the sharp edge by which consciousness cuts into the compact tissue of events, but the brain is no more coextensive with consciousness, than the edge 
is with the knife." This would be understood better, if the brain were comparable with the knife, and consciousness with the sharp edge. The edge of the knife is part of the structure of the blade. It is not anything different, or separate from the material of the blade. He says, "Thus, from the fact that two brains, like that of the ape and that of the man, are very much alike, we cannot conclude, that the corresponding consciousness are comparable, or commeasurable." The two brains are alike only in the organic-chemical composition of their tissues, but they are very much unlike in size, shape, and especially in the relative sizes of the cerebrum, compared with the cerebellum. They are unlike throughout the nervous systems, that of man being very much more complete. The ape, as far as his brain can give him choice, as far as it can give him power of action, does things just as man does them. That is, to that extent, he and man are parallel, in consciousness. Therefore, his is not a different kind of consciousness, but of the same kind, in less degree. When man's brain evolved beyond that of the ape's, it did not take on a new kind of matter, but the same kind, in larger and better proportions. This, it is, that makes man's consciousness, or psychical activity so much greater in degree only, than that of the ape. The same energy that gives the ape his life and mind is derived in the same way from the same sources, as that of man. How ean it be truthfully said then, that the "mind" of the ape is different in kind from that of man?

There is little doubt but that at one period of man's evolution he did things just as the animal now does, and could not do any more or any differently. The differerce between him now and then is an evolution of 
the same structure and function he then possessed, not the elimination of that and substitution of other of a different kind. All life, physical and psychical, is alin, berause it is evolved from the same material without the addition or subtraction of a particle of its essence or nature at any step of the process. That is the reason why structure and function are alike in kind and differ only in degree in all animals.

The present experiments that are being made in aerial navigation show very clearly the parallel working of the psychical device in man compared with the same device in the lower animal, when they are both confronted by an unknown problem. So do the efforts made to reach the north pole. They are a series of trials and failures. They are the reactions of the nervous structure to an objective stimulus, in an indefinite incoordinate way. The induced nerve molecular action is without any former experience in such line of action. and the line of least resistance for such response is not yet found. Like the baby learning to walk, such experiments are very hard work at first, but with the prospective result that eventually they will become as automatic as the flying of the bird.

Consider further the comparative daily life of man. and that of the animal with reference to their being alike in kind. Men seem to have done and are now doing instinctively those things that are concrete, and are not beyond their capacity. The great bulk of organized society confine themselves to agriculture, commerce, manufacturing-to money making in general. All these pursuits have reference to the support. housing and adornment of the body, and require a less amount of brain energy than purely intellectual work, such as biology astronomy, geology, and evolu- 
tion. That is, the great majority of the people are spending their lives in doing in a little higher degree just what the lower animals are doing in a less degree.

An animal's existenec in the wild state is a struggle; that is, an effort for existence only. If he can get enough to eat, and defend himself from his enemies, that is the sum total of his life. That is the business to which he devotes his mind. The man who gives himself up to industry or business does practically the same thing. His brain, of course, is very far superior to that of the animal's. But that extra brain, the difference in nerve structure between him and the animal, he devotes as a rule to higher quality of struggle, for higher physical existence only; the animal hunts and grazes, if a carnivora, he captures his prey; the man cultivates the ground for his vegetable sustentation, and selects his animal food by domestication. The animal wears the dress that grows upon his skin; the man selects his material and manufactures clothing. The man makes a fire, and cooks his food; the animal eats his raw. The animal as a rule (there being some exceptions), dwells and sleeps in the places he finds at hand without any contrivance or mechanism on his part; man builds himself houses of some kind in which to live, with artificial tools. The animal uses only the tools nature has given him. Man makes tools from the inorganic substances, which do his work in a variety of ways. The donkey, given his head, finds water in the ilesert that his intelligent driver cannot find; but the former is unable to construct a pouch by which water can be carried on the journey. Instinct is confined to one line of action, but intelligence can choose from many.

The animal changes localities on foot, or wing, or by 
swimming; man subdues beasts of burden, builds vehicles, utilizes the natural power of heat, or electricity, to carry himself, his food, and clothing from place to place. These differences in the methods of bipeds and quadrupeds are largely the result of man's acquired erect position, and his acquired intelligence. This position modified the anatomy and physiology of the whole human organism. The arms became shorter and unadapted to an arboreal life. The hands retained their prehensile power, but the feet lost their power of grasping the limbs of trees. The feet gradually flattened on the soles, and calves developed on the lower legs, adapting them to support, and steady, the body in the upright position. These changes contributed to the better defense from enemies, and the power to capture other animals for food, by throwing a missile with steadier and surer aim.

The upright position, also, gives a longer reach to vision, and must have modified the anatomy and hence the physiology of the lungs and throat. It is reasonable to suppose, it made possible articulate speech. The anatomist should be able to vertify this anatomically. But it is scarcely possible, that if man had continued, to the present time a quadruped, he could have acquired the function of articulation of words, in the way words are now used. The modifications that took place, in the anatomy of the human being, after he assumed the upright position, by the laws of equilibration, reached the anatomy, and through that the function, of every organ, and every part of the body. The muscles of the throat and neck must have been modified profoundly, because the forelegs, which by the erect position became the arms, are attached to the body so near the neck. It is most probable, that the 
modifications, that eventually occurred in the throat and lungs, were followed later on by the power of articulation, which prior to such changes was not possible. The freeing of his hands from mere aids to locomotion has, also, enabled him to contrive and construct. Indeed, man first appeared, when a tool lay beside the fire, he had built. With this tool, or a modification of it, he has carved his way to be monarch of all he surveys. The animal, on the contrary, has never invented, nor used tool, or fire. It works only with the natural organs born with him. He therefore cannot compete with man physically, or mentally, but originally and organically, there was no difference of kind in their instincts; but when man stood erect, and began to use fire and tools, intelligence was added to instinct, by an enlargement of the cerebrum, and the multiplications of its nerve connections in the body. He then began to choose new ways of fighting the natural forces, which before had kept him down, and which now keep the lower orders in the mental stagnation, now eharacteristic of them. But, this was not accomplished by the addition of matter of a different kind to that which prior to that human function, he already possessed. Instinct is confined to one way of doing things. Intelligence chooses from several ways open to it. The bird, the ant and the bee repeat, for all time, the pattern house and nest, and never rise to invention. They build as well, if not better, than man at first did, when instinct alone bound him down to use only the tools that nature gave him. But a genuine departure, a separation began, when fire and tool making, reacting on the brain of man, started him on the road to invention and choice. Certain instincts remained with him, and by long use certain habits, like 
walking and language, became automatic, and therefore instinctive, in his matured form, but it has taken ages to bring about this change. At first, intelligence was not equal to instinct in accomplishment. Instinct was quicker and more certain. But, intellect's potential achievements were infinitely greater than those of instinct. The animals, controlled by instinct, were better housed, and perhaps better fed, than man. But, when men's arms were freed from mere locomotion, and free choice given him by the birth of intelligence and reason, then he advanced, while the animals, possessing only instinct, remained in the mental condition they now are. When a man slaughters a hog, carefully cutting it up into appropriate pieces, salts them down in a barrel, made by his own hands, to prevent the meat from putrefaction, we call that reason, because it is a process that provides him and his family with sustentation, at a future time. But when a wasp stings its victim on just those joints where the nerve centers lie, and thus paralyzes the victim's power of motion, without killing it, and stores its body away for the wasp's future sustentation, we call that instinct, although the operation shows the wasp to be a learned anatomist, and a skillful surgeon. This example of the instinctive intelligence of the wasp could be repeated of other animals of the lower orders many times. When a bald hornet catches a house fly. it immediately cuts off its wings to prevent its escape. These parallel similar actions of man, with this difference; the surgical instruments of the wasp and hornet are made for them organically, as are all the tools of the lower animals, with which they work; but man makes his own tools from inorganic substances, with which he operates, and when he kills and preserves his 
meat, he can build a fire and cook it. These differences in action measure the difference in degree of power between the nervous systems. Instinct stops with its operations on things, it has no variety of doing the same thing. It has but one mode, or choice, and continues that method without variation. It is the reaction of a brain in which no new short cuts are formed by repeated effort. But intelligence seeks out many methods, and is constantly storing up discriminations between relations, and records, in written language, its discoveries. Instinct cannot follow it in these achievements, and is helpless before the power of intelligence in its ultimate use of the forces of materiality, to subdue all lower organisms. Bergson says: "Instinct operates upon life, and intelligence on things." But he is in the habit of using terms in a metaphysical sense, as if the terms instinct, and intelligence, were personalities directing and planning the colstant phenomena of life. For instance, he says: "The same instinct had gone on complicating itself more and more in one direction, and along a straight line, etc." He holds that instincts have not been acquired through inherited habits of millions of generations, and retained by natural selection, as instincts. He says. "there is no need of such a view if we suppose a sympathy (in the etymological sense of the word) between the Ammophila and its victim, which teaches it from within, so to say, concerning the vulnerability of the caterpillar." Max Meyer would account for this by nervous reflex as the cause within. It is to be presumed that each philosopher expresses in such statements his own mental make-up, or tendency. Bergson is an idealist, and Meyer is a materialist by nature, and those who adopt one view, or the other may be classified by the tenden- 
cies of their brains, and the necessities of their thinking, in the class to which they belong. But "sympathy" is not as plausible an hypothesis as that of original use of his (the Ammophila's) sting until he found the correct places, and in course of time, the habit became hereditary, as an instinct. Bergson admits that science treats instincts as at first intelligent action, afterwards reduced to automatism, and could not treat them in any other view, but that science seems to expect philosophy to adopt another view, viz., from the inside of life itself, and make everything connected with life an impetus from within. That is transcendentalism, and gives greater importance to intuition than to induction. The philosophy that ignores, or goes beyond, the induction of science, has none of the sensory evidence, that is the criterion of truth.

Bergson again says: "Instinct is sympathy. If this sympathy could extend its object and also reflect upon itself, it would give us the key to vital operations,just as intelligence, developed and disciplined, guides us into matter." It is more likely that instinct is experience become automatic by very long usage, and that it is limited by that origin to just what it doesthat it is altogether incapable of more than the primitive service it now makes to the support of life. Intelligence, also, is limited to the fabrications of matter, in the support of life, and the enlarging of life's functions. Neither it, nor instinct, will ever give us the true key to life processes, or rather to the origin and meaning of life. Science, which is the highest form of intelligence, will greatly extend its achievements, but not behind phenomena, except to implant in our brains certain inferences that will be of no practical benefit. 
It is suggested that biologists know the morphological forms of development, but fail to see the chemical phenomena connected therewith. In other words, they fail to see and act upon more than matter. The real movement of life development is beyond the reach of intellect, and unless this is disclosed, there will always be something left to conjecture. But matter always intervenes to bar the penetration of the human senses, beneath the integration, and dissipation of itself. Some other light beyond the X-ray may yet be discovered whose penetrating power will disclose, not only the chemical, as well as the geometrical phenomena of life, but also streams of becoming, and the reason why nothing is ever finished, the reason why everything always remains in the making.

Man gradually acquired the power to record with his free hands a written language to represent the sounds of his voice, and the images made upon his brain by objective things, by which any advance in the methods of the struggle for existence can be permanently communicated to his fellow men, not only to his own generation, but to those of the future. The result has been, that in addition to the former communication of new ideas and facts by direct contact and personal observation, distant peoples are rapidly informed by books, and periodicals of all new methods, and discoveries. The art of printing has thus given an immense impetus to man's efforts over those of the animal in the struggle for existence But notwithstanding all this, it is well to observe, that the men who use all these advantages, that man's enlarged brain power has given him, over the wild animals, who still use the primitive means of existence, for the mere support of the body, are still on a level only with the 
animal in the objects of his life. They accomplish the same object, only in a human and more complex way. The human way of sustenance, housing and clothing, is better in quality only. It has a better effect in prolonging life.

Man's advancement and civilization are almost literally carved out of matter, in mechanisms that serve his needs physically. There has arisen, from this characteristic, his mental habit of analyzing the psychical, as a mechanism, and treating nature and evolution, in the same way. He is not a spiritual being. Ideality and metaphysics, except as mechanisms, do not appeal to him.

Mind, the Aggregation of Feelings.-As many sensations received by the organism, do not reach the highest and largest ganglion of the nervous system. the encephalon, but are co-ordinated by the smaller ganglia, located in the various parts of the body, it follows that the popular idea that the brain is the sole seat of the mind, is erroneous. The cerebrum is, however, the seat of what is known as intellectuality.

Every obvious feature, of the organism, is some expression of the mentality, or character of the individual. And, therefore, to a certain degree, there is an adumbration of truth in the claims of the various advocates of special localizations, that the shape of the head, the physiognomy, the palm of the hand, the hand writing, the voice, the walk, all show character. But the interpretation lies in the combination of all external peculiarities of the body.

Phrenology assumed too strict a localization of mental function in the cerebral centers. Every psychical phenomenon is not only the result of the sensory excitation of its appropriate brain center, but is con- 
tributed to by other centers connected by cross associate conduction paths. If the appropriate sensory center becomes, more or less, abrogated from any cause, other centers, in time, vicariously assume, and perform its function through their cross paths.

The Objective And Subjective.-By bearing in mind, that the before mentioned definition of knowledge gives it two essential coexistent, or sequent parts, which might be called obverse and reverse side, or better still, scientifically, the objective and subjective; the absence of either of these essentials accounts for the unknown, while the two, acting normally, psychologically together, constitute the known. It is obvious that if the first essential is absent, namely, the objective, there ean be no knowledge. "Whatever it is possible to take interest in, whatever it is possible to describe, whatever it is possible in any way to apprehend, or think about, to remember, recognize, forget, consciously identify, anticipate, intend, or mean-such thing is a mental object." (James Mark Baldwin.) So the absence of the second element, which may be defined, as the co-ordinating process occurring in the encephalon, in its correspondence, between the internal nervous centers, and the external relation of things in the environment, (meaning by the evironment, all causes of sensation), would surely result in want of knowledge. The subjective is really the molecular motion of the structure in the brain that receives the sensations, and co-ordinates them into ideas. There is no way to examine it empirically, while the process is going on, and if that could be done, it is more than probable that all that could be discerned, would be physical motion of the molecules, resulting in more or less decomposition and releasing stored-up 
energy. Could observation of the molecular motion of the brain molecules be made, in such way as to show the forms and directions accompanying each psychical explosion, (mental phenomenon), the laws of the latter might be formulated therefrom, in the same manner that Kepler formulated his laws of planetary motion, from the molar motion of the planets. But it is plain that such observations are not practical. They are not practical for another reason. That is, that the images are so evanescent, and numerous, that man could hardly frame a law of their movements. Notwithstanding this fact, it is a mere arbitrary assumption to contend there is anything more in mentality than molecular motion, or metabolism. It is a motion which releases stored up energy, which is changed from a passive state to a psychical or dynamic force. For example, the want of this power of co-ordination in the brain of man, prior to the discoveries of Copernicus, kept men in ignorance of the true motions of the stellar bodies. The objective fact existed, but not the subjective correlative molecular motion of brain structure. The true image was not formed on the brain. Any knowledge is simply, and only a true image of the phenomenon. Therefore there could be no correspondence between the people, of the time before Copernicus, and stellar laws. The channels of this correspondence, in higher animals, are the five senses of sight, touch, hearing, tasting, and smelling. "Nothing is in our mind which has not been before in our senses" is an old and true saying.

Mind Making.-This correspondence of the exterior, with the internal nerve centers, is the process of mind-making in its simplest terms in the new-born infant. The infant, at birth, possesses the potential 
neural structure essential to this correspondence; but has no knowledge, until experience establishes certain relations of space, time, quantity, and quality, from which the present sensation can summon images of memory. By the fusion of the two images, a true one is obtained. That is knowledge.

These experiences are the rearrangement of the molecules of certain centers of the brain which produces the conception. This complex movement of structure constitutes the idea, and the latter passes away, when the pattern of moving molecules is transformed to other patterns. The recurrence of the same idea is the reformation of the same pattern on the tissue of the brain.

Of course, the process of the evolution of intellect, or abstract generalization in man, is extremely complex and involved. This comes only with years of experience, and the formation of new and higher reflex ares, in the brain. It is not the function of the brain to "store up" ideas or sensations. But a stimulation, often repeated, changes the more stable molecules of the nerve cells, to less stable ones, and thus increases the potential work, - the accumulation of what we call psychical processes. When this potential accumulation is released into actual work, the product is the more stable molecules, and the psychical phenomena are called, e. g., memory, or imagination, etc. Thus, there is always going on in the nerve structure, a change of the chemical composition of molecules resulting in either potential, or actual work. These physiological functions are the psychical phenomena of thought and feeling. Herbert Spencer says: "An idea is the psychical side of what, on its physical side, is an involved set of nervous plexuses. That which 
makes possible the idea, is the pre-existence of these plexuses, so organized that a wave of molecular motion, diffused through them, will produce its psychical correlative, the components of the conception, in due order and degree." So that, it follows, that the difference in ideas, expressed by different organisms, depends upon the organic structure of the nervous systems, and not upon a separate and distinct mental entity, that may be supposed to exist within the body of each. Mind is a condition, not a thing. "Psychical" means the effect produced in the motion of molecules of nerve tissue in the body, in response to some incidence of force from without, such as light, heat, sound, etc.

The sensations received through the sense organs from the objective, are the primary sources of all knowledge and mental development. But before there can be knowledge there must be hereditary structure in the organism, whose function is the co-ordination of these sensations, into what we call knowledge. The quality, and scope, of the knowledge depends upon the neural connections of the reflex arcs, or associative cross fibres over which the sensation may pass and their power thus to arouse dormant images into memory, reason, will, etc. The quality, and within limits, the quantity of the structure determines the limitations. It may with truth be said, that the real difference between the mind of Shakespeare, for example, and the lowest man, lies not in education, in the schools, but simply in the difference between the structure, and quality, of their nervous systems. Of course education in schools is of very great importance, in giving the growing organism experience of the highest value in the future interpretation of the problems, always 
presenting themselves for solution in life. It forms new molecular routes in the brain, and thus gives greater power. It throws out nervous short cuts to other sense centers, in proportion to the pertinence of the education received. But, unless the brain structure exists, or is thus formed, there can be no education; and the degree of its efficacy depends upon the quality, and power, of the structure, either inherited, or induced by education. In walking, every one has a stride peculiar to himself, and wears his shoes, at certain places on the soles, different from other walkers. What eauses these peculiar differences? It is the anatomy of the bones and muscles of the legs peculiar to each. On account of this anatomy, it is impossible for each to walk in any other manner. The physiology of the organism in every part depends, in the same way, upon the structure. The outer expressions, in the body movements, are all determined by the anatomical structure, so are the outer expressions of the nerve physiology determined by the ganglionic neural structure. They are predetermined, by the anatomy, and the personal differences, of individuals. Both the physical, and psychical expression have for their basis the variations in personal anatomy. The differences in the anatomy of the bones and muscles, and the consequent variations of their outer expression, are much more apparent to the senses, than are those of the nervous system. But the same law, of interaction of structure, and function, governs both; although the subtlety, and its location in the body beyond ordinary observation while life lasts, make it appear, to the indifferent observer, to be predetermined by a different law. In principle there is no difference between the equilibration of structure and function of both. 
Helen Keller.-Why Helen Keller has succeeded in knowing the relation of so many objective phenomena, through the sense of touch, almost alone, is that she was born with a finely organized nervous structure adapted to all five senses, which responded, by the associative brain centers, to sensations of touch. The auditory and optical centers existed in her brain the same as in the brains of those who have these peripheral sense organs. While these centers are not excited in the same way they would be by normal eyes and ears; yet they are not dormant by any means, in producing, by association, very much of the activity of her consciousness, - her correspondence with environment. Her visual brain center is excited, not by sight, but by touch, and thus she has a mental vision. It would have been very different had she been without the neural brain centers of sight and hearing. She is wanting only in the functioning of these peripheral sense organs, not in the brain centers of them. There is no doubt that her education consisted, in the ganglia of the touch centers of the brain, throwing out new fibres to the centers of sight, sound, taste and smell. As these enlarged in number and power, so her knowledge increased.

Educational institutions can only place the neural structures of the students in contact with a superior environment. In other words, education consists, or should consist, of repeated presentations to the sensory nerves of the most important objective truths, with which the nervous structure, by constant practice, can establish correspondence, and build up a method and memory. This is usually done by means of printed books, containing the best ideas, and by oral lectures conveying the most important objective truths. But 
the daily observations of natural phenomena in physies, psychology, biology, sociology, and ethies, by induction, are the main sources of desirable education. Each student brain responds to such environment, in proportion, to the brain's quality and intensity, and to the new channels possible to be opened, for molecular motion, to operate in the brain. A certain tonicity is thus given to after psychical processes, and those neural associative centers greatly increased and strengthened, which produce mentality. Memory consists of the readiness and power of the cross associative conduction paths, to recall; and the will, the power to apply, the images thus made, in all the psychical processes of after life. "Reasoning is a synthesis of images" by the following process: For example, the individual sees a funeral pass along the street. The image of it is instantly formed on the optical center of his brain, and there it evokes, by association, the memory of numerous other funerals he has seen, and what he has read, and learned, in the past, upon the subject of death. These like images fuse into a general image, viz., that all men will die, therefore he will die, which is an abstraction. Without the former experiences of the same, or similar impressions, he could not have thus concluded. A child gradually attains a knowledge of likenesses and differences,-all the relations that common objects bear to each other,--by the constant use of sight, touch, hearing, taste and smell. Upon the experience thus obtained his powers of mentality, in after life, are gradually developed, by their direct effect in improving the mobility of his brain in quantity and quality. The limit of these powers is fixed only by the physical complexity of his nervous structure,- those plexuses through which ideas are 
formed. Each idea arises out of former ideas, and gives birth to new oncs. The structure, and quality of the higher organism are the result of "Variation," brought about, in the same method, from the same causes, that produce other organic variations. The law of variation in the structure, as said before, of organisins, upon which natural selection operates to produce new species, is rather obscure. It is thought. that at certain periods, not definitely determined, especially for animal organisms, variation appears by a law of rhythm, in procreation. Sometimes, especially in low orders of vegetation, this law produces, at once, a new species. Yet the influence of environment, as well as inherency, is known to affect the offspring very de. cidedly. Max Meyer says that the ganglionic centers of the brain have the power to throw out new fibres and thus form new reflexes, and these are variations.

RACE Differences.- The variation in structure that enables one man to comprehend more numerous and obscure facts, and by virtue of former experiences, commonly called education, to draw more accurately the correct conclusions from them, than another man is capable of doing, is what is called the better mind. The ampler this responsiveness, the greater the knowledge. The known to him, is just what his nervous structure enables him to absorb from the outer realm, and co-ordinate into ideas. The domain of the knowable, is just in proportion to the development of this correspondence. Thus structure and function go hand in hand. They are simultaneous in development.

The colored children in schools are said to be quite as apt in the elementary studies as the white children, and in many cases, more readily absorb the teachings. But, when the higher branches are reached, the white 
children usually leave behind the colored ones. This is explainable, only on the theory of evolution, that function or use, and structure proceed simultaneously. The ancestry of the white child for innumerable generations have been surrounded by a civilization that necessarily resulted from a superior nervous system, and especially those higher qualities of the brain called intellect, and probably these reacted on the brain itself in improving its quality and structure. This difference in the brains of different races is a curious study. It is altogether probable it was caused by environment, in drawing out the power of the brain. For at one time, the races must have been practically alike in aptitude. But as they diverged, in geographical distribution, the influence of climate, soil, and consequent food and habits, began to work at once a difference in the anatomy and physiology as well as, of course, of the psychology. The white race spread over Europe and the black race over Africa. The physical differences of the two regions are so apparent as not to require notice here. The difference in climate alone would cause a great divergence in the races. When large numbers of the negro race were brought to America as slaves, their anatomy in time began to change, as they multiplied by heredity, although the southern states are not so very different in climate, from parts of Africa. After slavery was abolished these negroes began to improve. Now, here and there, are some of them who have shown ability equal to the average whites. In time, ( a long time), there is little doubt, but that they will develop, as a class, into a brain capacity equal, in natural aptitude, to the average whites. This will result, after many generations, from living in the same environment with the white 
race, and enjoying the same freedom and opportunity.

The superior form of the matter making up the organism of the white race, and inherited from generation to generation, must have come originally as a variation from such structure in his ancestors, by reason of the peculiar incidence of natural forces in his immediate environment, very likely by the superior sustentation, as Weissman believes, of the procreative cell. We infer, therefore, that the white race's superiority to the black race is the result of the natural selection of more numerous and important variations of neural structure, occurring in that race, brought about probably by a more highly complex form of sustentation and effort.

"The superior development of Aryans and Semites is perhaps attributable to the copious meat and milk diet of both races; more especially to the favorable influence of such food on the growth of children." (Engels.) This refers to the period of the lower stages of barbarism, in the evolution of these two races, when they began the taking of animals for domestic use. "Our conclusion is, that variation progressive, or regressive, and also mutation, in fact, any inherited modification of the race, is instituted by stimulus of the environment." (Montgomery). An environment remote as well as near. Though Darwin held that variations were the results of "inherent tendency," more than environment. But, it is likely that this "inherent tendency" originally arose from superior sustentation of those showing it.

"It is at least supposable that the Aryan and Semitic families owe their pre-eminent endowments to the great scale upon which, as far back as our knowledge extends, they have identified themselves with the main- 
tenance in numbers of the domestic animals. In fact, they incorporated them, flesh, milk and muscle into their plan of life. No other family of mankind have done this to a great extent, and the Aryans have done it to a greater extent than the Semitic." (Morgan in "Ancient Society.")

The term "inherent" must be interpreted, not as something given, but as an unknown cause. No evolution takes place independent of environment, for always there is at least an assimilation of matter from outside the structure. This is as true of the germ plasm of the germ cell, as of the cells going only to the formation of body tissue. This is the view of the Neo-Lamarckian school. There is no evidence of a "perfecting principle" in the germ cell, as claimed by Nagaeli-_"prophetically determining deseent with modifications ;" nor of a vital impetus.

There are no "inherent" tendencies in matter to assume consequent forms, or tropisms, or tendencies, unless they are natural. A response to a stimulus, of what is called an environment, or something beyond the body of the thing acted upon, is probably the principal cause. For example, there can be no change in the anatomy, or physiology, of an organism, unless it is a reaction to an external stimulus, such as the assimilation of food, and the reaction in an organism, is always different from stimulus in form. "Inherent" is frequently used to signify "unknown."

Therefore, variation is not produced by an inherent tendency; but probably by a change in the sustentation of the substance of the germ cell through the cytoplasm. The growth energy changes the matter absorbed, to something different, and sends it back to the evtoplasm. These environmental influences include 
the stimuli of the tissue cells upon the germ cells, the tissue cells having become specialized, in different parts of the body, and produce the peculiarities of the individual. These peculiarities react in some way upon the germ cells, and effect the subsequent chromosomes. The result is, that some acquired characters become hereditary. The question is, which ones? "All characters now congenital have been at some time acquired." (Cope, 1896.) "Inherited variation results from the interaction of external influences, and energies of the chromosomes." (Montgomery.) As said before, variations are said by De Vries to come periodically in the oftspring.

Function.-The energy retained in the matter, forming the organism, from the moment the germ cell is fertilized, and the cells begin to multiply, until its maturity, that is not dissipated in its growth, and development, forms the function of the subsequent organism. Psychical function is the continuing adaptation of the organism to relations in its environment. It is the individual's perception of phenomena, by the continuity of images perpetually produced. by the psychical patterns of the brain. As this adaptation enlarges, and becomes more complex, it is necessarily accomplished by an enlarged and more complex structure, of the matter of the organism. The two conditions are inseparable.

Considering the first formation of a nerve, in the course of biological evolution, as the beginning of a higher quality of mentality, than that existing without nerve structure, it was, of course; a variation favorable to the organism, in its struggle for existence. Natural selection would perpetuate this favorable variation; and progeny, inheriting the variation, would naturally 
be the ones to produce eventually another and still other variations of more complex nervous structure. The survival all the time of the best adapted, or the fittest, would end in a superior psychophysical unit.

Upon this theory, it becomes at once apparent, that the great variety of intelligence, or mentality, we see in animal nature, has been caused by the simultaneous variation of structure, and of the function thereof, in all the innumerable organisms of every line of descent, in the organic kingdom.

For example, two blades of grass, almost side by side, will often show a great difference in growth, because the rapid growing one happens to be in contact, at its roots, with a richer food, than its near neighbor, this richer food being a part of its environment; and immediately its function, to take in more and more sustentation, grows simultaneously with its parallel development of root and stem structure, until it overshadows its puny neighbor, whose structure remains adapted only to its function to take in the smaller, and less nutritious sustentation. This puny blade lacks the environment of richer food of its more fortunate neighbor. The former produces large and vigorous seeds, in correspondence with its larger function of sustentation; while the seed, of the weaker blade, will barely germinate at all, and perhaps dies out. But the difference between the successive generations of the two blades of grass, for all the time they may exist, is caused by the habits, or functions, begun by the two original blades, the difference of function producing the visible difference of structure. Weissman's theory of heredity includes just this principle of variation. He seems to think variation is the result of the larger difference in sustentation received by the biopher, pro- 
ducing the variation. In a forest there are a few magnificent, lordly trees to the acre. The original seedlings stood as many to the square yard. The difference is accounted for by the deadly struggle for existence. Those that have survived are the ones that had the better correspondence with the environment, and are the survival of the fittest. It is thus throughout the realm of nature.

So with the highest organism called man. His superior mentality has been evolved as part of, and simultaneously with, his superior physical organism. His nervous organization, composing the avenues by which molecular motion, producing that complicated and obscure aggregation called the mind, is made possible, is the material, or physical registration of all the previous structure, producing the habits, the peculiar line of action; in other words, the function, of all his ancestry back to the beginning of cell formation, from which originally his life began. This mentality gives him an immense advantage over other animals, in the struggle for existence.

When the variation, in nerve structure, occurred, which differentiated man's ancestral line from that of other animal forms, it probably occurred in the same way essentially that the variation did in the blade of grass above referred to. It was entirely material, and natural in its cause. Its eapacity for producing subsequent favorable variations, in the line of human evolution, was at that time established. Every successive organism, of this ancestry, inherited the essential structure, and function, of its predecessor. Occasionally one would show a variation favorable to its struggle for existence, which also became inherited; and the added function of this variation became, also, 
inheritable; and thus the present human organisms, on this globe, are simply the organized registration of the habits, and peculiarities, of all of their ancestry, back to the beginning of life. The process has undoubtedly been exceedingly slow.

Mentality Depends on Structure.-Nervous structures may be compared to an Eolian harp, which produces beautiful music, when the motion of the air strikes its chords. If the correct arrangement of the strings exists, the harmony is produced. The quality of music depends upon the structure. The higher the structure of the instrument, the higher the class of music. So the quality of thought, in man, is determined by the structure of the nervous system. If the structure adapted to respond to the higher and finer qualities of sensations, transforming these into percepts and concepts, is not there, there will be, either no response, or an abortive, or inharmonious psychical reaction. This high structure was in Shakespeare, and, in fact, in all the great thinkers; and was so responsive to the most acute and truthful sensations coming to it from the highest harmony of objective relationship in the environment, that the thoughts Shakespeare produced are among the most satisfying, that have been perpetuated in written language.

Why did Newton see the significance of the falling of the apple, while other men, with brains and nerves apparently like his, failed to make such an important discovery? It must be, because there was a small structure (a variation), of nerve matter in his brain, lacking in other heads, that responded to the sensation coming from the falling apple, through the optic nerve, upon the optic brain center, forming a series of successive images, impossible to the other brains. These 
were memory images, and innumerable past sensations of falling bodies, and of astronomical bodies revolving in apparent circles, and of Kepler's three laws, which were known to Newton. The fusing of these images, on the brain cortex, was the concept, or abstraction, of the great principle of the attraction of gravitation. This might, also, be the answer to Huxley's question, put to himself, upon reading for the first time Darwin's "Origin of Species," "Why could not I have drawn the same conclusions, from the same well known facts?' The point is, that all of Shakespeare's and Newton's contemporaries were in the same environment, but could not interpret it as these two did, because they lacked the brain structure.

If new fibres from the ganglia of reflex arcs, making more complex connection in the noetic device, can be formed by the exercise of mentality, then Newton, by his profound studies in mathematics, probably did this. In this nuanner, he may have greatly enlarged the power of his brain. However, it is best to remark here, that an inferior brain could not throw out these "short cuts" by any amount of mental exertion, which it is capable of making.

The Useful Is the Only KNowledge.-We do not need "noumenon" or "absolute truth," any more than we need an "absolute cause." Truth to us must be relative to our space, time and needs. In other words, as we are only relative beings, our knowledge, our truths, must be adapted to our conditions. Unconditioned, or absolute truth would not be applicable to conditioned individuals. It is only what has a bearing upon our dependence on a material environment, that ean be known, or be of use to us. Therefore the efforts to understand the absolute, or uncon- 
ditioned, is not only futile; it is wasted, because, if it could be successful, it would not be beneficial. All talk about "pure reason" and "practical reason," in which, by the former, man cannot prove the existence of a final cause, nor comprehend the unconditioned; and by the latter, that he must still believe in a final cause, notwithstanding his intellect is limited to time and space, or the conditioned, is an irrelevant conception, and an illogical philosophy. It is not "practical reason" to pursue the unattainable, but to confine ourselves to that which reason teaches us is attainable and practical. The understanding of our needs in the obvious relations we bear, to the real sources of our welfare, the physical and psychical universe, is what should be the aim of man. If truth is that which works to the benefit of man, and error that which works to his injury, or rather to the injury of the race, it is man's own brain that must determine what is truth, and what is error. Where else than his own brain, is he to form his judgments upon that matter? He must make the test,-his own welfare,-for there is no other visible power upon which he can rely in his every day practical problems. He must work them out himself.

Truth is the universe. There can be no absolute truth of a part separate from the whole universe. Everything is effected by every other thing, and therefore cannot be correctly interpreted apart. There is nothing existing that does not fit into the whole. and work with the whole. In this light only ean it be truth. The intellect of man cannot encompass the infinite universe, only a small part of it. Man's knowledge, therefore, is not of absolute truth, but relative only. He must be satisfied with this limitation of his knowledge. The term "self and not-self" is intended 
to represent the universe as one. Self, being the individual, is a part of the monistic universe, and the rest of it is that which is external to him; it is his environment. They must be interpreted together in order to arrive at the truth of either. The self without its correspondence with "not-self" would have no meaning, and the latter without the self, in relation, would be without meaning to the self.

The naturalist is necessarily a monist, a materialistic monist, because he believes in a material universe that was evolved, not created; and, of course, that universe is one and infinite. It is one, because every part is dependent on every other part, and could not exist without this relativity. The original nebula, from which the evolution of worlds began, was composed of homogeneous matter, and every sensuous form, now existing, is composed of the same atoms of matter. There is nothing palpable that is not an evolution from nebulous matter. So that, so ealled mind, or psychical phenomenon, is one with matter. Matter and motion are one, and that one, it is just as well, to call motion, as to call it matter. Everything can be reduced to energy, or force, and--every apparent phenomenona tree, or thought, or idea-may be called a form of energy. This energy, to man, is the ultimate, and his reason can go no further. Beyond is assumption, without the aid of reason. 


\section{CHAPTER VIII}

\section{SELF}

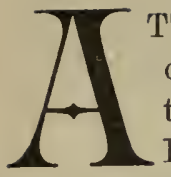

TTENTION is generally given to the thinking device of the human being, with the idea, that it is "the self," a changeless ego. Descartes founded his philosophy upon this idea. He said: "I attentively examined what I was, and I observed that I could suppose. that I had no body, and there was no world, nor any place in which I might be, but that I could not therefore suppose that I was not; I thence concluded that I was a substance whose sole essence, or nature, consists only in thinking, and which, that it may exist, has no need of place, nor is dependent on any material thing; so that ' $\mathrm{I}$,' that is to say, the mind, by which I am what I am, is wholly distinct from the body, and is more easily known than the latter, and is such that although the latter were not, it would still continue to be all that it is." This means that the process of co-ordination of sensations, in the encephalon, into ideas, i. e., the process of thinking, is an entity, the only abiding thing in the individual, or body. It means what later phychologists call "consciousness," or "pure experience," in which the only real thing is the object, is something entirely different from the rest of nature.

Bergson calls this "a flux of fleeting shades, merging into each other." "An ego which does not change, does not endure." All reality is a constant change. It is apparent, from the argument of the preceding pages, that this is only a passing phenomenon, that accompanies matter, when that matter is in the form of living tissue. 
$\mathrm{He}$, who is not able to conceive the thinking without a body, or that any part of the organism could exist without a material abiding place, such as the earth, will most likely adopt the theory of evolution; and as a starting point for the pursuit of truth, will begin with the nebula. As far as he can reason, from the present natural phenomena apparent to his senses, he can infer that the present state of physics and psychies has evolved from that primitive condition of all matter and motion. This method of philosophy includes the " $I$ " of Descartes, as a passing condition, and one of the phenomena of that development. This phenomenon is the product of a conserved energy, in the form of indestructible matter. Therefore its elements are infinite and perpetual. When its present evanescent form is changed, these elements will assume another form, equally short lived.

No Thought Withoút Brain and Environment.The philosophy of this age teaches, that this process of perpetual change will continue through infinity. But Descartes assumed that the form itself is what abides, without even stating of what it is composed. He did not treat the thinking process as a fleeting condition, but as an entity infinite in duration. Had he studied the close connection between brain and thought he would have seen that thought was produced by material objective things in the cnvironment, acting upon a material objective thing-the brain, and thus would have arrived at the conclusion that thinking could not take place without a material world. "Thinking is a physical process, and it cannot exist, or produce anything without materials, any more than any other process of labor. My thought requires some material which can be thought of. This material is furnished 
by the phenomena of nature and life." (Joseph Dietzgen.)

To common sense, there exist two things-self and not-self. The scientist knows they are one, but, in practical every day activities, they must be treated as two. Of course, the unscientific do not always see the "not-self", correctly. Otherwise mankind would not be deluded, or illuded. But suppose one should discard the use of his senses, and depend entirely upon what the idealist calls intuition, under the old definition, knowing without experience, would he be any the less deluded? He undoubtedly would be wrong in his facts, most, if not, all the time. In that case. the world would still be inhabited by ghosts, and the light of the sun, and stars, and the blue of the sky, would still he shut out by innumerable forms of angels and hobgoblins.

"The notion that truth external to the mind may be known by intuition, or consciousness, independently of observation, and experience, is, I am persuaded, in these times, the great intellectual support to false doctrines, and institutions. By the aid of this theory, every inveterate belief, and every intense feeling, of which the origin is not remembered, is enabled to dispense with the obligation of justifying itself by reason." (John Stuart Mill.)

The intuitive theory adopted, for its main support, the evidence of Mathematics, and the cognate branches of physical science. But Mill's "System of Logic" attacked this support, and sought to show that these sciences are, also, inductive. They are strictly material. "Our ideas and concepts, and scientific theories pass for true only so far as they harmoniously lead back to the world of sense." (William James.) So that 
pragmatism is in accordance with the theory of this book, that is, it is materialistic to that extent.

Sir J. J. T'hompson says: "Water vapor will refuse to condense into rain, unless there are particles of dust to form nuclei; so an idea before taking shape seems to require a nucleus of solid fact round which it can condense." He was speaking of the origin of some of the most comprehensive ideas of science. This is illustrative of the difference between the mental tendencies of himself, and Henri Bergson. It is the difference between intellect, and what the latter defines as intuition. Intellect seizes hold of matter, only after its evolution into certain forms, as the reservoir of facts important to the welfare, and knowledge of man. The forms of matter; - the stable forms we are in the habit of calling them, although they are in reality the entirely unstable; are always becoming, they are in the making, but never made. But intuition, which transcends experience, or is just beyond that consciousness which represents past and present experience, just as the $\mathrm{X}$-rays of light are beyond the sight of the natural eye; this is represented by the author of the new "Creative Evolution" as that which penetrates beyond the degraded static forms, to the flow of becoming. and plucks from it such facts as "duration," "vital impetus," and the "universal consciousness." Who can object? If any scientist is possessed of such intuition, which is an extension of intellect, or has grown out of it, or out of the experience of the human senses, or has obtained it in any real way, and with it, can give us knowledge of noumenon, or thing-in-itself, or the flux of the universal becoming, now beyond the reach of intellect, and of use to life forms, in their noetic limitations, he is a person entitled to the highest honor. Heretofore, 
the evolutionist, and the natural philosopher, have seized upon the motions of matter in its apparent changes, from the exterior, of course, because the intellect could not penetrate to the center, and work as life does, towards the circumference. It was compelled to reverse the evident method of nature, entirely, on account of the limitations of the intellect. Now if Bergson, can, with intuition, give the world a better system of philosophy than, so far, the scientists of the Darwinian school have given, who can object? He has given an intimation only of such in "Creative Evolution," but nothing like a philosophical system. It seems that it may be far beyond mechanism, and short of finality, in that a personal creator, and controller is not expected to be reached.

Bergson says that intuition is an enlarged instinct. Of course instinct is an inherited single choice of doing things, and is usually defined as a special innate propensity, which transcends the experience of the organism. This is also what intuition is. But intuition is usually attributed to human beings, and instinct to animals, as well as to the human being. If the intuition which Bergson calls an enlarged instinct, and which he also thinks grows out of intellect, shall be able to solve the enigma of origin, and vital impetus, he will have to revise his definitions, one or both. Intellect comes by experience, and if intuition grows out of that, how can it be an enlarged instinct, which he claims does not grow out of experience. He says instinct and intellect are different in kind. There is a paradox in his views upon these qualities of the brain.

The Ego.-Man is a product of evolution and a differentiated form of natural phenomena. Therefore it is best to view him in his bodily form, and consider 
the Ego to be the whole individual human organism.

It is a psychophysical organism. The psychical and the physical are inseparable, and part of the universal interaction of matter and motion. They are undoubtedly only differentiations of the same basic unit of cosmic energy. The Ego, as thus defined, has in nearly all the past been considered only as an entity, whose psychical and physical motions are not dependent on any connections they might have, with the rest of the universe. But, to the penetrating eye of science, it is a heterogeneous organism, whose specialized organs are co-ordinated parts of the general mass of matter, and whose functions are determined by their connection with the persistence of force. It is similar to a wheel, in complex machinery, whose revolving motion depends on the connection of its cogs with those of other wheels. What we call human life then, seems to be a correspondence between an Ego, or human body, and an environment with which, in order to maintain its continuance, it is necessary to remain in touch. Deatl is a discontinuance of this correspondence.

Thinking is a passing condition, depending upon its physical connection with the body. No one has perceived it except in that connection. This theory is diametrically opposite to that of Descartes'. When Descartes turned his attention to the introspection of himself, in order to determine the nature of the thinking process, he was a mature man. The function of his brain had acquired, by the experience of all the years, in which he had lived, a certain development by education and long use. The meditations, of which he gives an account, were the result of the maturity of his psychic function, and at that time, he was thinking upon the results, or effects, of years of training. This 
gave him the impression that the thinking process was to him so automatic, that it appeared to him, that it would proceed even without a body, and without an abiding place. At the same time he claimed that he had purged his brain of all previous impressions, or prejudices. We know that he was a believer in the current theology. One cannot help thinking, notwithstanding, he undoubtedly made every effort to forget, for the time being, these theological beliefs, yet how squarely his meditations supported on all sides these beliefs? But everyone knows how impossible it is to get away, simply by one's effort to forget, from the teachings of a lifetime, and the impressions made upon the young mind, by teachers. It can be done by a long line of study, in the natural sciences, the facts of which replace in the mind the former impressions. But Descartes had not proceeded in that way, nor did he desire to get away from theological ideas. To arrive at the idea of the true ego, he did not enter upon a scientific analysis of the connection of thought with the function of the brain. He made no genetic comparison of the growth of thought from birth to death, at maturity. He had already concluded that animals did not think, and, therefore he did not consider a comparative physiology, or psychology. Had he studied the infant "mind" empirically, he would have discovered that its thinking was very small compared with that of the mature "mind," and that as it grew toward maturity its jower to think increased only with the growth of its body, and brain. The use of the thinking process, stimulated every moment by outside influences, such as the matured actions and speech of its parents, teachers and playmates, shows that in infancy the chance of independent thinking without a body 
or abiding place may have been a very negligible possibility. He would have discovered that the infant, just born, had a brain, with all the cells and machinery for thinking, just as the matured organism has, but that it evidently did not think until it lived long enough to have a past, in which memory was weakly established by the experience of its five senses; and that, as this experience grows, with the years of its existence, the power of thinking is determined by the brain structure, and not by a thinking entity independent of such structure. Then, had he studied the thinking process in the last days of a man's life, when his power of thinking was waning, in his second childhood, he would have found that the process of psychical development, in the infant, is exactly reversed; it declines, as the time passes, just as the infant's increases; that those high modes of thought which come comparatively late in life. are the first to cease in the decline of life: and those instincts, apparent in the infant, survive to the last moment. Now, with these facts of the infant's and the aged mind before him, how could he conclude that the infant ego could think without a body, when it could not think with one? And if the body of the senile octogenarian ceases to live after a large part of his thinking process has departed, will his ego go on thinking in the incoherent manner it does at the time of his deatl, or will the process it has lost come back to it after death? If it come back, where does it abide in the meantime? Could Descartes' investigations into this process of thinking follow beyond the phenomenon of death, and could he see, with the huinan senses, the process of thinking still proceeding without a body, or a brain, there would be some evidence that such a process does not require those 
pliysical supports. But unfortunately for Descartes' theory, his human sense did not penetrate beyond death. He could only see the lifeless body which had lost the process of thinking, while the process itself, and its effects were no longer visible. How could he then "suppose that I had no body, and that there was no world, nor any place, in which I might be, but that I could not suppose that I was not?' By mere introspection, the mature brain cannot view consciously the thinking process. One is conscious of the effects of such a process, viz., the ideas and judgments. He is conscious of the impressions made upon his sense organs by objectivity, and of the final effects produced, in the brain, by these impressions, or sensations. But whether this conversion of sensation into ideas is done by a spiritual entity permeating and working the brain tissue, or simply by the physiology of the brain in molecular metabolism, must be determined by each one for himself according, as the evidence impresses his brain. But it cannot be determined by direct observation, viz.: introspection. Both sides, the idealist and the materialist, agree that accompanying every psychical phenomenon, such as thought, there is a certain molecular movement in the brain, or a chemical flux inaugurated by what is called an excitation of the sensory ends of the nerve fibres, which passes to the motor fibres, by a connection called a ganglion. The constant movement, in more than three billions of nerves throughout the body, gives it all its functions, and maintains life, thought, reason, and all the psychic phenomena.

Thinking Not a Measurable Thing.-But the contention of those who do not believe that this movement produces thought, viz: the parallelists, is that 
the molecular motion cannot be measured, as thought, the same as reflex action in muscular motion; that therefore the thinking process is a power independent of this "physical pulsation." So both sides are agreed upon the facts of molecular motion followed by the thought. One contends that the molecular motion, or movement, is the thought, and the other that the latter is really produced by a power that produces the thought through such movement, but is independent of physiological control. There is no proof of such independence, except the negative one, that the conversion of molecular motion, into thought cannot be measured in the way, that the conversion of motion into heat, or into mechanical power, can be measured. But this is not proof, except of the fact that no means have yet been devised to measure so delicate a thing, or more properly a condition, as thought.

The Relationship of the Ego.-Having thus concluded that each human being is a Phenomenal Ego, who has, in some degree, a different environment from every other, it will be interesting, and perhaps profitable, to endeavor to reason out the nature of this peculiar relationship, as a phenomenon. "The first decisive step, in the analysis of the complex web of phenomena, is the polarization of the data of experience, into their objective, and subjective aspects." (C. Lloyd Morgan.) That is, nothwithstanding the monism of phenomena, the unity of all phases of psychical activity, yet in order to study its nature, we must analyze its components, or at first divide it into two parts. The subjective aspect is the Ego's end of phenomena. It is the morphology of the energy, that the laws of nature aggregate in the individual organism. Dr. Paul Carus says: "Every mind is the concentrated effect of the 
whole cosmos upon one special part of the cosmos, not as it takes place in one moment, but as it has taken place in a definite and continuous period up to date." For the convenience of study, it is divided into two parts, one physical, by which the life of the organism is maintained, the other psychical, by which what is called "consciousness" is produced. In reality. they are both one.

The body is a differentiated part of the whole phenomena, and the most complex of organisms. The physical phenomena are sustentation, by which development and growth are produced, excretion. and procreation. Sustentation is only the building up of the tissues of the body, from the appropriate matter of the environment, the process,-metabolism,-being the chemical and mechanical motion; the aggregate process, being the integration of matter, and the dissipation during the process of integration, of a large part of the motion. The appropriate matter having become specialized into the structure of the different organs, the function of these organs is that part of the former motion, or energy, connected with the matter of the body, prior to integration, which is not dissipated in the process of its evolution.

Integration always occurs during a change, from a diffused to a less diffused condition of matter. Matter, in a greatly diffused condition, is always in much greater motion, that is. contains a greater mobility, than when it is solid. The lessening of this mobility, into a condition of comparative stability, means the loss of motion, and this motion is said to come back, when a change is made from a solid to a fluid. or to a gas. Hence integration means a loss of motion from the substance integrated. The reverse process is the 
dissipation of matter and the integration of motion. This occurs when a solid is converted into a gas. The organic body, dead, is in process of change, from the form of a solid, to that of a gas. Hence we call death a change of form. In this change nothing is lost. When the change is complete the weight of the resulting gases and residuum is the same as that of the body in the solid form.

The Psychical Phenomena.-The psychical phenomena occur through a peculiar or differentiated, structure of the physical,- the nervous system; and the resulting consciousness, or knowledge, or a wareness, or immediate experience, seems to be a condition, whose real nature psychologists are now studying, and about which, there is some difference of opinion.

The nervous system arises, like the other organs, through a division of labor, and takes upon itself, not a different function, in kind, but an increased degree of the functions of the tissues of the body.

The process of the physical is termed physiological, and the psychical, psychological. But this distinction is only one of ideal classification, for the purpose of study, and may not have any real basis in the natural phenomena themselves. For the material structure of the Ego includes, not only the bones, muscles, and vital organs; but also the nervous structure as well, through, or by means of which, all the psychical phenomena occur. This nervous structure is only differentiated protoplasm, of which the whole body is formed. Therefore psychology is frequently termed a branch of physiology. Jacques Loeb, in his "Physiology of the Brain," contends that, in function, there is no difference between muscular, and nervous structure, except in facility of the movement of its component molecules. 
It seems, the further experiment is carried, the greater the evidence for unity, in both function and structure. The five peripheral senses of the body may perhaps, in ultimate analysis, be reduced to one, the primal, from which all the others have been evolved. That is touch. The eye, and the ear, are morphologically identical with the vibrissae, or most perfect organs of touch.

Every observing individual is aware of the extreme sensitiveness of touch, in all parts of the body. Even on the soles of the feet, which are quite thick, a particle of sand, scarcely perceptible to the eye, will be instantly felt by the brain. The touch at the end of the fingers, and at the end of the tongue, is much keener, and that of the eye is aroused by the faintest ray of light. Even the quality of a substance is disclosed by touching it with a stick held in the hand. The impressions are carried, through the inorganic matter of the cane, to the sensitive skin of the hand.

An individual deprived of all senses except touch, in course of time, by repeated experiment, becomes in correspondence with an environment, not greatly inferior to that of all the senses. This has been explained some pages back, as the result of the brain centers of the same organs, being so intimately connected by wonderful complexes of nerve fibres. If the claim of Max Meyer is true, that the ganglia have the power of throwing out new threads of nerve tissue, under strong excitation, the example of the wonderful development of mind in Helen Keller by education through touch alone, is thus accounted for. Touch can well be called consciousness. It is the sense that is not specialized. If the other four senses can be called mere modifications of touch, then the latter may be designated as the method of the organism's correspondence with environ- 
ment, and that is consciousness. It is not so very surprising then that Helen Keller, born with normal sense organs, and therefore having a complete human brain, and long after birth losing the use of the sense organs of sight and hearing, should acquire, through touch alone, such a marvelous knowledge of objectivity. A knowledge of everything she was enabled to handle is possible to her. Touch is the sensibility to pressure, weight, muscular resistance, the sense of feeling, including the sensibility to temperature. The sense of sight is educated to the vicarious perception of form, and perhaps all the qualities of matter, except color, by the sense of touch. The marvelous arrangements throughout the human body for making the sense of touch so extremely acute, show how important natural experience, and natural selection have considered the evolution of this all pervasive sense is, to the welfare of the human organism. Not only is this so in the specialization of the sense of touch into the four other sense organs-sight, hearing, smelling and tasting-but in evolving in certain papillae of the skin small tactile corpuscles $1 / 300$ of an inch long and 1/800 of an inch thick composed of connective tissue, and supplied with one or more nerve fibres, which are branched and convoluted within the corpuscle. Remembering that, every point of the periphery of the body, and every point of the inside of the body, is the location of the arborescent receptive end of a nerve, which runs to some ganglionic center, which is also connected with the brain, we can see how completely the sense of touch is the correspondence of the individual with objectivity, and therefore is consciousness.

What Is Consciousness. - It is said above, the psychologists differ in regard to the nature of "conscious- 
ness." James says that consciousness, as a metaphysical thing, does not exist. Calkins says, "it is a self, conscious of itself." This is saying it is a metaphysical thing. Others say, it is a relation of objects. It seems certain that in the correspondence between the organism and its environment, or between the brain centers and the object, the only thing presented to the brain is the object. This is done by an image. The subject is not in the consciousness, to the perceiver of an external object, that is, while the attention is directed to an object outside the psychical device. Whether that object is a tree, or an idea, or a problem, or the effects of the thinking process, the fact, as it is represented to the brain, is the only conscious thing. It may be an hallucination, and not true; the brain "sees" it however as a true object. The brain may see it as an hallucination a moment after. But the hallucination, followed by its being perceived, as such, are both real to consciousness, the one is just as true an object as the other. Hallucinations are images, as if they were true.

Other definitions of consciousness are: "Consciousness is that, by which an object perceived, differs in that regard, from an object not perceived."

"Consciousness is the virtual, or potential presence of an object at a place, or time, in which it is not actually present." The same object can be perceived by several persons at the same time, or sereral objects can be perceived at one time, by the same person. But it seems, that when the energy which carries the object to the perception, produces the consciousness, a certain time has passed, and the object as perceived, is not in the same place, nor time, as it actually is. So that it is better to state, that consciousness is a perception, by the brain, through the senses, of an object entirely made 
up of phenomenal attributes once existing, which, to the perceiver. is reality. Whether we see a real object or not, what we do see suffices for actions and needs. It provides the only basis for our reason, judgment, memory, and life. This kind of correspondence with environment, which Spencer calls "transformed reality," has served so far to bring mankind, and, in fact all life, to its present state of evolution and knowledge. We do not seem to need any other. If we did, the necessary evolution of it, would come about.

The phenomenon of an error, or hallucination, so universal, is a serious problem to realists. But it seems that the theory of the materialist, that the matter of the brain is the producer of thought, and all psychical phenomena, and that its normal working produces the truth for that brain, and its abnormal working produces error, or hallucination-such as dreams, mistaken identity, or that its limitations prevent it from reaching the whole truth, is the theory, that will best conciliate the conflicting contentions of naive realists, dualistic realists, and subjectivists. In other words, what we do perceive is real to us, until a better working of the brain activities, reveals its unreality. The science of epistemology will always be only in the making. Perfection will not come. The very nature, of the apparatus and method, precludes the absolute truths about it, from being perceived by the present brain power of man.

"One is never conscious at all without an awareness, however vague, confused, unanalyzed and unexpressed of one's self,--being conscious." (Calkins.) She follows this with a parenthetic statement, that this is her conclusion from introspection. This could be discovered only by introspection. The attention must be directed to the process of thought, in introspection. This is 
making it an object, and thus whatever comes into consciousness, in doing this, exists. Now what is it one perceives thus? It is only the body, and its functions. This does not occur, when the attention is directed to another object-e. g. admiring a beautiful landscape. Then the only image on the brain is the object-landscape. There is no possibility while the landscape is the consciousness, that "oneself-being--conscious" can be any part of the object. But if, for a moment, the attention is diverted from the landscape to the fact of the connection of the individual; or body, with the consciousness of the landscape, then, for that moment, consciousness of the landscape ceases and another object viz. : the connexion spoken of above takes its place. The two objects may alternate, but do not exist simultaneously. When the attention is directed to the introspection, with the object of perceiving the "one's self-being-conscious" what does he perceive? Not the process going on in the brain, but the external form of the body only, and that this is connected in some way with the object that was just a moment before imaged on the brain. There is nothing else, that one can perceive, except what is already known as psychology viz.: the relation of the physiology of organism with certain relations in the environment between objects; and this is consciousness. The process of consciousness is never an object, and therefore cannot be perceived. If the body is the self, we are, of course, conscious of it, when the senses are directed to it, but what does not come through the senses, and that is the process of thought, is never a part of consciousness. A self is conscious of itself only to this extent. If a self is anything else than the body, and its functions, of what is it composed and is it palpable? 
"We have no direct acquaintance with consciousness. We are aware only of contents apprehended, never of the process to which this apprehension is due. We may, of course, be aware of the steps which are taken in order to place ourselves in a proper position, or mental attitude, for experiencing a content, but of the actual consciousness of the content we have no awareness. We have experience of pleasure, pain, desire, striving and the like. These, however, would seem to be, in all cases, experiences of what we are aware, but not to be,themselves describable as awareness." (Norman Kemp Smith.) This word content does not seem to express the fact of consciousness. The latter is a condition and not a thing, or receptacle. It is not a cup which may be filled with a tangible substance. The object is not in the mind, but the act of thinking of the object is.

"It would be as absurd to refuse consciousness to an animal because it has not brain, as to declare it incapable of nourishing itself because it' has no stomach. * * * This amounts to saying that the humblest organism is conscious in proportion to its power to move freely." (Bergson.)

But in another place Bergson says that the animal instinct by being confined to the use of the organic tools grown with its body has but one choice in its action upon matter, while intelligence, (intellect) has several choices, and that the difference between consciousness, or mind of the human being, and the animal, which cannot make fire and tools, is one of kind, not degree. He acknowledges the truth of evolution, which must mean that at one time the ancestors of man had instinct only. At what point in his evolution did the new kind of consciousness come to man? When he began to have more than one choice in his method of 
action? But this new choice came with enlarged development of the same nervous matter which he possessed when he had but one choice. It was a growth, in larger degree, of the same controlling cerebrum which he has always possessed. If it is a difference in kind, where did it come from? In such cases it would not be an evolution, but a special creation. If the latter, out of what was it created? Is Bergson not putting the label "New Kind" upon the enlargement, by variation, of the same old neural canalization of protoplasmic response to objective stimulation? In evolution, every organism is different from all others, in degree only, not in kind. One is made of the same protoplasm and simple elements, that all others are.

Nerve molecular motion produces a relation between objects. This relation is consciousness. It is a condition produced by cerebral activity. If consciousness is anything more, than the arrangement, or metabolism of the living molecules in the brain, what becomes of it, when it is temporarily lost, for instance, by a blow on the head, and when by a surgical operation it returns? Holmes reasons thus: "A man is stunned by a blow, and becomes unconscious, another gets a harder blow, and it kills him. Does he (the latter) become unconscious too? If so when, and how does he come to his consciousness? The man who has had a slight and moderate blow, comes to himself when the immediate shock passes off, and the organs begin to work again, or when a bit of skull is pried up, if that happens to be broken. Suppose the blow is hard enough to spoil the brain, and stop the play of the organs, what happens then?" (Richard A. Proctor.) Which is the more reasonable supposition, that the entity, that does the thinking, "goes off" and awaits the trepanning in the 
one case, and "goes off" and never returns in the case of no returning consciousness; or that consciousness is the physical process of molecular motion in the brain tissue? It ceases, as long as the motion of molecules ceases, and is "restored" when such motion is resumed. But if the molecular motion never resumes, then there is no restoration of consciousness. "Dual consciousness," "bodily illness," as mental stimulant, "somnambulism," "'hypnotism," "dreams," all subjects of abnormal psychology, can be scientifically explained by knowing the exact facts of each ease, on the theory that psychic phenomena are the products of physiological function -that consciousness is the result of molecular nerve action. On any other theory, they are inexplainable. The things we see do not exist in consciousness. They exist only where we perceive them to be. The experience, or image is in the brain, but the reality producing the impression is not.

Descartes' expression "I think therefore I am" is therefore a description of a process of imaging objective things, by molecular motion, and the fusing of images, by a change of molecular patterns, on the brain. It is. a passing phase of function of matter. Those immediate experiences that the individual cannot share with others, such as the voices heard by Joan of Arc, or the dreams one has, may be called subjective conditions, because if they were objective, others would also experience them. But these are mostly abnormal. "Immediate experience" is a condition in which the only conscious thing is that which is objective to consciousness. It is the constant awareness from moment to moment. The working of the device which is producing consciousness is not in the immediate experience of the thinker, but only something outside of it. 
Whatever is thought about, from moment to moment, is an object, even if it be introspection. In every experience, such for example, as listening to a song, there is just one element present to the listener, and that is the song, not the subjective listener, as defined by Descartes. When a fact, or physical thing is perceived, consciousness consists only of the thing. But if the attention should be turned from the fact, or thing, to the subjective process, then the latter would become immediaely objective. The whole process is part of the natural order of the universe, the same as other phenomena.

The meaning of pragmatism is, that every phenomenon should be interpreted, by the human brain, as to its bearing upon the welfare of man. The truth is that which works satisfactorily. This must be done by the methods of science, not by dogmatism. If metaphysics is appealed to, it must use the same intellectual method as logic and mathematics, or the inductive process.

The physiology and the anatomy of the body are perceptible to sight, hearing, taste, touch and smell. Touch is most largely the sense of self feeling. Pleasure is the harmonious touch of all function. Touch is not confined to the ends of our fingers, but is an all-pervasive sense, located in some degree in every surface both inside and outside; and pain. which is the alarm from the outposts of the neural fortress, that an attack of a destructive kind is being made, accentuates the great importance of the sense of touch to the organism. We are self conscious to the extent only, that self, or the Ego, is objective to the receptive nerves and ganglia. Whatever parts of the body, or their functions, make impressions on the senses, are objective. Almost every function of the body is part of consciousness, if 
not in its physiology, at least, in the effects of physiology. The simple emotions, as well as thoughts, such as fear, hatred, affection, self-feeling, and sexual emotions, are manifested by physiological marks on the organs that display the phenomena. The physical changes constitute emotion.

Self-Consciousness,-We are self-conscious to the extent only that we can study with our sense organs the vital functions of our bodies. Could the brain form a conception of the real nature of the relation between the subjective and objective, there would be added to consciousness the most valuable knowledge it could obtain. To know just how the different forms of energy, throughout our environment act upon the great central plexus of nerves, called the encephalon, in the way they do, so as to produce, what we call consciousness, would give the added power to know the reality itself. At present we have a faint vision only, of the apparatus, by which the wonderful phenomenon is accomplished, but cannot penetrate, with our vision, the abtruse process, except in a very vague and indirect method of the anatomist and physiologist, principally after death. The psychologist makes a working hypothesis also, which is serving only in a way to arouse the highest forms of intellectual effort. Now, some mental philosophers are reaching out to find a workable method, beyond intellect, that is, by intuition and metaphysics. These latter they are compelled to treat after the principle of all evolution, that is, that whatever is invoked, it must be something in touch with, and having the same qualities, in a higher degree, of the existing intellect of man. It cannot be a creation of a power, by human effort of a different and dissociated kind, independent of the natural evolution of the psychical device. 
The Process Natural.-The question is how the excitation of the receptive nerve, by an incident force, proceeding from objects in the environment produces in us a state of consciousness, and the particular forms of psychical phenomena, called conception, reason, memory and will. We can only recognize the physiological marks accompanying these phenomena. The manifestations are objective. When the images of externality are formed on the cortex of the brain, it is done by a natural process of molecular motion, and results in consciousness. It is also a passing condition _.'immediate experience." The difference between the perception of one person, and another, of the same object, as well as, the perception of an imaginary thing, not seen by another, can be called subjective. It is this excitation of the nerve tissue of the brain by the incident forces of objectivity, and the process of the fusion of the images thus formed, that is the thinking process. "A mind and its experiences are realities that are presentable to sense, as the brain, and its actions. In that respect the mind and experiences are not parallel with Nature, but a part of it. And on the other hand the facts of nature including the brain, whenever they are phenomena, are not parallel with mental phenomena, but a part of them." (W. Mitchell.)

Now, coming back to the physical marks accompanying the act of thinking, they are very clear to the perception.

"As a man thinketh in his heart, so is he." His thoughts are indicated by outward acts, in the motion of the muscles, e. g., in speech, or in written language. If not in either of these ways, then the intensity of them can be determined by the following marks; expansion of the arteries leading to the brain, and the 
consequent increase of the circulation to the brain. These accelerate the action of the heart, which modifies the whole vascular system; or by the fixedness of the muscles, controlling the eyes, or other organs of sense.

Brain Activity Exhausting.-What we call mental action is more exhausting of the metabolic process of the physical, or digestive system, than any other labor of the body. The more intense the thinking the more rapid is the flow of blood to the brain. Muscular tissue is heavily stocked with a large reserve of glycogen, which is potential energy, while the nerve tissue, is only served with this reserve from the muscular tissue, as it is wanted. It would thus appear that the rest of the organism is there for the purpose of furnishing the nervous system with the energy required for the mental operations, and the control over this energy is given to the nervous system. The body tissues will exhaust themselves, in order to keep the brain at work, as is frequently apparent in persons of weak body and active mind, all the sustentation goes where it is summoned by the nervous system, to the brain, at the expense of mere muscular energy. It is thus that disease is sometimes a stimulation of the brain. Some wonderful mental work has been done by brains, whose poor weak bodies have been kept exhausted, in supporting in vigor, a healthy brain. In starvation, the body tissues will exhaust themselves in supporting the brain, the latter remaining healthy, until the vital organs of digestion cease to operate. However, when death comes, the mental action ceases first, but only on account of the exhaustion previously, of the flow of the arterial blood, charged with vital energy, to the brain.

Cuvier said: "The nervous system is, at the bottom, the whole animal; the other systems are there only to serve it." 
Language of the Emotions.-All the emotions can be expressed without articulate speech. Laughter is the expression of joy, weeping of grief, smiling of pleasure, bodily attitude of anger or fear. These emotions are, more or less, expressed by the muscles of the face.

In fact, in a broad sense, the signs of life are the marks of thought. When the human senses become acute enough, they will perceive every thought in another, by its physiological marks. "It is right then to say that what we do depends upon what we are; but it is necessary to add, that we are, to a certain extent, what we do, and that we are creating ourselves continually." (Bergson.)

Should these physiological manifestations be prevented, in any way, as by pathological conditions, then there would be no thought; and, that interference with them, in any degree, would in the same degree lessen the coherency, and perspicuity of the thinking. If all the data of consciousness could be enumerated from the center of attention at any moment to the thousand things in the margin, or subattentive aurora of it, it would be found, that all are objective, and come through the senses. The consciousness of one, deprived of every sense except touch, would be found to be made up of sensations coming from the environment, that act only on that sense. Should that also be taken away there would be no consciousness, and perhaps no life. The word function explains all psychical phenomena.

Basis of Thought.- It will be found, also, that the basis of thought is physical necessity, or self, or race preservation. Why does the twining vine grow its first two joints rigid, and the third so mobile that it will vibrate in a circle, seeking an object round which it can twine? Or, why does the rhizopod contract, and 
appropriate the soluble nutritious particles, coming in contact with its surface, but rejects the insoluble, and inorganic, unless it is, that both phenomena, in all essential elements, are expressive of the same choice, in less degree only, as man makes, in his reasoning out a civil and moral code; which man considers essential to his physical welfare; the same essentially that similar acts by man, although more complex, constitute, what is variously expressed by the words, thought, reason, memory, will? This basis, or stimulus to all thought, is the necessity of the natural preservation of the organism, or of the race, to which it belongs.

Whatever an organism does, has at the bottom this basic motive. Even the social instincts of human beings, bees and ants, have this for a motive.

There are certain functions, of the higher brain, producing abstractions, and generalizations, whose connection with self, or race preservation, is difficult to trace. But there is a connection. Whoever is unselfishly pursuing truth in the abstract, is doing it by the compulsion, or tendency, of his organism. Truth is essential to his organized brain structure, or his nerve structure is in necessary correspondence with a higher environment, in which truth is the essential thing. He is doing it, also, for the benefit of the physical welfare of the race. All research, in whatever domain, is at bottom, the finding of better method of human effort. To the devotee of esthetics, the beautiful is a condition of natural existence, or at least of social existence to him. To him harmony, in sound and color, is necessary to the preservation of his organism. Whatever a man does, seems in the last analysis, to have, at bottom, the motive of preservation of either self, or the race. The principal is very apparent in all commercialism and 
industrialism. It is not so apparent in art or in poetry. Yet. when an artist paints a picture like the Angelus, or the poet composes a "Thanatopsis" or an "Iliad," its greatness really consists in its lessons of true life; it points the way to the higher, broader and deeper conceptions of man, and his relations to his fellows,that is, it shows man how to preserve and broaden his life.

All esthetics, music, poetry, the drama, the limner's art, like science, are the property of all nations, and however diverse the languages, these works of art have a common meaning, and universally appeal to all peoples. They are therefore, a universal medium for the promotion of the brotherhood of man; which means, that the destructive forces of human life, and welfare, are thus greatly modified, and will be finally abolished. Therefore, art is a promoter of the physical welfare of the race. The physical, economic conditions of all forms of society,- the municipality, or the state, or the nation,-always determine the political policy, and give the tone to its organized religions also. It is this principle that determines the difference between the Asiatic and European countries. England, from her isolated position, and contracted territory, is, for that reason, compelled to adopt an entirely different political policy, from that of Russia, for example. The political economy of a nation and a great work of art have for their common basis, that in proportion, as they are faithful to the laws of nature-exact copies of natural truth-so they are really great.

Auguste Comte in his positive philosophy, refused to lecognize psychology, as a science distinct from physiology. The reason is not obscure. It is, that every psychical phenomenon has its physiological marks, 
in the absence of which, there is no phenomenon. The new psychology is physiological. The old was metaphysical. Note the material elements of a Spencerian definition of an idea. "The psychical side of what, on its physical side, is an involved set of molecular changes, propagated through an involved set of nervous plexuses; that which makes possible the idea is, the pre-existence of these plexuses," and they are the only part of the phenomenon that persists. The assumption, that there is any other element, takes the statement of it out of the realm of psychology, or science, into that of metaphysics. Spencer's definition of an idea is inductive, or scientific. Note the contrast between that and Descartes' definition, in which the physiological element is omitted. Descartes says: "By the word idea, I understand that form of thought, by the immediate perception of which I am conscious of some thought." No scientific definition can be given, except that the physiological changes, constituting the phenomenon, give the psychical effect. Descartes meant that self-consciousness-the perception of the thought -is the distinction between man, who has a "soul," and an animal who does not perceive his thoughts and has no "soul." But why should an idea, or its definition, be confined to this narrow conception? An idea is the conclusion of thought, a conception of what is best, or ought to be, an opinion.

The reason why the physiological, or material definition of thought is more comprehensive, is that it embraces the idea of the close connection between all thought and life preservation. Whatever appeals to man's physical nature, and preservation, is better understood, than an abstract idea dissociated from any physical connection. 
Structure Determines Difference.-The thought of one man is different from that of another, because either the brain centers are different in construction, or the aptitude of the original cells, to throw out crossassociative threads making new connections, is greater in one, than in the other. The differences in character in all animals, is the difference in physical structure. This difference produces different phases of intellect, and emotion. All animals are characterized by the emotions, and whichever one, fear, anger, affection, or self-feeling, predominates, gives the tem: perament. These emotions, in the lower animals, are unmodified, or very little modified, by the brain, or intellect. But in man, the superior quantity, and intensity, of brain matter, puts him in so much wider, and more complex correspondence, with obscure and complex relations in his environment, that the impulses of the simple emotions are greatly modified, or checked; but the process, in both, is molecular motion. That form of consciousness called reason, and memory, seems to be, merely arrested reflex motion. The reflex arc of the nervous system, in lower orders of animals. consists of a receptive nerve, a central ganglion, and a motor nerve running from the ganglion to the muscle. The motor action, or the emotion, follows im mediately the sensation. In the nervous system of man. there is the same unit of simple reflex, and as many, or more, simple responses to sensory stimulation, without the interposition of consciousness. But there is, also, the large ganglion called the cerebrum, into, and from which, run nerves, in continuation of the simple reflex. Those sensations, too complex for simple reflexes to solve, pass over the more complex ares into the brain centers. 
The emotions and impulses are inhibited, or modified by these higher connections. The action is more deliberate. The resulting perception, or conception, or abstraction, is a higher phase of consciousness. That is, these higher centers of psychical action arrest the flow of sensory activity, and turn it from the motor channel, into the ideational centers. The psychical result is a relation called consciousness. It is the physiology of the organism, that is modified by the difference in structure, and at the same time there is a corresponding difference in its psychology.

Freedom of Choice.-Freedom of choice makes the real difference between instinct and intelligence, or reason. In instinct nature does all, in reason man does much, in addition to what nature does for him. Instinct, having but one choice, does not hesitate, it does not reason. When we say that freedom of choice is the difference between instinct and intellect we state a result of the real cause of the difference. The real difference is in the complexity of the cross associative paths in the brains of the organisms. Instinct has a limited neural complex, compared with that of intellect. The freedom arises only when new short euts to the cerebrum, from the sense centers, are added to the old reflex ares of instinct. Freedom is a result of a material cause. It is psychological, while the cause is physiological. This is an example of the real difference between psychology and physiology.

Reason is arrested reflex. Consciousness is therefore, the interval between the excitation of a ganglion, and the action, or conclusion. However, no sharp line can be drawn between the "mind" of animals and man. There are some acts of animals, that show remarkable hesitation and reason. The beaver, for example, while 
confined to one mode of cutting down a tree, by his teeth in lieu of an axe, yet when the tree, in order to serve the purpose of its cutting, viz.: to become part of a dam, must fall, after the cutting, in a particular place, the beaver cuts the tree with his teeth, so as to make it fall where he wants it to fall, as surely as an axman could do. Both of these acts involve knowledge and reason. If there is a difference, it is one of degree, rather than kind. As Bergson says: "So long as consciousness is all we are concerned with, we close our eyes to what is, from the psychological point of view, the cardinal difference between instinct and intelligence." At least it seems, what instinct does is for the best welfare of the life represented by it, quite as much so, and perhaps oftener, than it is, in case of intelligence. Both are hereditary, and therefore both must be the results of evolution.

At least, the babe which seeks, at once, unconsciously its mother's breast, displays just the same kind of intelligence, that the atom of the nebula did, when it moved unconsciously, in the proper direction of condensation, for the formation of a universe, instead of in the wrong direction, by dispersion. The movement of the babe, so unconscious, and fraught with so momentous consequences to itself, and its race, was inherited from the atom of the far away nebula, - the instinct and intelligence both, of doing the right thing consciously, or unconsciously, in unison with the cosmic movement, in the evolution of the present flux of duration, called the universe.

It is true, the intellect has more than one choice in its manner of adjusting the ego to an environment, which it is unable to control in the least degree. This adjustment is very limited. It seems to be confined to 
a remarkably small number, of the infinitely large number, of phenomena. The response of the ego to these, is limited to the range of the five organs of sense. There is an infinite number of phenomena, in the immediate and remote environment, of which the ego is entirely unconscious. Such an ego being a phenomenon itself, could not penetrate behind the manifestations. It even seems to be far inferior in power, to some of the other phenomena. For instance, matter and motion, in the transformation of a nebula, to the present status of the universe, has produced in physics, the harmony of the stellar bodies, in chemistry, the atmosphere and water, and the transforming of the light of the sun, which falling on leaves and flowers, reappears as life. Whether the true theory of light is that of Newton,-the corpuscular; or that of Huygens,- the wave, yet we know it conveys to us by photography, and the spectrum, information of the remote parts of the universe, beyond the power of any other known form of matter and motion to convey. It is true, before man can interpret these, he must have a nervous power; yet power of nerve tissue, or thought, or any psychic phenomenon, is tame in comparison with this phenomenon. And these material phenomena, from which the brain of man derives so much knowledge, must have been in operation just as they now are, ages before there was an Ego. 


\section{CHAPTER IX}

\section{ETHICS AND ALTRUISM}

T having been contended, so far, that life, in the aggregate, is a differentiated form of phenomena, whose evolution has occurred by precisely the same L method, as all other evolution, the relation that all forms of it, bear to each other, as well as to the aggregate, must be governed by the same fundamental natural laws. The phases of this relationship are of such infinite variety, that to undertake to formulate a conscious duty by man, adapted to each variation, would evidently be impossible; nor would such formal eategory be useful. A human adjustment, that must be eventually readjusted, to conform to local needs, just as the ideas of man change, as the centuries go by, or as the brain power increases, is the only progression, that gives increasing strength and more persistence.

This does not mean that these readjustments should, or do occur in the lifetime of one individual. They are made, at very long intervals, and are so inconspicuous and harmonious that, unless science, or history mentions them, they remain unnoticed. They are not catastrophic.

Therefore, it is better to state the principle that most obviously lies at the bottom of this perpetual readjustment; and then, if that principle is correctly stated, it will be the human guide in those conscious situations, daily presenting themselves to the individual for solution, and adaptation, wherever and under whatever conditions he may exist. A general statement of this principle would be, in an all covering sense, that man's natural ethies is his normal adjustment to environment, 
human and nonhuman. "Normal adjustment" here means the relative power of the brain to comprehend phenomena, and keep in necessary correspondence with them. It is necessary to be borne in mind, that man is a part of phenomena. It is plain that such ethies will greatly vary throughout the world. This definition it will be observed, is also precisely the definition of psychology, of evolution, and of life itself. This fact preserves the continuity of thought upon all vital subjects. In the treatment of universal evolution it is thus found that whatever division may be made of the physical, or psychical phases of organisms, for the purpose of analyses and study of their processes, they are so intimately unified that the scientific definition of one phase, is that of all, and of the whole as a unit. This is not only the principle of evolution in the organic realm, but also of the inorganic. The universe is a unit. While the brain of man does not comprehend, in a complete conception, the whole in one idea, yet he dissects the parts, in his immediate environment, manufactures tools to bring his sense organs nearer to other parts, and thus discovers the laws, in sufficient amplitude to satisfy his intellect. He finds that every phase of it has a moral bearing upon himself. This oneness of type and definition in natural inorganic and organic phenomena has a very profound significance. It means monism. What is true of one natural phenomenon is true of every other. A conception of evolution, in life forms, such as Darwin has formulated, if true will be satisfactory evidence, to the real student of physics, of the same evolution throughout nature. It is exceedingly strong evidence against dualism.

The statements in this chapter, regarding the moralities of different communities, throughout the world, by 
which they naturally adjust themselves to each other as individuals, and to their natural environment, are purely historical. In no sense, are they intended, as an ideal code, approved by the writer. They merely form a historical presentation of what seems to be a law of nature. The whole theory of universal evolution, is a fact, not as a sympathic, benevolent person, imbued with the tenets of Christianity, would desire it to be, but as an evident law of nature.

As there is no absolute standard of truth, nor of beauty, so there is no absolute standard of morals, because every phenomenon apparent to man is relative, limited, at least to time and space, presenting a different impression to different individuals; so it is evident that the only code of morals that can be more applicable, than any other, is that based upon man's relation to phenomena, especially to his fellow men and society. While his relation to, or more properly his correspondence with nature, and its laws, can be comparatively stable, and fixed, when once such laws are understood, yet his correspondence with his fellow man, and society, will be more or less modified by the very mobile variations of social customs, and laws, according to locality, which create that peculiar emotional condition in every individual, called conscience. This can also be called, shame, remorse, or regret, which acts as a stronger control of motor action, than does the ordinary intellect. This is the public opinion in communities. Whatever the public opinion requires is historically moral for it, whether it is the fighting of a duel, the murdering of a witch, the keeping of plural wives, or the worship of an idol. But the principle itself is universal, not local.

The customs that are deemed moral, or immoral, in one community, may be viewed inversely in another. 
The same principle will apply to the standard of beauty.

Darwin, in "Descent of Man" says in regard to beauty: "The men of each race prefer what they are accustomed to, they cannot endure any great change; but they like variety; and they like each characteristic carried to a moderate extreme." The African greatly admires a black skin, flat nose, and colored teeth; the European altogether a different type, and the American, and Malay still others.

As Kautsky says, "Prison, poverty, and death are preferred by people to shame. Kautsky also quotes some curious letters of a converted Esquimo. For instance, "My country-men know nothing of either God or Devil and yet they behave respectably, deal kindly, and forcibly with each other, tell each other everything, and create their means of subsistence in common." This is a natural morality.

Nansen says of the Esquimo life, "One of the most beautiful and marked features in the character of the Esquimo is certainly their honorableness." Honorableness means their morality.

There are two phases, of man's correspondence with environment, that should be considered in the treatment of any natural ethies. The first is man's relation to the forces of nature, as such. This relationship is purely intellectual, and not moral, in the current definition of the word moral. Yet in one aspect, it has a most decided moral bearing.

Unless man conceives the truth, regarding the material facts of the universe, and its laws, he cannot properly adjust his organism to his environment. He cannot formulate a correct philosophy. This is illustrated, by the delusions under which all mankind were struggling, in regard to astronomy, prior to the discoveries of Coperni- 
cus, and Galileo. Before Newton mathematically demonstrated the truth of the attraction of gravitation, even Kepler, who formulated the laws of planetary motions, thought that the stars were held in place by an angel at each one. Prior to Darwin, there was merely a vague idea here and there, as shown heretofore in these pages, of the origin of species.

So that, until man comes into correct relation, intellectually, with what is termed the physical laws of nature, it is very doubtful whether he could form a natural code, that would be at all adapted to his need of a desirable correspondence with his physical environment. Ignorance is a strong support of immorality.

The same conclusion drawn above from the errors in astronomy and physics, will apply to man's conception of other branches of science, such as biology, chemistry, anatomy, and physiology. The proper care of his body is a question of hygiene very largely, but as its condition affects his offspring also, there is thus a moral bearing, to his treatment of even his own body. Hence, the necessity of considering man's relation to inorganic nature, as not altogether intellectual and unmoral. To some extent, in every thing a man does, from the unconscious act of breathing, up to the highest thought produced by the molecular motion of the brain tissue, there is a right, or moral, way to do it. The man who breathes correctly is doing more good to his body, than he would do, by abnormal breathing. The assimilation of food, the walk, the manner of wearing clothes, the expression of the face, the articulation of words, even the selection of the proper words in speech, all have an ethical bearing. If these are well done, it means that they fit into the noiseless correspondence,- the life, - of the organism, and its surroundings; the individual thus 
preserves his normal correspondence with physical environment, and an attractive, not repelling, attitude to his fellow men. But if they do not harmonize with the environment, then they are evil,--immoral, and the violator, as well as the violated, suffers some pain, or unhappiness.

The laws of nature, which are also those of evolution, are unchangeable in their method; therefore, man's welfare, his morality, consists in adapting himself to these laws. This he cannot do without understanding them in a scientific way. That is, by a knowledge shorn of all its fanciful, and mystical aspects.

The man who so controls his functions, as to meet all the varying phases of climate, gravitation, sustentation, etc., is not injured, but benefited by them. An indirect benefit is, that the effort, the exertion, he thus makes, develops him into a self-reliant and powerful organism. Figuratively speaking, nature can make no mistakes, and does absolutely right at all times. Everything it does is not only absolutely right, but it does, in every instance, that which is for the best and moral welfare of man himself. Whoever is in normal attitude, toward his environment, would not be wishing for rain when it is dry, nor for cold weather when it is hot. $\mathrm{He}$ will be perfectly satisfied with whatever comes, because he will be in proper correspondence with it, and will know he cannot change it.

The difference in the moral codes of the world is determined by these differences in intelligence. It is a gradation of intelligence and morals from savagery to civilization. That people who takes the correct view of nature and her laws, has a higher code of morals, than the people who takes an incorrect view.

DeatH.-A perfect man, if such an organism were 
possible, would be in perfect correspondence with all the requirements of natural law; and death to him, which is a cessation of correspondence, would then be postponed to the latest moment compatible with the welfare of the race, and then would be regarded, as it really is, only a change of form. The survival after death of all bodily elements, and the perpetuation of the race, constitute an immortality which is natural, and does not require a miracle to make it possible.

The body, and its qualities, being the products of indestructible matter, and the persistence of energy, death simply changes the form of it back to these original elements, and probably, they come together again, under favorable conditions, and form a new body similar in kind, but not conscious of the former body. This immortality is entirely confined to the earth.

Death is now regarded as a calamity, although an inevitable natural law. But in the ultimate analysis of it, there will be found this essential definition; it is the closing of the correspondence between the organism, and its environment, by reason of that organism's violation of some of the essential laws of that correspondence, or from the necessity of race maintenance, under the law of the survival of the fittest. If men everywhere viewed death in this light, there would be more attention paid to physiology and hygiene, and the death-rate would be largely reduced. This is another instance of the moral bearing of man's attitude toward nature at large.

In death the elements of the organism are dissipated and transformed; but not lost. But the objective environment remains the same. Nature is not affected by the death of organisms. The inorganic remains unconscious of that event, which is so dreaded, but certain, to the organic. There is a seeming eternal round in the 
flow of phenomena, in the condensation of matter into organic forms, the development of them by growth, and their return to the inorganic. So that birth and deatk are merely natural phases of universal evolution.

Death therefore, when it occurs naturally, is not a calamity, nor a thing, in the abstract, to be regretted. The attitude of mankind toward this necessary step in evolution is not according to the best reason.

Of course, this definition of death makes it an essential link in the method of evolution. But its occurrence too early in life, if caused by preventable violation of physical laws, is a sign of a certain phase of immorality, and can be avoided by a wise system of education, in physiology and hygiene. Death from old age can perhaps be thus postponed to a later average date, than it now oceurs.

In Egypt, death in whatever form was considered by the priests an assassination. From their standpoint, it was the act of man, an animal, or a spirit, or of a God. It was not a natural phenomenon. This idea, in a modified form, is still held by civilized people. It was the province of biological science to discover that it is a natural process, that can be regulated, as to time, to a very great extent, by man himself, when his intelligence is brought into accord with what his attitude should be to, and correspondence with, the laws of nature and being. This refers to the method of education in the natural sciences. Man's mental powers are so limited, that this method has not always given true knowledge. But an immense advance has been made in astronomy by the discoveries of Copernicus, but not until the 16th century; in geology, not until Lyell, in the 19th century; in biology, not until Darwin in 1859. There is no other method known that has given so much knowledge 
to man, of those essential phenomena, with which man's life is so connected, and on which he must rely for his existence. This is especially so in anatomy, chemistry, physiology and medicine, and just as essentially so, in morals.

The neglect of society to avail itself of sanitary measures is the highest immorality. It seems then, that the highest code of ethics will be based on this necessity of maintaining a rational correspondence with physical environment, as one phase of its composition. Education should be directed to that end. Perfection may never come; but we can make an immense advance beyond our present ignorance of this great truth. This phase of a code is not included in the existing code. It does not say as an eleventh commandment, "He who remains ignorant of the evident laws of nature is on the road to an early death." It is apparent that such is the natural law, because men are dying daily on account of preventable conditions. They are being overwhelmed by earthquakes, tide waters, floods, and epidemies, because they are not in intellectual correspondence with the physical forces producing these things. Therefore an important commandment of the code should be "Strive to master the laws of physics."

Man, a Natural Product.-When man shall fully understand the principle of evolution, he then only, will begin to comprehend that he is not a stranger to his environment. As soon as he shall become convinced, that he is not a manufactured article, set down from an unknown region, into a strange country, for a slort stay only; but that his organism is evolved out of his habitat; that every apparent thing organic, or inorganic, is akin to him, composed of the same material, shaped by the same force, and governed by the same laws, he will then 
begin to formulate a new ethical code, and a new philosophy. He will look around, to see what can be done to increase his correspondence with this kindred environment. Proficiency in biology and kindred science will teach him, that his pedigree reaches back to the very beginning of the universe; that the interaction of matter and motion, beginning with the atoms of the nebula, continuing in the molecule, in the crystal, and the sphere, did not produce a unit, mobile and adaptable enough to enter into the formation of organic life, until the alembic of perhaps untold eons had refined the matter, by the immeasurable heat, and chemical action, of an evolving universe.

If there was any beginning to life, it was, when the laboratory of nature had worked upon the material long enough to first produce the universe, as we now see it, before the organic unit, now called a cell, could be evolved, and from that previous product of Nature's refinery, man finds himself evolved, by the same slow process of growth and elimination.

What dignity and nobility does this hypothesis give to man! It makes him the apotheosis of cosmic, not personal forces. He is the product of the ages, and akin to all that has gone before. There is not only reason, and dignity, in this view of the place of man in the universe, but warmth and glow, which no other hypothesis can give.

This view of man makes him a product of nature. He comes from the matter of the earth, which is the same as that of the universe, and his mental power is thus derived.

This natural derivation of man means, that the human organism, as it is now developed, was evolved phylogenetically, from an order of lower organisms, 
which, when traced back scientifically terminates, at its primitive end, in the inorganic, or that it always existed as life, in some form. When this line is traced back ontogenetically, it is found to begin, as an embryo, in the form of mere protoplasm, or animal life of a very low order; that not until evolution has produced a nerve structure, does it exhibit the higher phenomena of life called psychic. Its basis, therefore, is in the physical, and its very power of existence and therefore, all its mental and moral force, depends upon its drawing its life sustentation from the earth. Here and there only, e. g., in the writings of Darwin, Spencer and Huxley, in the history of man, has it cropped out, that he is at all a natural product. The family, society, and government are crystallized around the conception, that the universe is a personal emanation, and under personal laws.

Whatever finality the imagination may attribute to phenomena, it is evident, to the senses of man, that nature itself is the immediate power that holds the fate of man in its grip. That works by certain uniform and unchangeable laws. But these laws can be known by man. He can, by such knowledge, not change these laws, but can adapt the stream of his life to them, in such a way, as to have them serve his needs and desires in a life prolonged by this knowledge, made sweet and pleasant. This is true righteousness. The reverse side of this is ignorance.

Ignorance is a struggle, aided, not by intelligence, but superstition, not in the direction of light, but toward darkness. Intelligence takes the right path out of the jungle, where lie so many enemies; but ignorance circles within its borders, and early falls a victim to these enemies, long after intelligence has escaped, and pursued 
a new path of health and happiness, to a natural termination, which it welcomes as a relief from further wearisome pursuit of happiness. The difference between the career of the two, above depicted, is the natural morality, immanent in a well adapted organism.

Man's Relation to His Fellow Man.-The second phase of a natural code of ethics, is man's relation to his fellow man, as a part of his general environment. In reality, the former relation, - that to nature at large, -is one, rather of adaptation and defense. In that part, the questions generalized into the golden rule, viz., altruism, justice, mercy, love, etc., do not properly arise. The treatment we receive from the laws of nature is only justice, in a very abstract sense; the fact being, that all are served alike in proportion to intelligence. But mercy, love, and the beatitudes do not seem to enter into it, in the personal sense of those terms, as they do in the relations between mankind. Impersonal cosmic power has not the same warm grip upon the consciousness of man, as has the personal power, exerted by men, toward each other. It is only in the associations of men, and the relations growing out of these, that a code of natural ethics evolves, which includes those conditions resulting from attributes peculiar to animal life, such as fear, love, anger, and the sexual emotions. This personal code, includes the altruistic, which is characteristic of all animal life, having nervous structure.

Of all animals, man is the least physically able to supply his own wants. Therefore some kind of co-operation with his fellow man became a necessity to primitive man, and this has continued to the present time. Only animals with great power of supplying their wants can live in solitude. This weakness in man is the very element, that has worked, and is still working, not only for his higher 
morality, but also for the most subtle altruism. It has caused, also, the greater growth of his brain and psychical device. These have rendered him far superior to other animals in his acquired powers of defense and support. The morality, altruism and intellect are, therefore, natural evolutions from the physical nature of man. If sociality is essential to his proper sustentation, and defense against enemies, the increase of the number who stand together for these purposes should increase the tenacity with which they stand together, and render the aggregate body more weighty and enduring; and thus evolve a natural civilization. If all mankind should stand mutually on the same moral and intellectual basis, that would be the brotherhood of man.

The necessity for men to combine in societies for mutual protection and advancement compels them to adopt such laws and customs as will promote the public welfare, and at the same time the happiness of the individuals. It is easy to trace to this fact the evolution of love of man for his wife and children, and to a less degree of his fellow men in general; hence the evolution of the gens, the tribe, the confederation, the state, and the nation, in succession; hence patriotism, and all virtues. The highest evolution from this necessity is the brotherhood of mankind, which will eventually come, by the working of the same natural evolution.

Man may fill the earth with written codes of morality, which can be changed by the same hands which wrote them, but the unwritten laws of nature never change; and no human hand can make them other than they are, always liave been, and always will be.

This natural kind of human ethics (adaptation to nature and to each other), is not confined to the human being. All the lower animals exhibit it in certain de- 
grees. It pervades all nature, and is always just and impartial.

The evolutionist views man, in his primitive stage, as little above the animal, governed by passions, desires, and instincts, inherited from his remote ancestors. His altruistic evolution comes from his association with his fellows for the purpose of mutual protection, and is correlated with the economic, political, and intellectual evolution of society.

Man's moral nature is thus evolved biologically from the very nature of his life itself; from the nature of all life: not only this; but from the atoms of the nebula, whose moving principle is condensation. This is the criterion of the strength, and binding force of natural ethics. Man was never perfect, even in his own view of himself. But he has been, ever since he built the first fire and made the first tool, evolving into a better adapted organism to his environment; his primitive instincts blindly led him to those efforts, which conduce to his physical welfare. This effort has been his salvation. When the struggle ceases, that is death. But he passes life on to his offspring with an inherited periodical variation, which prolongs and widens it, generation after generation.

RighteousNess.-All men properly organized are desirous of promoting the growth of what is generally called "righteousness." That word, however, is quite indefinite in its application. In some localities, and under certain conditions, it is considered quite compatible with a state of external war, of slavery, of injustice; and in others, with a state of what we would call decided personal immorality.

In 1820 the American missionaries to the Sandwich Islands found the inhabitants living in the lowest stages 
of savagery. The family was the punaluan, in which, under the laws of the gens, half brothers and sisters were lawfully living in wedlock. Polygamy and polyandry were universal. These were the customs, and considered by them perfectly innocent and moral. They undoubtedly had been the legal and moral customs, throughout the world, at the same stage of social development, viz.: the lowest. and the middle stage of savagery.

The gens at that stage of development was the unit of society, the same as the family is the unit in civilization now. The gens consisted of a supposed female ancestry and her children, together with the children of lier daughters, and of her female descendants, through females in perpetuity. The geneology was traced through the mothers, while ours at the present time, is through the fathers. The law of marriage was, that it could not occur between members of the same gens, but that each male, or female, could marry any member of another gens. The children, both male and female, belonged to the gens of the mother. But if the same father begat children by different wives, of different gens, then these children could legally, and morally, marry each other, because they belonged to different gentes.

The immorality consisted in violating the law of the gens, not in complying with the law, whatever that was. Our ancestors, when they were passing through the same status of savagery, prior to historical time. had the same marriage rites under the same form of the gens. So the missionaries in so strongly condemning what they called the great immorality of the Fijiens, were really besmirching the character of their own ancestors, who practised the punaluan customs, in their savage and barbaric status, and were as innocent 
and moral as we are in following the monogamic laws of eivilization.

Righteousness is that state of social, and individual relationship in which, the material welfare of each and all is best promoted. It means, that the right thing shall be done, at the right time, to the right person, and in the right way. All these terms are relative, and these "rights" are determined by the aggregate community, according to its intellect; and the test of them is, the experience of their pragmatic working. It would be a state of righteousness, that cannot exist in a monarchy, nor in slavery; nor where the laws are unjust, and unequal, though under such conditions some individuals may be called righteous.

Unless the people themselves are free, unless they are their own rulers, and law makers, as they were in the primitive gens, there must be unrighteousness as a whole. In short, the ideal state of righteousness is, in a broad sense, freedom, governed by only selfimposed law, such as theoretically exists in a republic, or democracy.

In primitive barbarism, custom was based on mythology, because men's brains could not conceive any other basis. That was natural to their stage of evolution.

Franz Boas says: "The dislike of that which deviates from the custom of the land" (in primitive life) "is even more strongly marked than in our civilization."

* * * "I think we are justified in concluding from our own experience, that as among ourselves, so among primitive tribes, the resistance to a deviation, from firmly established customs, is due to an emotional reaction, not to conscious reasoning."

In a community of scientists, every problem of 
judgment would be solved according to scientific principles; in one of theologians according to the categories of theology. Everywhere all questions are answered according to the prevailing views of either philosophy, science, or theology.

Steps of Evolution.- "Civilization is simply the process of an adjustment on a large scale, whereby man's whole nature, physical, intellectual, and moral, develops in all its marvelous complexity in response to an environment, also increasing in complexity." In this way the adjustment is made by the natural law of evolution. If made in any other way it is weak and tottering.

Mark the order of the adjustments as stated:-First, physical; second, intellectual; third, moral. This is the natural order of evolution in general if there is any succession. The first development of an organism, from undifferentiated protoplasm, is into the purely physical cell,- the amoeba, for instance, consisting of one cell, and all stomach-no nervous structure. It is not until the organism has attained considerable complexity that nerve structure is evolved; then intelligence begins to dawn. But it is not until it becomes so complex in correspondence with the like complexity of environment, that it requires what are called memory, reason, and will, that the intellectual is evolved. Lastly, the moral, or ethical, is evolved from the intellect, or develops co-ordinately with it. It is the same way in the evolution of society from the primal gens, leading a purely natural life, to the present complex civilization. The present code of civic morality is not the "root but the fruit of civilization." A natural code founded on the laws of evolution is the root of all civilization. It has been the real root of what is strong, and enduring, in the present rapidly changing civilization. 
The reasons of this, in addition to those already stated, may be given as follows: Since the natural code is founded on the necessity for the adaptation of man to his environment, the complexity of it depends on the complexity of his nerve structure, which gives him greater and greater conception of the relationship, just in proportion to the development of his nervous system. In other words, the more complex the intellect, the more numcrous and profound the objective truths revealed to it. It follows, that these higher adaptations, and correspondences, are the various aspects of that persistence of force, which working through what intellect man has, produces more numerous and stronger variations in individuals and society; and these being perpetuated by the principle of natural selection, a corresponding civilization would be produced thereby.

It is not necessary to further analyze such a system of morality in order to show that it is a promoter of higher civilization. The Anglo-Saxon race is a fine example of the evolution of the ideas of the people, parallel with their growth in knowledge of natural science, and their consequent correspondence with a more complex environment.

The United States, the freest of political countries, in which the general education of the masses, in natural science, is far advanced, and growing, is at the same time the most tolerant. It is the finest example of codevelopment of a high civilization and freedom of conscience.

Free Industrialism.-It has been clearly shown, in history, that industrialism, as it gradually became free from all kinds of slavery, and every worker is allowed to enjoy the fruits of his own labor, and to think as he pleases, is at the foundation of all social progress. In 
the middle, or dark ages, war, not industry, was the means of accumulation, and industry was the pursuit of slaves alone. Not until labor became free, and respectable, and other education, than mysticism, was introduced, did society begin to evolve along the line of better civilization. It was the working of the principle of natural selection that determined the best method of advancement. The best method survived, and the unfit died. Along with economic freedom comes what is called spiritual freedom, or intellectual freedom to think as one pleases upon all subjects. So that freedom being once established in any one of the organic functions, by the principle of equilibration, all other functions eventually become free.

Now, the monastic, and ascetic ideals of the middle ages were utterly incompatible with a free industrial and commercial spirit. So that it was no accident that the reformation of Luther, as well as political freedom, made most progress in the free towns of feudal Europe at that time. It was the natural evolution from the old order, co-existent with that of free industrialism.

It thus results from the logic of facts, as stated, that while emancipation from superstition is not the first impelling cause of eivilization, yet, that industrial, and political freedom, and naturalism, as opposed to slavery, war, and authority, go, hand in hand, in the progress toward a higher civilization; and that our own country, as representing. perliaps, the highest example the world has yet produced, is at the same time the freest from the old superstitions, and the farthest on the road toward the freest naturalism. This proves that not only is mysticism and authority not essential to a desirable civilization, but that a really desirable civilization eannot be evolved without at the same time slowly eliminating false ideas from the human mind. 


\section{CHAPTER X \\ ETHICS AND ALTRUISM \\ Continued}

7 He Great Movement.-The universe is infinite. The human intellect is incapable of penetrating to the infinity of it, or to see behind it. The laws of it, as far as man has yet learned them, teach him that they never change, and that the flow of duration cannot be altered by any power, but that a rhythmic evolution is the power producing those manifestations which the limited intellect of man can see.

Evolution applies its great method of development, natural selection or the survival of the fittest, to every change in organic life, from that of an amoeba to man, including the change of man's condition from a solitary roamer of the forest to his social status, as the citizen of a great civilized community. It applies equally to the changes, now going on in man's brain.

All social evolution depends, of course, as already stated, on the combining of men in social communities; that is, men acting upon each other in a social capacity. The intellectual, and moral character of a community, is the aggregate of that of the individuals composing it. Whatever is done thus, is done, of course, by the action of the individual members. The savagery, barbarism, or civilization characterizing it, is said, by some writers, to be created by the reason of the aggregate men composing it. But if this reason is the result of biological evolution in the individual, and is limited to organic adaptation to the inorganic, by the neural and anatomical structure of the members of the community, 
in correlation with the natural forces in the environment, then all the effects, or results, of that reason are really evolved from these physical correlations. In other words, all social conditions throughout the world are evolved through the brains of men by natural forces, whose requirements cannot be ignored, by any assumed independent action on the part of men. In this view, which seems to be the correct one, man really exercises no "free will" in social, the same as he does not, in individual affairs. Every effort, and every function is bounded by the limitation of the human brain.

While the aggregation of men in society gives them power in the direction of defense, preservation of life, and the perpetuity of the race, yet, it must be borne in mind, that except indirectly, in the establishments of educational institutions, it does not increase the power of the intellect, to penetrate further into the flow of existence-the reality of things. But men are learning now that better civilization means a better conception of social science, and that comes only with a better conception of all science.

The fact is well known, that ever since the beginning of historical time, society has been advancing in the forms and essentials of its civilization, only as it discarded delusion, and adopted the truths of natural science. This advance is not in a direct line, but as all progress is made, rhythmically, in periodical ups and downs. Today, the conditions are almost infinitely better than they were in the dark ages, when the densest superstitions ruled men, and authority was in the full control of men's ideas; very much better than two hundred years ago, when witcheraft and slavery were quite universal; and when the death penalty was attached to a large number of simple misdemeanors, and debtors were imprisoned in filthy jails. 
Hobhouse says, that in England death was theoretically the penalty for all felonies, except petty larceny and mayhem, from the middle ages, down to 1826 .

The excessiveness and cruelty of punishment for offenses seem to have been proportioned to the weakness of the people in their efforts to defend themselves. They were the result of fear and weakness. When lareeny and robbery were more or less prevalent among the powerful, who stood together as clansmen, those whose duty it was to make the laws, and inflict the punishment, involed heavy penalty, as a preventive of crime. But when public opinion became more moral, it took the place of unusual punishment, and the powers, having the public opinion behind them, as an aid to good order, abolished excessive penalties for milder ones. This sort of evolution will continue, parallel with the growth of intellect and morals, until eventually mankind will do right without fear of punishment, because they will then perceive that crime brings its own punishment, when the community at large keeps control of it. That is, men will do the right for its own sake, or rather because that habit brings the greatest welfare, to both the individual and the community.

Hobhouse says also, that serfdom was finally abolished in France, without compensation, on the night of August 4th, 1789, along with the other incidents of the feudal tenure. At the same time fell the whole system of privileges, which had made the nobles, and the clergy, castes set apart from the mass of the people.

It perhaps could not have been done, in France, in any other way, than by the French revolution, or for that matter, great reforms are forced by the people, who need the reforms, never by the oppressor. 
An evolution of intellect brings with it an evolution of religion. The subjects and methods of ministers of the Gospel, as a rule, are quite different now from what they were even fifty or more years ago. There has been a constant tendency toward tolerance, in differences of creeds; less and less emphasis upon a literal heaven and a local hell. Correct living, personal morals, kindness, charity, mercy, are more dwelt upon in latter day sermons. There has been less encouragement given to emotional forms of religious expression, and more to the attitude that man should cultivate toward his fellow man. The reformation of Luther meant that an evolution from authority, from ceremony, and ritualism was taking place. Protestantism means that religion is a personal matter, that its institutional features should come nearer to the individual, that the clergy should conduct the teachings in a language understood by the people, and that the laity should determine for themselves who their teachers shall be. There has. been a very great erolution in the intelligence and spirit of the pulpit. Fifty or sixty years ago, untrained and uneducated preachers and exhorters droned to the people the physical attraction of a local heaven, and especially the eternal torments of a literal lake of fire. awaiting the death of unbelievers, in which to plunge their immortal souls. This specialized kind of cruelty has largely passed away. Students are now educated to the ministry. They preach less cruelty and demon worship and fear. Love, the beatitudes, peace, happiness, the Golden Rule, the sermon on the mount, form the themes of an educated clergy. A personal devil and his imps, and all agents of torture are neglected. They have passed away as did witcheraft, slavery, the 
inquisition and the dark ages. In those days, also, there was a polemic struggle between the various sects for survival of immaterial doctrines. Fiery pulpit orators were challenging each other to debate the merits of each other's creeds. But now there is none of that spirit. The different Protestant churches join in working together, in spreading the fundamental tenets of the Christian religion. The tendency now is to consolidate, especially in ethical, altruistic and missionary work. The line of separation on the minor themes of mere church government and creeds. is being more or less obliterated. in the growing importance of peace, charity, the Golden Rule, and the brotherhood of man. This has been an evolution, and the survival of the fittest religious views, is the bringing forth thus of a new species of religion, as plain as is the evolution of an organism, from a lower order. As a republican form of government evolved in America from the monarchy of England, or as the French republic evolved from the empire of Napoleon 3d, so Protestantism is an evolution from Catholicism, and the modified forms of religious tolerance of the present day, a like development from the intolerance of the first Puritans, who came to America. There are yet many reactionists in the churches, but they are utterly unable to stem the tide of natural evolution that always attends upon advancing intelligence. This evolution in religion is merely typical of that in all things, physical, intellectual and moral. It is universal, and cannot be controlled by man.

It is a wide stretch, from the conception of a literal hell, and a material heaven; from special creation; the constant cessation of natural law, in order that miracles might occur; the killing of men for opinion's sake; 
from the inquisition, and the holy wars, to the present day conception of natural evolution, the reign of cosmical law, that never changes; tolerance of opinion; the freedom of religious views, and the evident tendency of all countries toward peace, and good will.

The Universal Application of Natural Ethics.This natural generalization of morality, viz., man's normal adjustment to his environment, is appliable to every condition and to every spot on the globe. It is a universal method of religion. There will, of course, be a certain local peculiarity, as said before, in the environment of every people, and in the greater, or lesser, development of intellect, that will make the natural morality of individual correspondence with such environment, different from that of other localities. But, men everywhere of equal development of intellect, and acquirements of scientific knowledge, will, as a class be equally naturally moral. The principle of conformity to natural law, as the true basis of ethics, is not affected by these local phases. The principle is really the Golden Rule, "Do unto others as you would have others do to you." Man's normal adjustment to his fellow man, as part of his environment, could mean nothing else. This is a normal adjustment of man to his fellow man. It is just as moral for the East Indian to worship Buddha, as it is for the Jews to worship Jahveh. The Golden Rule is moral to both, and is common to both. because it is a general principle, that should govern people everywhere. Whoever conscientiously conforms to the laws and customs of his tribe, or country, or locality is in normal adjustment to his environment, and is moral. His conscience has evolved in that mode, and regulates his morality, because it is a creation of the locality. Some Mohammedan tribes consider smoking, as one of 
the worst of offenses, a sin in comparison with which murder, and adultery, are trivial. An Arab chief is unable to see how a man can be contented with one wife. But were they less moral for these beliefs? There is no natural law regarding marriage customs. These are made by the communities themselves, and are based, in every community, like all human laws, upon the idea of that, which will bind the community together more strongly.

If man does violate some unimportant requirements of the natural code he will suffer only in proportion to their importance. For instance, should he imprudently expose his person to a draught he takes cold. If he eat indigestible food, or drink intoxicants, his digestion is upset. If he violate any social law, or legal enactment he suffers accordingly.

It is stated above that a natural code of ethics is applicable to every place, and is therefore universal. This means that the correspondence of the organism with its environment, so as to conserve its welfare,its preservation and its perpetuation, and strengthen the bond of society,-is the same principle, in one place, as in another. This correspondence included, of course, his fellow man, the peculiar form of society, under which he lives, and the laws and customs of that society. These vary with the locality, and with the state of evolution of the intellect of the society, and the individual; but the principle is everywhere the same and always natural. Therefore, this principle is a universal religion. That is man's normal intellectual adjustment to his environment, narrow, or broad. It will be altogether different in form in the United States, from what it can among the natives in Central Africa. 
A fixed categorical imperative, a prescribed written code, made to fit the a priori ideas of one social unit in one locality, has never become the guide of men in all communities, everywhere and under all conditions. Nor can reason determine beforehand, by a written prescription, the morality of a future action, because it cannot anticipate all the possible conditions of the entire environment, to which it may be necessary, at another time, for man to readjust himself in all his heterogeneous relations. Man's moral relations to his fellows, in times of peace, and good will, are altogether different from what they are, in a state of war, towards his warlike enemies. His attitude towards his friends, is necessarily different from his attitude toward one who wishes to murder, or rob him, and both may be moral. The divine prohibition of pork, as a diet in Palestine, may have been correct, because of its supposed injurious effects there, but not in Europe, where it does not cause leprosy.

In a tribe living in the lowest degree of savagery, it was a rule that when a wife died, it was the duty of a husband to go to another tribe, and kill a female member of it. It is said, that unless the husband performed this divine command, he pined away and died. This rule was part of the moral code of that tribe. Civilized man regards this as not only immoral, but criminal. But all the tribes of savages regarded it as moral. The rule is always abrogated, when such tribes grow to regard human life as valuable,-worth more living than dead. They, in time, grow out of such horrible moral ideas. The similarity however of the morality, between this rule of a tribe of savages, and the international code of civilized countries, in making war upon each other, for the acquisition of territory, will be apparent to the thinker. 
In the war of 1871 between Germany and France, and that is only an example of others, thousands of lives were taken apparently for the acquisition of Alsace and Loraine, and of a thousand million franes as indemnity.

The Principle Works-Regardless of Human OpPosition.-It is evident to the student of anthropology, that nature is now enforcing and always has enforced, this natural morality of human adaptation, without the least regard for any artificial code; and the punishment for violations is being enforced daily before our eyes. But we refuse to see, that our short comings are lapses in immorality, that term being applied exclusively to acts, which meet the approbation, or reprobation of another; and seldom, if ever, to lapses of natural laws, or human laws founded on the laws of Nature. Unbelief, for which Nature has no punishment, is to the Council of Trent, an unpardonable sin.

Sir Francis Drake, commanding England's fleet in 1586, wrote the Lord High Treasurer, on his return from an expedition to the West Indies, where he captured, and put to ransom, the Spanish towns of San Domingo and Cartagena, that on his expedition, the Spanish treasure of the Indies escaped him only twelve hours, saying "the cause, best known to God." He meant he would have waylaid the Spanish vessels carrying the treasure and taken it, as he had done other piratical things, and "God work it all to his glorye." It is not possible that God had any hand in such erimes.

But could men be aroused to see that sudden, or premature death, or exclusion from society, for social violations, are really avoidable by living up to a natural code of ethics, it would soon be perceived that the proper education, is that, which teaches how the most health and happiness can be gotten out of life, by a study of 
man, and his relation to his complete environment. If men build cities near a threatening volcano, or on a level with tide water, and get overwhelmed, or destroyed, that is a punishment that Nature metes out for ignorance and stupidity; not from design, but because the great law of Nature is the survival of the fittest, which, in this case, would be those who avoid the destructive forces of life, in the shape of fire and flood.

The endeavor has above been made, to outline a universal principle, which being applied in every spot, and under any and all circumstances, will produce automatically, that condition in man, which is called ethics, or morality. That principle is, the adaptive adjustment of the psycho-physical organism. This adjustment will necessarily be different in different communities, and in different places. For the scientist, whose knowledge of the laws of nature is greater, than that of the native Australian, or of the North American Indian, it should be more completely and highly ethical and moral. But the latter's adjustment being better adapted to him, than could be, that of the scientist, it gives him a better morality for his welfare, his preservation, his happiness, than would be that of the scientist, if such a thing could happen, as that the higher adjustment of the scientist could, by any means, be taken over by the Australian, without his intellect being made equal to that of the scientist. In other words, there would remain as much difference in the ethics of the peoples of the world, then as now, unless all sliould become equally enlightened, in the scientific truths of natural law.

One category of natural ethics, therefore, cannot prevail until all men perceive the same necessity for the application of the principle.

The principle of ethics, being the adjustment of the 
individual with his environment, is that of evolution, and it follows in natural order the biological evolution of the organism. In this sense, true natural ethies is an evolution, and its elements are accounted for thus naturally and logically. But when an author, in trying to account for morality in some other way, says it is within us, and its roots can be sought in the obvious motive forces of human action, he can be askeil whence came these motive forces?

The evolutionist meets the inquiry in a natural way by saying they were biologically evolved, with experience, as part of life itself, and are a part of the constant readjustment of the psycho-physical organism to a constantly changing environment. That part of the readjustment, pertaining to the inter-relation of life forms, and their aggregation into societies, is generally exclusively called morality. But there can be no hard and fast line drawn between the latter and all other adjustments that the individual is compelled to make, to his general environment.

This principle of moral adjustment to local eustoms is really the same as that laid down in Adam Smith's "Theory of Moral Sentiments." He says, "Our continual observations upon the conduct of others, insensibly lead us to form to ourselves certain general rules concerning what is fit and proper either to be done or avoided. $* * *$ It is thus that the general rules of morality are formed." This means that local customs form the morality of the location of such customs.

"When the development of agriculture made a captive neighbor worth more as a slave, than as roast meat, the great wrong of roasting him was a natural deduction. But that conclusion was not drawn from 
anything else that man ever did, or taught, or from any inspiration ever given him during all the thousands of years of his previous labor, philosophisings, and forming of ethical codes." Richardson, in "Industrial Problems."

In fact, all advancement in ethies, art, in literature, in philosophy, in civilization, followed from some new industrial, economic relation, discovered by man in nature, making it easier for him to supply his wants.

Darwin's comments on the "moral sense" in chapter 4 of "Descent of Man," are acute and elaborate. And he connects it as a fundamental growth in a clear way, with the principle of evolution. Conscience is a pure product of the long continued habits of the social unit. Whatever the customs of the gens, or tribe require, is moral. The remorse comes when these customs are violated. It makes no difference whether these customs accord or not, with our ideas of morality, they are moral to the members of the gens, or tribe, and that gives satisfaction to the individual, who conforms to that custom, and remorse when he violates it. And who is to judge except the tribe itself, whether such customs are not in accordance with the best welfare of the gens, at the period of such customs?

Morality has widened, and become more humane, as the customs within the tribe, pertaining to the attitude of the individuals thereof to each other, have been extended to all human beings of every tribe. or nation. In primitive tribes murder, robbery, treachery and such crimes were not legal within the gens, but were not considered criminal when practiced against other gentes, or tribes. This does not differ very greatly from some customs of civilized countries, in their methods of hringing on war. Customs could only be 
abolished when tribes became consolidated into a nation, and it became impossible to continue to carry out the custom, as a national law, on account of the physical obstacles. In fact, by the time the members of primitive tribes had evolved sufficient brain power to combine into nations, they had, also, subjectively created a superior authority who did not, in their opinion, require a sacrifice so absurd as the killing of innocent females of another tribe. These advances in morals and brain power are simultaneous. The principle applies, not only to the barbarians and savages, but in the days of slavery it was not considered. in otherwise civilized countries, a crine to enslave those of a foreign race, but to enslave those of the same race was a heinous crime. Thus the roots of our own customs reach back into savagery.

The nearer society comes to perceiving the truth. everywhere apparent to high intellects, the greater the number of functions it develops; and, therefore, the higher will become the civilization. That civilization is high, where individual opportunity for growth in intellect, altruism, and longevity are great, and that this individualism is at the same time subordinated, in the proper degree, to the welfare of the aggregate.

When man obtains the right of freedom, the right to enjoy the fruits of his own labor, without the fear of exploitation, then happiness naturally follows. $\mathrm{He}$ must have freedom of mind and conscience. All he can ask of the state is, that it will protect him in his natural rights, in return for what he contributes to the welfare of the state. Such an adjustment will produce a stronger bond to society, than any other.

Paine says, "The more perfect civilization is, the 
less occasion has it for government; because the more does it regulate its own affairs, and govern itself." $\mathrm{He}$ mears by this, that the more the intellect is developed, the less is man inclined to encroach on the liberty of his fellow man. Thus intelligence, and altruism, are evolved simultaneously. As soon as man becomes intelligent enough to perceive, that interference with the rights of his fellows, jeopardizes his own rights, then he needs much less than ever before, any governing power to compel him to keep his hands off the person, or property of another.

In our own country, where our organic law is in theory based on the legal equality of all men, the inherited taint of this division of the people into classes,- - one the ruling class, and another the ruled,--still lingers in the habits of the people, and in many of the iniquitous laws that are kept upon the statutes. A natural code of ethics will bear equally upon all men, and not require one to "bend the pregnant hinges of the knee, that thrift may follow fawning;" nor will it make of an elected executive a ruler, but a servant of the people. Oppression, in the form of legal enactment, can have no place in a natural code; nor, under it, could a class of citizens, who have the mental power, obtain control of government, for the purpose of depriving another class of the benefits of its own production. Under such a code, human laws must follow the laws of nature, in bearing equally and equitably upon all.

Evolution an Equitable Law.-Evolution is a natural law, and fortunately not arbitrarily controlled. Whatever method, either in the physical, or in the psychical world, falls within the principle of evolution, is equitable law. Those functions of matter and motion which are essential, in the integration of forms, 
or in the dissolution of them, no less than in the formation and growth of social units, such as tribes, states, and nations, are natural laws. It is so, also, with those functions of the members of such social units in making the rules, customs and laws necessary to preserve the integrity and growth of them. These must conform to the natural laws, always governing the evolution of such bodies, or they will not produce the objects of such organizations. The law of contract is a natural law, for without the fulfillment of contracts, no society could long survive. The laws for the protection of person and property are natural for the same reason. Without these society could not exist. This is why human law must conform to natural laws. The natural, under the principle of evolution, is that which produces only the essential things in the preservation of the cosmic process, and strong, enduring aggregations of mankind, are among these essential things. A civilization, adapted to the intellectual and ethical development of the members of it, is evidently that form of society which will give the greatest strength to the aggregate, and the most happiness to the individuals. Every custom, rule, regulation, or law that will work toward such a civilization is a natural law, while every one, that retards, or opposes the coming of such a civilization, is unnatural.

In the physical world the laws of the indestructibility of matter, the conservation of energy, of condensation, of the attraction of gravitation, evidently are essential to the integrity of the universe. Should there be any power which could, and would change one of these laws, the effect would be disastrous to the whole. It is the same in human affairs. Those laws which work for harmony, and what is called righteousness, are natural sociological laws, and those that work for dissolution, 
or inharmony, are unnatural. It is evident that those laws, that receive the assent of the greatest number of the units of a society, are the ones which will hold such a society together, and will produce the greatest strength. Slavery, oppression, witcheraft, magic, sorcery, are entirely human, there are no such things in nature. Should human institutions cease, these delusions would cease with them. The farther from natural law society departs, the more deluded it is, the more fragile, and less permanent. Human law may give one man special privilege over another, but natural law leaves evolution to act only by general, not special methods. There is no repeal, nor amendment to natural law, because no error has been made in the first instance. Human law is a history of error and amendment, or trial, failure and renewed effort. But science discloses that evolution has been continuous under the same law always; that matter is indestructible, force is persistent, the same effect always follows the same cause, that no natural law has ever been suspended for an instant to correct any error, or to favor man, or any organism, or to relieve him - from his necessary response to an unchanging environment. These are the reasons why the rule for our guidance in this life should be based on our knowledge of phenomena. One defect of human law is that it is so full of misconceptions of this principle. Our courts follow the precedents whether they are equitable or not, and lawyers keep up the sacredness of statute law and decisions. Our lawyers say this should be a government of law. But it should be a government of equity, which it-will not become, until laws are equitable only, and shall be construed between litigants, on the basis of equity, or what the people conceive as equity. The present unrest concerning courts, and their decisions 
have this as the eause of it. As long as a lawyer who has a ease important enough to justify the eost, ean go to the legislature before filing his eomplaint, and have a law passed to fit his ease, so that a judge will have to decide in his favor, whether he is right, or wrong; so long, will the people hold legislators, and judges in little respeet. No wonder the people are struggling with sueh lawyers and legislatures to obtain the reeall, the initiative and referendum.

Altruism.-The psychology of the Christian doctrine of unselfishness, or altruism, or the principles of kindness to, and preservation of, the community as a whole; - the establishment of insane asylums, eharitable institutions of all kinds, orphan asylums, care of the blind, and deaf and dumb, is a study of most profound interest. Little of this was found in savagery, more in barbarism, and most in civilization. It is a growth parallel with the evolution of cerebral power. It has developed, hand in hand, with wealth accumulating power. The red Indian, who lived from hand to mouth, who roamed the forest, or prairie in pursuit of sustentation, who lived in movable tents, eould not eare for the aged, or disabled. They were abaniloned to their fate. In his loose ties of tribal assoeiation, he could not develop the idea. He could not coneeive, with his relatively small brain develop. ment, the abstraet prineiple, that, until he exereised unselfishness, there would be none extended to him. But when the Aryan and Semitie raees began farming, and raising domestie animals for food, wealth began to aceumulate, closer ties of citizenship were formed, eommunities became loealized, and the hard struggles of savagery, and barbarisnl, gradually passed away. Then unselfishness, or local morality, or limited altruism 
grew rapidly. The Golden Rule was soon established as a principle, long before it was formulated in words, although constantly violated. Then it became easy to establish a religious cult, founded on that principle. The conditions, such as the greater brain power, and the ability to accumulate wealth, after the smelting of iron ore was invented, and marriage began to be founded on sexual love, and not mere passion, were brought about by natural evolution. The Christian religion grew out of these conditions. They were not male by the religion, but the natural conditions made the religion. It is not an intuitive principle. If it had been implanted, and not a result of physical evolution, it could have been implanted in the savage, or primitive man, as well as in the Aryan or Semitic race, at the time it appeared. But the primitive man was not prepared for it, by previous industrial development, and therefore could not comprehend it, nor adopt it. Altruism which includes all unselfishness and ethics, can only arise when nien see the necessity of doing away with war in all its forms, and when the true value of life is comprehended. It is conceived, only when peace is discovered to be more economically valuable than war. In order to maintain peace, cruelty, oppression, and all forms of selfishness, must be either entirely abolished, or exercised in such a way, as not to appear to the victim, as such. In order that men may live and thrive together, each individual must concede many of his individual rights and desires to the maintenance of the bond of community. This inspires him with an unselfishness which grows, as his conceptions of what is best for his own welfare, reveal to him, that this means the welfare of the community at large. As he grows old, he needs 
the care of others, therefore, he cares for others. He and his are liable to become insane, or if the insane generally are left to roanı at large, his life is in danger. therefore, he contributes to the establishment of insane asylums. In short, whatever preserves the integrity and strength of the community, contributes to his own comfort and health. This is the principle at the bottom of the evolution of unselfishness and altruism. It is not a condition produced by the reason of man, but the reason is the product or effect of the conditions. Man is forced to reason thus, when he is able to perceive that nature so operates, and his preservation and perpetitation require him to reason thus. After the principle is once fixed in the mind of man, and he has thus reasoned for generations, man naturally increases the forms or phases of it. He then invents many subtle forms of altruism. The forms of public charity, and numerous societies, organized for its application, are constantly increasing, and these give plausibility to the contention that man's reason. and his religion, are changing the natural law of evolution, in the survival of the fittest. But the principle itself was first established by natural evolution. As society becomes more complex, so does the growth of the principle become more complex. Just as nature first established the principle of the birth and growth of organisms, and afterwards man invented the garden, and farm, where, by artificial selection, he has produced variations of both animals and vegetables, unknown in the wild state, so he has produced variations of the principle of natural morality in civilization, unknown to primitive tribes of men. But in both instances his method, or reasoning, has always been derived from his correspondence with the laws of nature in doing the same 
things. He cannot depart very far from nature's method until there comes failure and disaster. However much his liuman sympathy may lead him to lighten the weakness of old age, he cannot make it young and strong again. However much he may protect the insane, the blind, the deaf and dumb, he cannot prevent the same causes that brought on these abnormalities from continuing to bring them on. However much he may try to make the weak equal to the strong, in perpetuating the race, and molding the world, he always fails to thus reverse the law of evolution. So that, however much it may appear to us that man's efforts or reason have introduced a new principle opposed to the law of evolution, in the natural survival of the fittest, yet it is not so, in reality.

All the scientific efforts of the hydraulic engineer to carry water to the arid land have had no effect on the natural law that water must run down, and not up. Neither can the efforts of man, to mold society, affect the principle of "matural selection in the survival of the fittest." The farmer, in the semi arid region, when he has carefully tilled the soil and raised several crops, frequently thinks that the rainfall has been increased thereby. If this were so, then the efforts of man would control a seeming law of nature. He has only succeeded in utilizing the former amount of rainfall, and not in increasing the amount of it The average rainfall, at any locality, will likely remain what it is now, however many trees are planted, or whatever may be the area cultivated. Irrigation has been practiced for two or three thousand years, on the lower Nile. But the rainfall there has not increased.

"Self-sacrifice is no less primordial than self-preservation." (Spencer). The view must be taken that life and 
morals, as well as "mind," are natural products of antecedent natural causes.

The dependence of each organism of the innumerable host, upon all the rest, compels it to regard, by the very deepest law of nature, the welfare of all. This is altruism in the highest degree. Conscious altruism in man, arises from this law. But when an organism rises to the complexity of man, whose psychic life is so complex as to appear as "free will," the units combine into society for self protection by the like natural law. and thus conscious altruism arises naturally from the necessary dependence of each one upon the all. Thus ethics and altruism naturally evolve from antecedent, causes that are perfectly natural. It is the survival of the fittest that makes at first the family, then the tribe, then the state and the nation, ending in the highest form of religion, the brotherhood of man, and even more than that,- the unity of all nature,- - the absolute dependence of each unit, upon the well-being and adaptation under the existing law of evolution of every other unit.

"Nothing in the world is single

All things by a law divine

In one another's being mingle.'-(Shelly).

Man is only a product of elemental morality. . In him it finds its highest expression; but without the natural morality accompanying all the forms, whether inorganic or organic, from which man has evolved, there could be no such organism as man.

The Future of Social Evolution.-The civilization of the past was an evolution by natural selection, or the survival of the fittest, handicapped by superstition and credulity. It was at every stage an adapta- 
tion of a limited intellect to a correspondingly limited environment. The defects of the present form of it can be accounted for, on the same principle, and they cannot be claimed as not defects, because of their historical persistency. So in the same manner will the civilization of the future be evolved. It seems that the evolution toward the natural will be much more rapid, in the future, than it has been in the past; because of the numerous scientific truths revealed to the people, and because the number now doing their own thinking is so much greater than ever before. When the thinkers and reasoners become numerous enough, the less informed majority will follow in the same line of thonght. It will be necessarily a higher and better type of civilization, and at the same time there will be a very much higher or a more scientific conception of man's relation to the universe. It is probable that the order of evolution will be:

First:- A better system of education, wherein biology. psychology and sociology, especially the bearings of these sciences on the relfare and happiness of the human race, will replace all the fantastic and unreal, in the present system of education.

Second:-Following the above, but apparently coexistent with it, as the intellect expands by such studies, the idea of the personal in natural and human phenomena, will give place to the idea of the natural and impersonal,- - the inductive method of dealing only with facts. A brain will eventually be evolved whose "pure experience", will, as Avenarius expresses it, be "deproblematized". In other words, it will perceive only an object. a fact, or a condition that is true; a perception that will be common to all sane people. Delusion will have disappeared. 
It will be observed that the natural code of ethics consists of man's constant readjustment to his environment; in other words, his reactions to constant impressions. These are as numerous and persistent almost, as his heart beats. They must be regulated by the correlations made by these impressions in the brain, and constitute the aggregate of his life and habits. It is thus apparent that these cannot be reduced to a universal written code. The details must be left to the local laws and customs of each community.

There is too much difierence in the structure and function of human beings to expect that the same customs will obtain in all.

The principle alone can be stated in a treatise like this. Each response to an impression must be that which will best meet the requirement of the law of evolution, the survival only of that which is fittest under all circumstances for the welfare of the race, even to the sacrifice of the individual.

Righteousness, including ethics, will develop incidently and equally with the above-mentioned forms of successive evolution. A man's proper relations become apparent to him by scientific study in psychology and cognate science. It will become equally apparent that the highest ethics will be man's best correspondence with that wide environment, with which the intellect of man is capable of coming into correspondence; or, in other words, the natural use of all the functions he now has, and those he is likely to acquire in the future. 


\section{CHAPTER XI}

\section{A FINAL WORD}

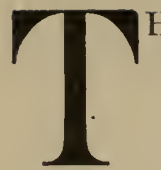

HE foregoing chapters contain only the merest outline of the great principles of universal evolution. Each chapter could be elaborated into a volume of facts of current events, in proof of the principles. But, in a popular treatise of the subject, space will not permit. It will be well, however, to succinctly retrace or summarize the argument in as brief space as possible.

In the universe of phenomena there are only two phases-self and not-self. The perceiver, and the objec- . tive phenomena perceived, are the fundamental aspects of one great truth,- - the integration and dissipation of some thing, which, for a better definition, we divide into two aspects, called matter and motion. But scientists are fast concluding that they are one in reality, and that one is motion. The hypothesis has been formulated, that whatever this oneness of matter and motion may be, it probably had no origin, and that, in its primitive state it was in the form of nebulae of attenuated gas, from which, by the laws of energy, the present solar system, and all systems in the universe have been evolved. The original nebulae were composed of atoms which are mere centers of energy. The fundamental property of these centers of energy, is condensation.

Hence, the condensation of the nebulous matter into the globes, now moving in space, and all the phenomena, thence resulting, have been simply the operation of a principle, immanent in the matter itself. The 
globe, on which we dwell, is a condensed portion of a nebula. The sun, and the other planets of the solar system, including the asteroids, are the remaining parts of the same nebula. The sun is still condensing, and the heat of it is produced by the arrested motion of the atoms, in process of condensation. All these bodies are composed of essentially the same elements; and these elements are the chemical combinations of the original centers of energy, in proportions varying, with the nature of the resulting element. After the earth had attained its present outlines, density, temperature, and differentiated its components into what are commonly called solid, fluid, and gas, that is, into earth, water and air, life began to appear in the lowly forms of vegetation. From this humble beginning, all the forms of the vegetable and animal kingdoms, have been slowly evolved. This evolution has occurred from the comparatively homogeneous, in apparently an undesigned progression, from the simple to the complex, not in a straight and unswerving upward line, but by rhythm of motion, which seems to be functional, and universal, in all natural phenomena.

This progressive evolution, of life forms,. is accomplished by the methods of heredity and variation, followed by natural selection. These laws operate effectively in producing more and more complex organisms, by eliminating the weak, by a process which we call death. That is, by integrating matter into forms, and dissipating it back into its former condition. A constant alternation of development, by integration of matter, and death by dissipation of it, during which the motion, or function accompanying the two opposite methods, undergoes the reverse process, has been going on from the formation of the first vegetable cell to the 
present time. This integration of organic matter occurs by a multiplication of cells, and a differentiation of the growth, into the heterogeneousness of organisms. Thus, the great variety of species, now existing, have been produced by the adaptation of an occasional variation in the anatomy, and a corresponding variation in the physiology, of the hereditary form. Whenever the variation proved of benefit to its possessor, in its struggle for existence, that organism proved more likely, than its less favored companions, to live and multiply. This is the principle of natural selection, in the struggle for existence, and is the theory now generally held by scientists, as the one most likely to account for the origin of new species.

The evolution of what is called physical life has long been recognized, and acquiesced in, by the scientifically educated, but for a long time after this acquiescence, the psychical life was still deemed unexplainable by natural laws. Modern psychology, however, has demonstrated the dependence of psychical, or as formerly called mental life, upon the physical, and that these phenomena are as much under the operation of natural law, as is physical life. This is so, whether psychology is to be considered a science in itself, or a branch of physiology. Whether we view mentality as like, or unlike, the condition we call matter, yet the facts show that they are inseparably connected in function. They so perceptibly fuse that it is impossible to distinguish the line of separation. Matter, whether in body tissue, or in brain cells, is made up of centers of entrgy. The explosion of these centers, in the brain, releases the energy in the form of psychical phenomena. The substrate of mental operations, as Wundt calls the nervous structure, is a form of specialized matter, and 
passes through certain motions simultaneously, with every psychical phenomenon. This phenomenon is so closely connected with the motion of the nerve tissue, as not to be distinguished, as a scparate existence. The complexity of the matter is perfectly parallel, with the complexity of the phenomenon. The effect of the molecular motion or the releasing of potential energy, of the living nerve tissue, is the mentality, and without this motion it is not apparent to the senses. In fact, we do not perceive anything in the operation, except some material facts, i.e., the movements, of the material body in thinking, in articulating, or writing words, or in muscular motion. The whole perceptible operation of reasoning is the production of images, and the fusing of them in the brain cortex. These images are produced by objective things, the sensations of which are carried by molecular motion, or a movement of nerve elements, similar thereto, to the brain.

So, it is of the utmost importance, that the phenomenism of consciousness, be largely considered in its relation to its substrate of neural structure, and in its conformity to the natural laws of evolution. For, if it is a function of neural structure, and, in its more complex and obscure form, is never manifested, except in connection with a like complex and obscure physical structure, well known to brain anatomists, as the cerebrum, then it must be deemed as much a product of natural evolution as the cerebrum is. Here science finds, as in the physical realm, only phenomena, and postulates only a reign of natural law. Not only the normal workings of the psychical life, but the abnormal phenomena, such as illusions, hallucinations, hypnotic states, somnambulism, etc., are shown, by the experiments of the psychologists, to be explainable by natural 
law. The idea, that any psychical phenomena, although so faint as to be called subconscious, and therefore very obscure, can have a doubtful thither side opening into a supernatural realm, is a surrender of the postulate of the universal reign of natural law, in all phenomena.

All real progress in human affairs is a natural process of reasoning, by which one is converted to a new belief, from a former abnormal one. Reasoning is the fusing of images naturally made upon the brain, whether real; or hallucinative. Whatever appears other than natural in the psychic process, can be paralleled by the mystery once surrounding certain physical phenomena, whose natural cause is now well understood. Since modern psychologists have written upon these subjects, all thinkers have modified their views of them. "Faculties" have given place to "brain function." "Mind" and "soul" have been renamed "consciousness." “Reason," “Memory," "Imagination," "Will," are presentations, or images fusing with immediate sensations, forming physiologically, those psychological effects named perceptions, conceptions, and ideas. Some psychologists are substituting "immediate experience" for the term "consciousness." "The self" is no longer an entity that thinks. "I think." as a phrase, is imperceptibly fading into the more logical, and rational, "it thinks." - being the reactions of the brain structure, to sensations and images. We recognize, not by intuition, but by the physiological exercise of the old-fashioned senses of touch, sight, hearing, taste and smell. Our instincts are inherited automatic reflexes of nerve structure. In short, all former so-called mental acts are the reactions of the brain centers to sensations, by which, such 
centers are indifferently excited to produce images of former like sensations. These latter images, fusing with the immediate sensation, produce a new, and different image, which is the idea, the perception, the conception, and abstraction, or the motor action. Of course, there are idealists, who refuse to believe that these psychic effects can be produced by the machinery of the nerve structure. They say, the psychic phenomena are accompanied by a nerve motion, but the two are only parallel, and simultaneous, that the two operations are independent. They say that a machine, that turns out a piece of cloth different in pattern from the material put in it, is not the maker of the pattern. But a machine made by human hands is altogether different from the human brain. For convenience, we call the brain a device, but it is a natural growth, not made with hands. It is a self-acting. organism. But a macline is not self-acting, and has to be operated by a human brain. Of course, then the human brain is the maker of the pattern turned out by the machine. But if the brain is the maker of both the machine and the pattern, it can also make its own ideas. The eyes, which see the making of the machine and the pattern, do not see any hands making the brain and its ideas. The evidence, in the one case, is not applicable to the other. There is no parallel.

The limitations of human knowledge are the results of man's inefficient nervous structure, and its limited correspondence with environment through only five peripheral sense organs. These sense organs receive impressions from phenomena only, and are limited to them. The images resulting from these impressions formed on the cortex of the brain centers, and fusing into perception, conception, and reason, are not the 
images of the reality but of relativity only. We perceive what suffices to us for the thing itself, by certain attributes, or properties, such as, form, color, resistance, motion, sound, odor, and taste. The thing, thus defined, is real to the perceiver, and is the "thing-initself" to us. We know ourselves by the functions of our bodies. What we have been calling "mind" is not an entity distinct from the body, but is best perceived as the psychical function of the individual organic body, considered as a phenomenal ego. Consciousness is a condition, ever varying, produced by the images above spoken of, forming, and reforming, in the sensory centers, by the incidence of objective energy.

How LANGUAGe Is Evolved.-In ordinary conversation, and in nearly all literature, the mind is spoken of as a producing entity, distinct from the body. Language, descriptive of this phenomenon, has been evolved from this conception. That is, there is very little language capable of expressing other than the idea of entity, and the power of that entity to produce the psychic phenomena, every moment observed. For instance, the phenomenon of "absentmindedness" is ordinarily spoken of as "the wandering of the mind." That is, it is a thing,-an entity, - that moves away from the body, or, at least, leaves the object, to which the eyes, or some of the senses, are directed. This language does not express the psychical phenomenon taking place, because the present conception of that phenomenon is of such recent origin. That is a process, unconsciously and instantaneously occurring in the appropriate brain centers, but which, in consequence of its being heretofore unknown to the real makers of language, viz., the masses of articulate be- 
ings, requires a new application of words, in a very unusual, and long drawn out combination. In reading a book, for example, the flow of thought is maintained, by a constant succession of sensations of words, first on the retina, and thence transferred, by the afferent nerves, to the optical centers of the cortex, upon which the image of them is formed. These sensitive images call up, or excite, by the law of association, other similar images; but connected, or fused with these latter images, are all the images of former sensations called experiences, with these same words, by which the meaning of them have been derived; such as the touch, and reading of books, the hearing of definitions of teachers, and all the mechanism of school education. The memory images, render the meaning of words and sentences, clear to the reader in proportion to his former experiences with the subject, about which he is reading.

These images of former sensations, by similarity, and contiguity, having fused into a new associative image, heretofore called memory, which being similar to the image immediately produced by the present sensation coming from the book, fuses also with that, and the two images form a resulting image, called a perception of the ideas of the author. This is the continual psychical process of forming thoughts upon, not only the contents of a book, in reading, but upon any objective thing, capable of producing a sensation upon any peripheral sense organs, and through them, upon the brain. It must be plain, from this explanation, why it is so difficult for the young child to learn to read. The child is lacking in memory, and former experience; therefore, no image of memory is aroused. Now, if the associative image thus formed upon the matured brain, from past experiences, happens to be 
so dissimilar to the present sensitive image, as not to fuse with it, the resulting perception of the idea, intended to be conveyed by the language of the book, does not take place, and the attention is absorbed with the non-fusing image of memory,-the mind is said to "wander from the subject." It is plain, that the latter term being based upon the conception of the mind, as an entity, which directly produced the conception, is comprehensible to every one who takes this view of the nature of the mind, and that means the great mass of the people. And being concise, as well as comprehensible, it is the one commonly used. But it is founded upon a misconception of the phenomenon. It is further plain, that until the majority, of those who make, and use language, comprehend the scientific, and actual process of the nervous functioning of thought, and reasoning, there will be little effort to frame a language that will convey that idea, in the short method expressed by the term "the mind wanders." But the evolution of language is trending in that direction. The evolution follows the idea, and something like this will express the true idea, viz., instead of saying "the mind wanders", it will be, "a new image absorbs the attention." But this will not occur, until the principles, of physiological-psychology, are nearly as well understood, as is now the ordinary conception of the mind. This process of making language is illustrative of how all language has evolved. The same argument will apply to all phenomenism. The scientific view of all phenomena must replace the present views, before language can be changed from the present short cut, but expressive terms of present perception, to equally short cut, and expressive terms of a scientific perception. There lies beneath the conscious- 
ness of a mature person a slumbering knowledge, that is aroused only by the image of the words, so arranged, as to embody the elements, or at least one element, of that knowledge. This sub-consciousness or sub-attention, is the result of former work, in investigation of analogous theses,--the residuum of education in science. It is evident, that language has cvolved from perception and conception. Words symbolize the "pure experience" of the mind. Lower animals reason in their way, and convey ideas without articulate, or written words. But there are forms of reasoning in its higher human conditions, that would seem to be impossible without language, with which to make, and hold, the psychical continuity. It seems that the language succeeds, not precedes, the conception. Some authors contend that "the schematic products of ideational construction," meaning the higher ideas of normative science, cannot be produced without language, as an instrument of analysis, and synthesis. Of course, we could not have any evidence, of the product of any thought, in the brain of another, without the physical marks expressive of those thoughts; and there is no way of expressing the ideational conceptions apparently formed in the cerebrum, except by spoken, or written language. The simple ideas of primitive man, confined almost entirely to simple concrete things, no abstractions, could be conveyed by manual signs, and very few short words. But, just as the ideational centers of the cerebrum, and the conceptional psychic phenomena of the human organism, are simultaneous in appearance; so is language simultaneous in evolution, with "the schematic products of ideational construction," that is, those ideas which arise in the nerve tissue without external stimulation. We do not, first, 
manufacure a language suitable for the expression of the ideas, and then mechanically fit the idea to the language; but the brain centers, the idea, and the means of expression are evolved, without our cognizance of any orderly succession. This conception is in harmony with the theory of monism in all evolution.

One of the most interesting and significant phases of evolution is that of language. By a comparison of the carly, with the later dictionary, for instance Noah Webster's with the Century, this fact will be very striking. The larger number of words in the latter, means the great evolution in the last fifty years of the perceptions and conceptions of the users of language. This is especially so in scientific terms. An American Indian, whose conceptions are confined to his physical needs, which are as simple, almost, as those of an animal, will carry on a conversation with another Indian, without the use of an articulate word, by the sign language alone. But he will use no abstractions, or generalizations. His whole vocabulary is confined to the concrete nominals and the simplest verbs. From that language, to that of William James, in his lectures on pragmatism is a wider stretch, than from the wagging of a tail, and the bark of an intelligent dog, to the sign language of the Indian. Such an evolution in language is significant of the mental evolution between the gens of savagery, and the civilization of $\mathrm{New}$ England.

Untrained minds are incapable of understanding the meaning of a profound treatise. Words alone cannot convey the meaning, without the previous work in the intellectual field. A trained mind is therefore in correspondence with a more complex, and subtler environment, one that brings to such a mind a wealth of 
discernment, and comprehension, far beyond the reach of those less educated. But there must always exist a structural adaptation to such training, before the organized memory can be established. Otherwise the conceptual images will never,- -however long and arduous the training,--coalesce into reason and will. Hence the substrate, as Wundt calls the nerve tissues, is the all-important, and abiding thing, in psychical phenomena. If this structure is lacking no amount of training will suffice to make potent the psychic phenomenon. Neither will the cosmic energy that assumes, through the persistence of force, such a multiplicity of effects in nature, ever assume the psychic form, now commonly called the human mentality in this highest form of organized memory, unless by way of nerve tissue in the cerebral centers.

Phenomenism.-Phenomenism is the psychological condition existing in the "mind," being the correspondence between the individual and his environment. It is also defined as "self" and "not-self." "Not-self" is the realm of phenomena objective to our sense organs, and reaches all things making sensations, or images on the brain centers, from the rays of the farthest fixed stars, to the subtlest reasonings, and the most esthetic judgments, as well as the most altruistic relationships, implied in the expression,- "The Brotherhood of Man." Therefore, it is this realm of phenomenism that receives the direct attention of consciousness. It is the really knowable. To keep in proper correspondence with it, is the highest wisdom, and the only preventive of illusion and delusion. He who confines his attention to it is sane. The insane are those who claim correspondence with things, that have no objective existence. All life depends on correspondence with phenomena. In this 
sense, the term life includes every phase of physical, and psychical phenomena, viz., those aspects of life treated in biology, psychology, sociology, and ethics. There is unity not only in body and "mind," but in the laws of society and of ethics. The scientific definition of one is the proper designation of all. Therefore a sensible code of ethics is the natural correspondence of self with notself; just as the proper definition of social law is the correspondence between each individual, and that part of his environment, included in the term mankind.

Beliefs Founded on Phenomenism.-The beliefs of man depend upon the development of his brain structure. His discrimination, between the true and false, depends upon the images recalled by sensation, in the higher centers; and the coalescing of these images into other conditions called perceptions. It is a process of reasoning, which depends upon the quality of the brain, and the perfection of his past experience; that is, the quality of his education in the past. But the education of the past has been largely confined to either immaterial things, or fanciful objectivity, or to the realm of the unknowable. Fiction has occupied the brain too frequently. Mankind has been in the attitude of childhood on all of these questions. It readily believed anything concerning the different phases of philosophy, that was solemnly asserted by either writers, or speakers, who appeared to have a little more learning and boldness than the masses. This condition, of helpless mental dependence, is the same as that of childhood, which believes in the actual reality of Santa Claus. The child grows out of this belief, and is finally convinced that the saint of gifts is only a subjective generic image of a generous, but natural giver of good things, because reason takes the 
place of emotion. The same knowledge will come, in time, to the brain of mankind, concerning all purely subjective ideas. It is not required, that psychical phenomena should be given a final cause in order to impress their power, beauty, utility, and adaptability upon man. Natural cause and effect are the great facts of life.

There is now an environment of scientific literature upon these questions which fifty years ago did not exist, and more and more of attention is being given every year, by students, to natural phenomena. While much of former educational influences still lingers, even in the methods and ideas of the ablest scientists, yet the leaven of phenomenism is working.

The Essentials of Knowledge.-One of the essentials of human knowledge mentioned, is, that impressions must be made, upon the peripheral sense organs by real objects, as a prerequisite to knowledge. In the mature mind, the idea may be initiated in one of the neural centers; in which case, it will be some form of a former peripheral sensation, and will take the form of an image, objective to consciousness. In the infant brain the image, other than color, is comparatively meaningless. But, in the mature mind, it immediately excites a molecular motion, which produces another fainter image, similar to the one produced by the sensation. The whole process, down to the final perception, is so instantaneous, as to be unconscious, and therefore impresses the ordinary brain, as being not physiological, and natural.

Said M. Taine, "Just as the body is a polypus of cells, the mind is a polypus of images." Each sense forms images, on its appropriate brain center, these sensory images being visual, auditory, tactile, and 
motor. The type of the image resulting, from the fusing of these images, i. e., the percept, depends upon the type of the organism. The degree of perfection of the nerve structure determines the type of the image. The images, are the same as the feelings, and are the result of a process of nerve molecular motion.

"To know, to understand, to explain, to know the why, and the how of things,-all this culminates in an act of vision." (Alfred Binet.)

But, if the image is an essential element of human knowledge, it must be produced by a sensation, from what to us, is a real thing. How then can the induced hallucinations of the subject of hypnotism be explained? The experimenter in hypnotism makes the subject see, or feel, or hear, a thing that does not exist. Likewise the hallucinations of the insane are real images produced by the diseased conductive paths of association, upon the brain centers. When insanity exists, it is an abnormal working of the molecules of the brain, in producing images. In such case, the image will be an abnormal one, that is, a defective, or untrue pattern of objectivity, because the psychical device is out of order, by disease.

In the subject of hypnotism, who has a weak brain, the first image may be produced on the auditory center, by the suggestion of the operator, e. g., that the subject is a king. The conductive cross fibres from the visual center are immediately excited, by the auditory image, to produce any former experiences the subject may have had by having seen, or heard, or read of a king, and his retinue,-in short, all the accompaniments, and surrounding of royalty. The variety and complexity, of the associative image, will depend on the intelligence of the subject. The absurdity, and 
incongruousness, of the image, that is, its departure from the normal, will depend on the degree of lesion of the brain centers, excited to the production of images. The voice of the operator is the exciting cause.

Binet and Feré have proved by experiments in hypnotism in the Saltpetriere at Paris, France, that the hallucinations are images formed upon the sensory centers, not true, of course, but they are immediate experiences of the deluded subject. It is the same, witl illusions of the sane, e. g., when one person is mistaken for another. The similarity of the immediate sensory image formed upon the visual center, to the one it recalls from memory, produces the conclusion that they are one and the same, by the two images perfectly fusing. The illusion is not dissipated, until a new image, formed by a closer inspection, produces a new, and truer, perception of the true objective. But the hallucination, whether produced in hypnotism, insanity, or in mistaken identity, brings no knowledge, because it lacks the essential element of truthful objectivity.

The importance of this process of sensation, and images, resulting from the conveyance of the sensation to the central cortex, and to the memory of former sensations, cannot well be overstated, because memory replaces the absent sensation, and is thus a supplementary sense. It is also reasoning, freed from the condition of time and space. Memory is the seeing of the past, as if it were in the present, and reasoning, being a passage from the known to the unknown, is seeing the future. There could be no reasoning without memory. Perception, being thus the known product of three images, is parallel with the three terms of a syllogism, and is thus reasoning logically, and the same as knowledge. 
The Nature of Consciousness.-When one sees, and touches, a thing, the experience is of the thing, or fact, or problem, not of the image on the cortex of the brain. Whoever harbors a delusion as true, is passing through a "pure experience;" as much so, as one who sees only the true. As to the contention of some idealists that the image, or presentation, is the only real thing, this conception ignores continued external existences. The idealist's position is that an object under study in any of the physical sciences is merely mental. We do not know the object, but only the mental conception of it. This seems to imply that we have no proof of existences. The materialist holds that our sense impressions are satisfactory proof of external existences, that these impressions would not occur unless they were made by existing things. It seems that this theory, viz.: of idealism, does not take into account, that the forms and substance of the environment remain, and make the same impression on successive generations of sensuous organisms, and that history is the product of these repeated conceptions, identical in facts, impressing the senses of succeeding generations of men. The impressions from the same forms are essentially alike to successive generations. The perpetual apparition of the physical universe persists to all organisms that have lived in the past, and that will live in the future. It is true that the only knowledge a single individual has of it is the impression it makes upon his sense organs, but that it exists as an objective relation to successive generations of men, and as the source of their impressions, is not only, a scientific view, but a common sense conception. Of course, the correspondence between the individual, and the objectivity, depends en- 
tirely upon sensations, or impressions. Berkeley contended that everything is "mind," or in the "mind." He conceded that things may exist outside the human mind, but that all things exist, in the mind of God, or in infinite "mind."

Evolution the Real Maker of Civilization.-Such civilization, as we have, is crystallized around the emotions of fear, in the first instance, and affection, as secondary. But mingled with the subjective conception of finality, and really underlying it, is the great natural principle of evolution that had been, although unrecognized as such, the natural force that had evolved the brain of man, through all its heretofore uncertain, and partial correspondence with natural phenomena, to its present more complex correspondence, in spite of its persistent hallucinations. As long as hallucinations linger in man's brain, the civilization is perhaps the best we can expect. At least, the advocates of evolution must assume that this artificial, and evanescent, but widespread human orientation, (the present civilization, with its hallucinations), is a condition, not incompatible, for the time being, with the operation of natural law, in the rapidly changing, and gradually enlarging, circle of human consciousness. In other words, it has its part to do in the natural interchange of matter and motion, which we call evolution.

History is almost wholly a chronicle of the delusions, that have controlled mankind. Some of these are monarchy, imperialism, militarism, constant warfare, almost universal slavery. Can it be that these were merely the mobile, automatic expressions of the varying limitations of the human intellect? If so, of course, they were better for the aggregate welfare, than the ill adapted,-an unfit higher condition of natural law 
and ethics. Yet, if the rulers, priests, and teachers, all through historical time, had comprehended, and put in use, a free democratic form of society, or government, in which the natural rights of man, as determined by the people themselves, had been enforced under the Golden Rule, even the ignorant masses might have been much more able, than they now are, to govern themselves, independent of hereditary rulers, and unfit codes. It must be understood, that a better and more intelligent comprehension of a code, and its sanction in phenomenism, will be evolved, only when the majority are ready for it intellectually. This change will be, and should be only gradual, in fact, so imperceptible as not to produce a single reaction. This is the way important evolutions take place. The ancestral line of man has gradually evolved from the lower to higher orders; not only in historical time, but in all time preceding that; from the formation of the first cell to the present heterogeneous organism, classified by Cuvier is bimana. There never was a period of that evolution, when the correspondence between the organism, and its environment, was perfect in a way that would be ideal. But it was the best for the organism at the time. It was this that maintained the survival of the fittest, and worked out in a natural way, the general rhythmical upward tendency of the line, toward its present culmination in complex man.

Methods of Evolution are Best.-This sentence is used in "Origin of Species :" "When we no longer look at an organic being as a savage looks at a ship, as something wholly beyond his comprehension; when we regard every production of nature, as one which has had a long history; when we contemplate every complex structure and instinct, as the summing of 
many contrivances, each useful to its possessor, in the same way, as any great mechanical invention is the summing up of the labor, the experience, the reason, and even the blunders of numerous workmen; when we thus view each organic being, how far more interesting,-I speak from experience,-does the study of natural history become." One can imagine, in comparison with this feeling, the comparative difference with which the naturalist views the history of an organism, in all its parts, useful or rudimentary, which he believes was created outright. Such an one does not try to find the genetic history of his specimen, for an origin given, shuts out all interest in any other; nor do extraordinary structures strike such a naturalist with any wonder or curiosity. As a classifier, Linneus must have had a tedious and monotonous round of labor, compared with the interesting investigations of Darwin, after the latter began to study organisms with reference to their affinity, by descent, and modification. The reader of the two naturalists can form a reasonable idea of this difference in their work, which perhaps would be similar, to the two ways in which their writings interest, and please the reader. The evolutionary theory is not only very much more attractive and entertaining, it is equally more reasonable, and satisfactory. It is interesting to know that species are constantly changing in form and function. The generation which will succeed the present one will be unlike, in several characteristics, the present one. We are living in the quarternary epoch. This succeeded the tertiary, and the flora and fauna now, is decidedly different in many ways from those of any preceding epoch. The earth is a little different in many ways. The present, or the past can never be 
repeated. A change will always be taking place. It it always a becoming, that will never be finished. It is well that it is so. If it were not well, the flux would cease, and a static condition, in which no change would occur would take its place. A mere statement of the two conditions shows how much more desirable the movement is, than the immutable would be. Our own lives are typical of the flow of reality. Life is an expectation, a reaching out, for something that is never so tightly grasped as to be held; it is an effort, which must satisfy us, because it really accomplishes that which it should accomplish, but does not accomplish that which we think it should. Our expectations are not quite in harmony with the becoming apparent in nature, but the becoming continues without reference to our expectations, and we are kept within the flux of things by a satisfaction, brought to our limited intellects, by the little round of organic functions, vouchsafed to us by nature. Our bodies are in the flux, while we are really unconscious of the cosmic movement. It is our glory, that we are part of nature and reality. We could not survive, as beings, if we lost touch with them for a moment. Our present, and ultimate fate depends upon this connection. We, and the universe, have one origin, and one destiny. Human organisms cannot be taken out of the general flow of reality, and subjected to a capricious, arbitrary, separate philosophy.

Creation.- There is creation, in one sense, but not out of nothing, it is out of something. This creation is an evolution of forms, by the rhythm of motion, and the laws of energy. These forms are never completed. they are constantly changing to other forms, and these to still others. This is the flux of reality, 
into which intellect has scarcely penetrated. But whatever it is, it is the best condition for our welfare. We seem to want the flow to stop, and every form to become fixed, so that our feeble intellects can have "time" to examine them, and take them apart by analysis, and put them together again in our own way, by synthesis. Any how, our philosophers seem to have formed their theories of the reality upon this method, not being able to comprehend, and control the real method. That is the reason that all systems of philosophy and science are mechanistic, and anthropomorphic. We are only capable of conceiving, that nature works as man works, notwithstanding, it is plain to sight, that what little of nature's work is done on this little speck of matter we call the earth is not done according to the plan of man at all. But, what is the philosopher and scientist to do else? Simply to adopt the most plausible theory, and then continue to reach out by experimentation, for one more plausible. So they, in their mental operations, follow the supposed plan of nature, in the flux of reality, always making, but never made.

The Real Benefactors of Man.-It is proper, that a few words should be said, in regard to the importance of the work that original investigators of natural phenomena are doing for mankind. The laws of nature are so necessary, to the life and knowledge of man, that he who makes a new discovery of them, is a real benefactor. These laws which are merely the inevitable succession of cause and effect in the universe, have heretofore been so little studied and known, that most mankind became indifferent through sheer ignorance. The phenomenon of life, on a globe like ours, being in unison with the other phenomena, is 
conscious of the close connection. How few organisms are aware that if this connection were broken for a moment the effect would be fatal. That broken connection is death to the organism. The more man knows, of the laws of this connection, the better he will be enabled to so adjust himself to the overpowering forces of nature, as to make his correspondence therewith one of immense benefit to himself. This adjustment is not only personal to himself, but must be done largely through the race, and the social units, which have integrated during the existence of man, by an unconscious law of nature, by which, like units, inorganic and organic, are brought together, in forms like the solar system, and organisms of life. Human societies, like tribes, states and nations, have established rules and laws for their own government, without any reference, of a conscious nature, to the cosmic laws. They have done this because they did not study natural laws; and perhaps in most instances, their intellects could not pursue the study with satisfaction. The result has been, that innumerable errors have been made, and are now existing. Those statesmen, who have come nearer than others, to formulating social laws for the guidance of people, in their aggregations, according to natural law, of which they were entirely ignorant, have been given great public honors, and are the subjects of history and literature. But when Copernicus, Galileo, Newton, Adam Smith, J. S. Mill, Darwin, and other great thinkers, made discoveries of true science, little attention was paid to them, by the people at large. The first Napoleon, having at first adopted the side of good government, by suppressing the French revolution, soon made himself a warrior, at the head of a French army to harrass Europe; and when victory 
perched on his banners, he arbitrarily made himself an emperor and despot. His downfall soon oceurred, because he was ignorant of the law of nature, that the strength of a social unit resided in the unit eharacters of the aggregate, just as it does in the atoms and crystals making up the bodies everywhere in nature. The aggregate body is nothing, but the strength of cohesion of the atoms. Napoleon had on his staff a naturalist, named La Place, who was the real discoverer and mathematical demonstrator of the nebular theory, of the making of solar systems. He taught mankind that the universe is a natural production, by the evolution of solid bodies, from gaseous nebulae. He started a revolution of human ideas, which is growing yet in strength. He brought man closer to his probable origin, and taught him that his welfare depended on natural cause and effect. But human history is full of Napoleon who sneered at the theories of La Place, and attributed every effect to a personal causc. That was a reason, unconscious on his part, why he strove to be a personal ruler of the world. But La Place whose achievements, compared with those of Napoleon, were infinitcly superior, remains in comparative obscurity, scarcely mentioned in history. The real bencfactors of mankind are the discoverers of abstract principles, which applied science is using, to increase human comfort and happiness.

When the people of the world evolve to the intellectual conception of natural cause and effect, to which they now pay so little attention, then history will be a chronicle, not of the infamous careers, and abnormal ideas of such as Napoleon, but of the achievements of such men as La.Place, Kepler, Newton, and Darwin. 
UNiversal Evolution.-It is thus apparent to the student of the phenomena of nature, that the universe has been evolved. Everything apparent to man, from the largest astronomical body, down to the minutest organism, has developed from centers of energy, so minute, as to be invisible, in the most powerful microscope. The principle affects every phase of every structure and function. In the organic kingdom not only has life been evolved, but also every feature, physical and psychical.

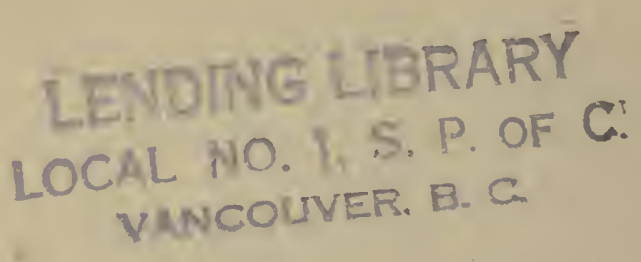




\section{INDEX}

Atoms, in constant movement, 10,11

have reason, 11,174

what they are, 12

Aluminum, an element of earth, 27

Arrhenius quoted, 31

on life germs, 36

Animals and regetables compared, 42, 98, 106

Advances, in physical sciences, 47

Anthropoids, and man one in structure, 50, 103, 178

Australian fauna, 60

Stationary since Cretaceous period, 62

Animals, under domestication, 70

have only organic tools, 119

Archebiosis, 94

Anti-intellectualism, 99

Abnormal mentality, 109

Altruism, how evolved, 115, 273

and natural selection, 138

Anabolism, 158

Attributes, evidences of reality, 296

Brain, aggregation of atoms, 12 cells in, fixed in number, 111, 113

have memory, etc., 167

effect of removal, 166

difference in brains, 130

Biology, its importance, 15 its development, 46

Bergson, Henri, 16, 17, 18, 99, $177,184,185,223$

Bichat, the great scientist, 46

Breeding organisms, 70

Bees, how propagated, 72

Big-horned sheep, 79

Bird's love of the beautiful, 83 Burke, J. B., 96

Behavior controlled by nervous system, 106, 107, 113
Binet, Alfred, 129, 130

Beagle, the voyage of with Darwin, 147

Baldwin, James Mark, upon an objective thing, 188

Beauty, no standard of, 241

Beliefs, founded on phenomenism, 292

Creative Evolution, 8, 16

Changes in the earth constant, 10

Condensation, the principle of matter, 22

Collisions of stellar bodies produce nebulae, 25

Chamberlain, T. C., and planetesimal theory, 27

Calcium, an element of the earth, 28

Concordance of planetary motion, 29

not perfect, but will be, 30,31

Cellulose, binding vegetable cells, but not animal, 53

Cell fertilization and growth, 54

Classification, of Cuvier and Linneus biblical, 40

more or less artificial, 41, 43, 44

object of, 45

significance of, 46

Cuvier, opposed evolution, 41

undermined, 59

created special order for men, 41

on the nervous system, 229

Chlorophylian power of the vegetable, $42,98,175$

Crystal development similar to that of cell, 54

Croll's theory of glaciers, 63, 64 Consciousness, how produced, 108, 111, 218, 219

what it is, 169,219 , et seq., 296

defined, 240 
Civilized environment, 132

Correspondence between man and environment, 157

Chittenden, R. H., quoted, 162 Colored children compared with white, 195

Cirilization, how promoted, 255,256

Christianity, its evolution, 274

Creation, out of something is evolution, 300

Darwin, Charles R., 7, 8, 15, 40, $45,46,48,59,68,70,82$, 103,268

Dualism, 12

Duncan, Robert K., 34

Darwin, Erasmus, conceived evolution, 40

Derelopment of an embryo, 53,54

Distribution, of vegetable forms, 63

Death, an important factor of evolution, 77

a change of form, 217, 243, 244

De Vries, 57

his work and theory, 89

not in conflict with Darwin, 90,102

Domestication, enhances intelligence in animals, 124

Dog, intelligence of, 124

Dreams, $12 \overline{5}, 126$

Descartes, 206, 211

Evolution, definitions of, 13, 14 not mechanism, 19

shown by fossil forms, 55 all forms of alike, $13 \bar{T}$ steps of, 254

an equitable law, 270

the real civilizer, 297

methods of, best, 298

Evolutionists, take for granted matter and motion, 16

Error, the conception of inharmonious working, 19

Energy, never lost, 22, 26 ever changing its form, 165 how ascertained, 23

work of phenomena, 23

the ultimate, 205

Environment, non-adaptive, 79 , 80

Elements of the earth

80 in number, 27

same throughout universe, 28

each gire distinct lines in spectrum, 28

Earth, its age, thickness of rocks and heat 31,32 Embryology, a proof of evolution, 36,46

England, result of social erolution, 153

of what it should consist, 193, 194

Education in schools, of great importance, 191

Ego, The, the human body, 210,211

the relationship of, 215

Ethies, man's normal adjustment, 238

no standard of, 240

not confined to man, 250

erolved biologically, 251

follows intelligence, 254

the principle universally applicable, 262

works despite opposition, 265

bears equally on all, 270

"First Principles" of Spencer, 8

Finality, 9

Fission, the process of developing organisms, 39,106

Formation, of types, 51

Fertilization and growtl of a cell, 54

by insects, 96,97

Fossils, 55

Fossil discoveries since Darwin, 58

and their significance, 58 
Fauna of Australia, 60

of Galapagos, 61

Fraunhofer, the spectroscopist, 174

Function, what it is, 199

illustration of it, 200 et sq.

Free industrialism, 255

Final word, 280

Genesis, the account of

ereation out of nothing, 14

Germs, eternal, 35

Geology, evidences from of evolution, 55

Geographical distribution, 60

Galapagos Islands, fauna of, 61

Glacial Epoch, its influences on species, 63

Girard, Alfred M., quoted, 90

Generalizations, how produced, 109

Genius, what it is, 114

Gens, defined, 252

Great Movement, in universal evolution, 257

Humanism, 12

Heat, lost by condensation, 24

IIaeckel, 37, quoted, 50

Heterogeneousness, 38

Huxley, quoted, 59, 75, 138, 158, $159,172,174$

Hybrids, 75

Heterogenesis, 94

Hunger, what it is, 119

Heredity, 132

Human law must conform to natural law, 154, 271

Hume, on mentality of man and animals, 177

IIypnotism, 294

Idealism, 7

Intuition, 8, 16, 99

Instinct, 8, 16, 99

hereditary, 113, 117, 120 and intellect differentiated, 235

Intellect 8 , as treated by Bergan, 99
Inorganic matter not inert, 10

Inorganic evolution, 20

Iron, an element of the earth, 27

Insects' nouths, 50

Immigrants to the United States, why they come, 66

how improved, 64,65

Images, on the brain, 111

Immortality, 244

Kant, Emmanuel, 28, 29

Kelvin, Lord, 31

Kingdoms, animal and vegetable merge, 42

Knowledge, defined, 170

confined to the useful, 203

Kirchoff, the spectroscopist, 174

Keller, Helen, why so intelligent, 193

La Place, 21, 28

Life, conditions of, 26

depends on the inorganic, 33,34

began in water, 34

theory of origin of life forms, $34,35,36$

definition of, 37

distinctive features of, 105

why different in form, 52

Lamarck, conceived evolution, 40

La Conte, Prof., 56

Loeb, Jacques, 96

Line of least resistance, 133

Language, the growth of, 186 et seq.

of the emotions, 230

how evolved, 286

Light, theory of, $\cdot 237$

Materialism, 7

Mechanisin, 8, 9

Monism, 9, 11, 159

Matter and motion, 9

Movement relative, 9

Man, not reality, but manifestation, 12

only a family in order of mammalia, 107 
why right or left handed, 115

a vertebrate animal, 44

anatomy of same as that of anthropoids, 50

his distribution, 64

his relationship to environment, 241

power- over nature limited, 72

how differs from animal,120 still evolving, 150, 176

his behavior compared with animals, 179

results of his upright position, 181

a natural product, 246

his relation to his fellow men, 249 et seq.

Mind, evolved entirely along practical lines, 13

the aggregation of feelings, 187

defined, 19

not confined to man, 107 , 172

produced by a nervous system, 107, natural, 169

not confined to the brain, 187

clearly allied to physical features, 53

its evolution materialistic, 122

its traits heritable, 123

its function, 157

property of all organisms, 172

depends on structure, 202

mind making, 189

Movement, the reality, 18

Moment of momentum, 22

Motions of stellar bodies, 25

Meteors, 27

Magnesium, an element of the

Moner, 37 earth, 28

Metazoon, 39

Mosphology, 48

Morphogeny, 52
Marsh's specimens of the fossil horse, 56

Missing links, 56

Method of evolution, 68

Malthus' "Principle of Population,"' 69

Mendelism, 100

Mental and social evolution, 105

Molecular motion of waves, 108

its nature, 157

Memory, how produced, 111, 194

Meyer, Max, quoted, 112, 115, $122,133,184$

Misconceptions, of the principle of erolution, 139

Mode of production, determines reason, 146

Metabolism, 158

Macauley, Lord, quoted, 163

Mill, John Stuart, on intuition, 208

Morgan, C. Lloyd, quoted, 215

Nothing is something, 9

Nebulae, immense in size, 21

Nebular theory, 21

Nebula of solar system spiral, 24

Neptune and its satellites, 30

Nervous matter, 106

its activity exhausting to the body, 229

Newton, Sir Isaac, and the falling apple, 202

Nature, makes no mistakes, 243

Natural Selection, its meaning, 73,74 , et seq.

illustrated, 79

its universality, 81

it develops ethies in all animals, 84

protective features, 85

a negative term, 87

"survival of the fittest" better, 87

not a conscious conflict, like a battle, 144

works upon mind as rell as matter, 107, 127 
Origin of the Universe, 14

none to matter and motion, 14

of species, 15

of organic matter, 95

Organic evolution, not a diversion from the inorganic, 20

followed in organic, 33

Oxygen, a large element of the earth, 27

Organic preservation, 160

Objective, the, 188

Organisms develop from egg cells, 36

Philosophy, schools of, 7

Physical and psychical law similar, 10

Paley's illustration, 19

Parallel between Nature's and man's works not apt, 19

Phenomena, the multiplicity of effects, 23

manifestations of movement 58

Planetesimal theory, 24, 26

Similar to the nebular, 24, 25

Potassium, an element of the earth, 28

Protozoon, 39

Paleontology, 55

Pithecanthropus, 103

Physical and psychical phenomena one in reality, 105,176

Protective features, 85

Protoplasm, the basis of life, 106

Psychic phenomena, 168, 217

Phrenology too local, 187

Proctor, Richard A., as to lost

Pragmatism, 226 consciousness, 224

Phenomenism, 291

Reality, or thing-in-itself, not useful to man, 13
Radium, 31

its wonderful power, 31,115

Rudimentary organs, valuable for classification, 45

carried by all organisms, 48,49

Romanes, on fossil forms, 56 on environment, 132

Reflex ares, of nerves, 110

Rulers, selected by natural law, 141

Ritchie, David G., quoted, 170 Race differences, 195

superiority of the Aryan and Semetic, 197

Righteousness, 251, 253

Reformation, progressed by the progress of freedom, 256

Religion, evolution of, 260

a universal method of, 262

Reason, limited, 127

a synthesis of images, 129

arrested reflex, 129

how it must act, 134, 142

a product of evolution, 143 , 194,284

Spencer's mistake, 17

definition of life, 37

definition of an idea, 159, 190

Sense impressions, 19

Sun, part of an original nebula, 22

many times larger than the rest of solar system, 22

Silicon, an element of the earth, 27

Sodium, an element of the earth, 28

Spectroscope, reveals the similarity of formation throughout the universe, 28

St. Hilaire, conceived evolution, 40

Schwann and Schleiden, established cell theory, 46

Schultz, Max, the basis of life is protoplasm, 46 
Similarity of parts in animals, 48, 50

Scott, W. B., quoted, 59

Special creation mentioned, 61, 62

Social units, subjects of evolution, 66

Selection, artificial different from natural, 71,72

Special forms of artificial selection, 74

Sexual selection, 82

Spontaneous generation, 94

Selenka's study of embryos, 103

School education, benefits of, 112

Second ehildhood, a profound truth, 120

Sleep, how caused, 125

Society, forms of, 145

Slavery, came with commodities, 149

Survival, of human laws, 152

Social erolution, illustrated by ancient manuseripts, 154 its future, 277

Superstition, specimens of, 161 Subjective, The, 188

Shakespeare, difference between his brain and the lowest man, 191, 202

Self, 206, 221, 222

Smith, Norman Kemp, on consciousness, 223

Self-conseiousness, 227

Structure determines difference between brains, 234

Smith, Adam, quoted, on rules of morality, 267

Thing-in-itself not practical or desirable, 13

Time, a change of forms, 18,37

Truth is what works, 19

is relative not absolute, 203

is the universe, 204

Types, formation of, 51

Tower's experiments with the potato beetle, 74

True species are wild, 76
Tissue, its renewal, 66

Thought, molecular motion of nerve tissue, 114

based on self-preservation, 160,230

not reasonable, 161, 214

reproduction of sensations, 168

none without brain and environment, 207

always accompanied by physical marks, 228

Thompson, J. J., quoted, difference between him and Bayson, 209

Toueh, the primal sense, can be called consciousness, 218

Unknowable Absolute, 8

Uranus and its satellites, 30

Utility of investigation, 103, 104

Unity of definitions, 239

United States, an example, 255

Volcanism, constantly in action, 10

"Vital Impetus," not known, 18

Von Baer, founder of embryology, 41

Vegetable and animal life, compared, 42, 98, 106

Von Mohle, named protoplasm as life basis, 46

Variation, a law, 57

adaptive, 59

of form, 92

Tigor, in offspring, 78

Venus's Fly Trap, 118

Vivi-section, its effect on psychic phenomena, 120

Verworm, Max, quoted, 163

Tissmanism, 39, 88, 100

Wallace, Alfred R., 40, 68, 150

Whale, The, a mammal, 44, 45

Wilson, E. B., quoted, 86

Webber, Prof., on Mendelism, 101

"Will", 129

Wasp, compared with man, 183 



\section{Date Due}

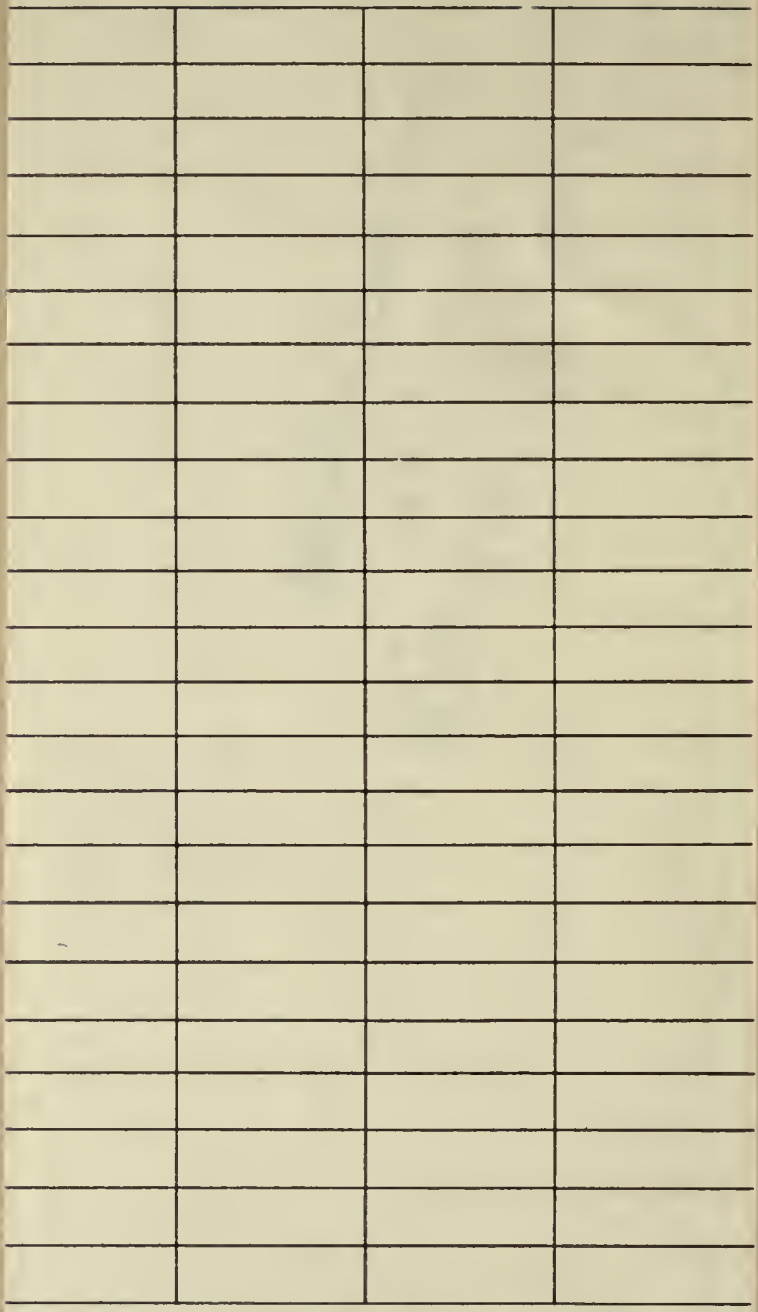



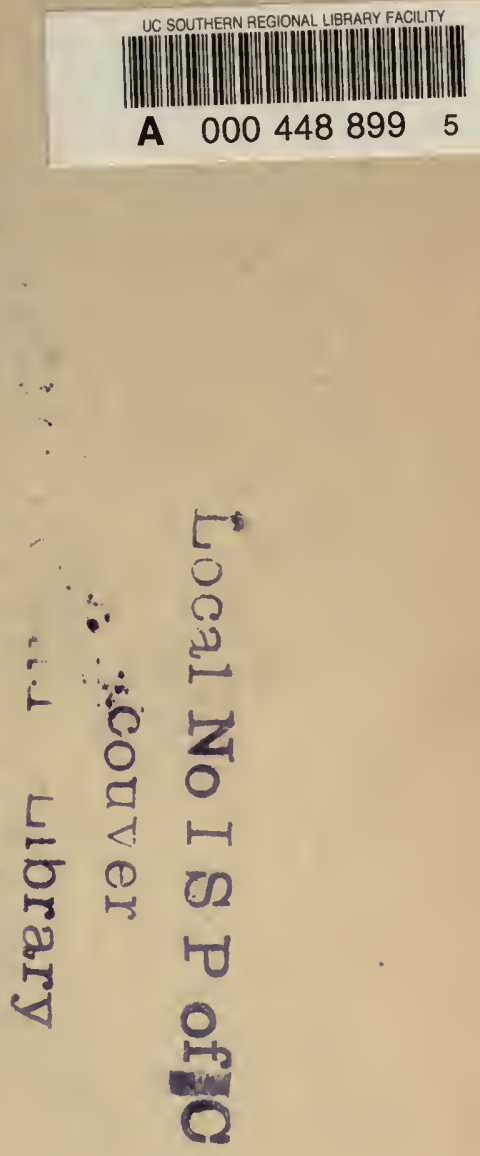
Uni 